\title{
A STUDY OF EFFICIENCY IN NEW ZEALAND ELECTION PREDICTION MARKETS
}

\author{
by \\ TRAM P. CAO
}

A thesis

submitted to the Victoria University of Wellington in fulfillment of the requirements for the degree of

Masters

Victoria University of Wellington

2015 



\section{Contents}

1 Introduction 1

1.1 Research problem and objectives . . . . . . . . . . . . . . 1

1.2 Structure of the thesis . . . . . . . . . . . . . . . 3

2 Prediction markets, iPredict and 2011 New Zealand Election markets 5

2.1 Prediction markets . . . . . . . . . . . . . . . 5

2.2 iPredict and its trading mechanism . . . . . . . . . . . . 7

2.3 The 2011 New Zealand Vote Share Prediction Market . . . . . . . . . . . 11

$\begin{array}{lll}3 & \text { Efficiency in Prediction markets } & 16\end{array}$

3.1 Theoretical foundation . . . . . . . . . . . . . 16

3.2 Empirical evidence . . . . . . . . . . . . . . . . . 21

4 A study of Arbitrage 24

4.1 Theoretical Background . . . . . . . . . . . . . . . . 24

4.1.1 The role of Arbitrage in Market Efficiency . . . . . . . . . . . . 24

4.1.2 Arbitrage in Prediction Markets . . . . . . . . . . . . . . . 31

4.2 Theoretical Framework . . . . . . . . . . . . . . . . . . . . . . 34

4.2.1 Arbitrage Framework: Without bid and ask Spread . . . . . . . . 34

4.2.2 Arbitrage Framework: With bid and ask Spread . . . . . . . . . . 42

4.3 Empirical Results . . . . . . . . . . . . . . . . . . . . 47 
$5.1 \quad$ Literature Review . . . . . . . . . . . . . . . . . 57

5.1.1 Stationarity in stock markets _............... 57

5.1 .2 Stationarity in prediction markets . . . . . . . . . . . . 59

5.2 Expected property of prediction market prices . . . . . . . . . . 62

5.3 Testing prices for unit root . . . . . . . . . . . . . 64

5.4 Empirical Results . . . . . . . . . . . . . . . . . 66

6 Relationship Between Market Prices and Opinion Polls 72

6.1 Description of Roy Morgan polls . . . . . . . . . . . . . . . . . . . 74

6.2 Differences of forecasts implied by iPredict's prices and opinion polls . . . 79

6.3 The accuracy of iPredict's election market and Roy Morgan Research's opinion polls . . . . . . . . . . . . . . . . . . . . . . . . . . 84

6.3.1 Definition of predictive accuracy . . . . . . . . . 84

6.3.2 Literature review . . . . . . . . . . . . . . 86

6.3.3 Comparison of forecast error . . . . . . . . . . . . . . . . 89

6.4 Literature Review . . . . . . . . . . . . . . . . . . . 100

6.5 Testing Models and Results . . . . . . . . . . . . . . . . . 103

6.5.1 Property of market price changes . . . . . . . . . . . . . . . . . 104

6.5.2 Alternative models of market price changes . . . . . . . . . . . . . 105

$\begin{array}{llr}7 & \text { Conclusion } & 119\end{array}$

$\begin{array}{ll}\text { Bibliography } & 122\end{array}$ 


\section{List of Figures}

2.1 An example of buy and sell offers in iPredict . . . . . . . . . . . . 9

2.2 Market maker price setting sensitivity . . . . . . . . . . . . . . . . 10

2.3 The effect of transaction fee on trading activity . . . . . . . . . . . 14

3.12004 U.S Presidential Election . . . . . . . . . . . . . . . . . . . 21

4.1 An example of a price schedule . . . . . . . . . . . . 46

4.2 Daily average arbitrage returns vs. risk free rate . . . . . . . . . . . 49

4.3 Positive arbitrage returns as a proportion of total transactions per day . 51

4.4 Arbitrage possibility in the vote share market over the whole contract period 52

5.1 iPredict market-based forecast of 2011 General Election vote share . . . . 70

5.2 iPredict market-based forecast of the Māori contract . . . . . . . . . . . 71

6.1 Roy Morgan's opinion poll results . . . . . . . . . . . . . . . 77

6.2 Comparing the poll results of the Green party and that of the sum of the National and Labour parties . . . . . . . . . . . . . . . . . . . . . 78

6.3 Trading activity by traders . . . . . . . . . . . . . . . 83

6.4 Forecast of the National's vote share by iPredict and opinion polls . . . . 92

6.5 Forecast of the Labour's vote share by iPredict and opinion polls . . . . . 93

6.6 Forecast of the Green's vote share by iPredict and opinion polls . . . . . 94

6.7 Forecast of the New Zealand First's vote share by iPredict and opinion polls 95

6.8 Forecast of the ACT's vote share by iPredict and opinion polls . . . . . . 96 
6.9 Forecast of the Māori's vote share by iPredict and opinion polls _ . . . . 97

6.10 Forecast of the United Future's vote share by iPredict and opinion polls . 98

6.11 Forecast of the rest of the vote share by iPredict and opinion polls . . . . 99

6.12 Graph of Bush' prices in IEM . . . . . . . . . . . . . . . . . 102 


\section{List of Tables}

2.1 Summary of the vote share market's contracts . . . . . . . . . . . . . 12

2.2 Summary of trading activity in the vote share market . . . . . . . . . 13

5.1 ADF test results of price level . . . . . . . . . . . . . . 69

6.1 The margin of error published by Roy Morgan polls ${ }^{1}$. . . . . . . . . . 75

6.2 Forecast errors of Roy Morgan polls and iPredict's prices on November 24,

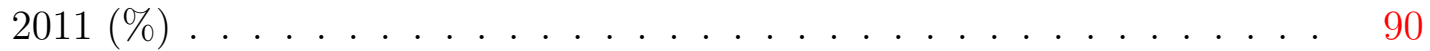

6.3 Forecast errors of Roy Morgan polls and iPredict's prices over the full course $(\%) \ldots \ldots \ldots \ldots \ldots \ldots$

6.4 The immediate effect of opinion polls on market prices . . . . . . . . . 109

6.5 The permanence of the opinion polls' effect in the National, Labour and NZ First contracts . . . . . . . . . . . . . . . . . . 115

6.6 The ex-ante and ex-post effect of opinion polls on market prices . . . . 118 


\section{Acknowledgements}

I would like to express my gratitude to my supervisors Professor Dean Hyslop, Professor Lew Evans and Dr John Randal for their useful comments, remarks and engagement through the learning process of this thesis. Furthermore, I would like to thank Professor Neil Quigley for introducing me to the topic as well as his support on the way. Also, I like to thank Matt Burgess (former CEO of iPredict Ltd), who provided me with the data to support this study. I would like to thank my family, who have supported me throughout the entire process, and helped me putting pieces together and especially my husband, Dr Andrew Fung. 


\begin{abstract}
The development of prediction markets has naturally given rise to studies of their efficiency. Most studies of efficiency in prediction markets have focused on the speed with which they incorporate information. A necessary (but not sufficient) condition of efficiency is that arbitrage opportunities must non-existent or transitory in nature so that the systematic generation of abnormal profits is not possible. Using data from New Zealand's first prediction market, iPredict, I examine the potential for arbitrage in the contracts for the party vote for the 2011 General Election. Relative to the risk-free interest rate, the returns from arbitrage are generally low, consistent with an efficient market. Regression analysis requires that the data not be subject to the possibility of spurious regressions - something that is not addressed in the literature. After confirming the nonstationarity of the price level and the stationarity of the price changes by the unit root test, I use the iPredict data in conjunction with opinion poll data to test whether the polls impact on market pricing behaviour. Using a number of different model types, I find that the opinion poll data has a very limited impact on market prices, suggesting that the information contained in the poll is largely already incorporated into market prices.
\end{abstract}





\section{Chapter 1}

\section{Introduction}

A prediction market is a relatively new form of financial market. The first prediction market, the Iowa Electronic Market, (IEM) was developed in 1988 by three economists at the Iowa College of Business. They ran an experimental market offering a place where traders could buy or sell contracts which paid $\$ 1$ if a given candidate won the U.S presidential election in that year. Its purpose was to predict who would win the presidential run. Since then prediction markets have become more and more sophisticated serving as a prediction tool for both research and commercial purposes. Despite being controversial in some applications, this new form of market has gradually gained public attention and been recognized as a tool that can support decision making in many contexts including political, economic and corporate. This thesis examines the efficiency of prediction markets in the context of data from the 2011 General Election in New Zealand.

\subsection{Research problem and objectives}

Due to the similarity in the operating mechanism with stock markets, the Efficient Market Hypothesis (EMH), should also be applied to prediction markets. The EMH asserts that in a perfectly efficient market "prices fully reflect all available information" (Fama, 
1965b). As buyers and sellers interact in the market through trading activities they reveal information they have about the value of the trading asset. During the trading interaction, prices incorporate information relevant to the trading asset that buyers and sellers possess. In an efficient market, the price is the best indicator of an asset's value and any information will be incorporated into prices as soon as it arrives.

Until the introduction of prediction markets, the revelation of an asset's value depends on the existence of a market on the relevant commodity. When the underlying asset is not a "real" commodity, it is almost impossible to identify its value. This is the situation where prediction market is most valuable. Where there is no futures market in the relevant asset, for instance political outcomes, or markets in which trading on the relevant asset is too thin, prediction markets can provide a vehicle for people to trade on relevant information and become valuable means of informing market participants.

The ultimate purpose of a prediction market is to offer a vehicle to aggregate information. One question that remains controversial is how efficient thee prediction market is as an information aggregator and how well prices replicate the underlying event's likelihood. This is the objective of my research. I use data collected from iPredict - the first real money prediction market in New Zealand. iPredict offers contracts to predict outcome of many events in various contexts such as political events, economic indexes, environmental issues, Fonterra's payout etc.

The efficiency of prediction markets is examined in a few aspects. First, the primary focus of this thesis and the necessary condition of market efficiency is no-arbitrage: when the price is at the efficient level, the market is free from arbitrage opportunities; no trading technique can create opportunities that can consistently earn abnormal and riskfree returns. Prices in prediction markets have a distinguishable feature from those in other financial markets which is that the aggregate price of contracts predicting various 
outcomes of a specific event represents $100 \%$. This feature creates an unique arbitrage opportunity when the aggregate price diverges from $\$ 1$ or $100 \%$ probability. Second, I examine the properties of the market price level, more specifically stationarity. Last, the degree of market efficiency is reflected by how well prices incorporate information; in this study it is how well prices incorporate information revealed in opinion polls - a direct competitive forecast tool.

\subsection{Structure of the thesis}

Chapter 2 introduces prediction markets and their theoretical principles; together with iPredict and its operating mechanism. and the 2011 New Zealand vote share prediction market. The first section of Chapter 3 is a brief review of the extensive and vast literature on the Efficient Market Hypothesis. The remainder of Chapter 3 summarizes the result of studies on the efficiency of prediction markets. It includes studies comparing the performance of a some particular prediction markets with their competitive forecasting tools and studies on why prediction markets can be classified as having weak-form efficiency.

Chapter 4 investigates the degree of arbitrage possibility by testing the hypothesis that the market is able to eliminate arbitrage opportunities and whether profit gained from such arbitrage practices is sufficiently significant to indicate market inefficiency. A literature review is followed by a description of the condition for when arbitrage arises in iPredict, and how to calculate the arbitrage profit. The last part reports empirical results.

The properties of market prices are studied in chapter 5 . A literature review is followed by a detailed description of the Unit Root test by which the stationary property of prices are examined and then the reporting of the empirical results. Chapter 6 studies the effect of opinion polls on market prices as an indicator of how well prices incorporate information contained in polls. The first section discussed the differences in the forecast of prediction 
markets and opinion polls - the two serve the same broad purpose but operate by different principles therefore their forecast outcomes should be interpreted differently. The relationship between market prices and opinion polls will be examined by three models; each derives from an alternative of the behaviour of market prices. The empirical results follow.

Chapter 7 concludes. 


\section{Chapter 2}

\section{Prediction markets, iPredict and}

\section{New Zealand Election markets}

\section{$2.1 \quad$ Prediction markets}

Prediction markets are defined as markets that serve "the primary purpose of aggregating information so that market prices forecast future events" (Berg and Rietz, 2003) and are also known as idea markets, information markets, decision markets, electronic markets, forecasting markets and virtual stock markets. A prediction market serves as a common place where people trade contracts whose payoff depends on the outcome of an uncertain future event. In an efficient prediction market, prices are the best predictor of the likelihood of an event's outcome.

Despite being a form of financial market, prediction markets distinguish themselves from traditional financial markets in a few respects. First, prediction markets have a primary purpose in research because its main purpose is to reveal and aggregate information dispersed among market participants. In contrast, stock and other financial markets serve as tools to allocate resources, hedge risk and to raise capital. Second, there is no underlying asset in prediction markets. In other financial markets assets are exchanged 
for money and thus prices indicates the value of those assets relative to others. These markets, therefore, exist to offer a common place for traders to interact and transact and prices play the role as a mechanism for the exchange to take place. Trading in prediction market, in contrast, has no economic function where no real asset is exchanged. Market participants trade according to their expectation of an event hence market prices reflect the trader's estimate of a specific parameter value of the underlying event (Abramowicz, 2007). The fact that prediction markets are not tied to real assets makes them unique. Last, assets traded in prediction markets are contingent claims and contracts are tied to a future event. The direct dependence of traders' returns on an event, rather than other traders' expectations of outcomes, distinguishes prediction markets from most futures and options markets (tet, 2008).

Prediction markets are often mistakenly perceived as a form of gambling or betting market due to the similarities in their operating mechanism. Betting markets are mainly for entertainment while prediction markets are a research tool. Betting markets do not allow bettors to change their betting position once the bet is placed. If a bettor changes his mind after placing a bid, it is not possible for him to correct his previous bid and update his bet so that it matches with his most recent expectation ${ }^{1}$. This is a limit preventing betting markets from reflecting real-time information. Prediction markets, on the other hand, allow traders to change their trading position according to their new expectation. The shift in trader's expectation is mainly due to the arrival of new information. Allowing traders to update their trading position at any time helps new information to be incorporated into prices instantly.

\footnotetext{
${ }^{1}$ Thus a bettor cannot undertake an offsetting trade that leaves him in a net neutral position.
} 


\section{2 iPredict and its trading mechanism}

iPredict $^{2}$ is New Zealand's first and only real money political prediction market. iPredict was established in 2008, shortly before the General Election that year, as a market-based political and economic forecasting system. Today iPredict has over 5,000 traders, and has launched over 1500 contracts. iPredict Ltd is owned by Victoria Link Ltd, or "Viclink", the commercial arm of Victoria University of Wellington. It is authorized as a futures dealer by the Financial Markets Authority. The iPredict market operates 24-hours a day. Traders trade with their own funds in real money, and conduct their own information search.

iPredict is an institution where traders make predictions and earn money by buying and selling event's futures. iPredict stocks work like a share market. Traders can buy stocks in a future event today and sell them on the open market at any time in the future. Or wait until they close and pay out. iPredict offers stocks in a range of events, and set new stocks up frequently in response to political and economics events. Traders can suggest new stock ideas (most of the stocks started with ideas from traders). iPredict operates like a stock market where traders can buy stocks of a future event today and sell them at any time in the future or wait until the maturity and receive the payout. For instance, with regards to the General Election's results in 2011, iPredict launched a number of contracts three of which each of which paid out $\$ 1$ per share if after the 2011 Election there was to be a National or Labour or non-National-and-Labour Prime Minister respectively, and pay nothing otherwise. Those who were sure of a National victory would buy as many shares of the National contract within his budget constraints. By the act of buying National shares, the trader simultaneously gives a signal to other traders that he expects National to win. Through this mechanism, prediction markets exploit the "wisdom of crowds" (Surowiecki, 2004) to help predict the outcome of many

\footnotetext{
${ }^{2}$ http://www.ipredict.co.nz
} 
events that occur in the real world.

Trades in prediction markets happen in a variety of different market designs which defines how buyers and sellers' want match. They includes continuous double auctions (CDA), implemented market-scoring rules (MSR), call auctions and dynamic pari-mutuel pools. However, I will only discuss the MSR mechanism because it is adopted by iPredict.

The mechanism implementing MSR developed by Hanson (Hanson, 2003) acts like a market maker which plays a role of both buyer and seller in order to provide the market with liquidity. As soon as a trader places his order, the market maker will create a matched order on the opposite side so that his order can be executed immediately. Implementing MRS is most suitable in small and less liquid markets.

The market maker continually makes offers to buy and sell according to a price schedule rule that is determined at the contract launch. With a market maker, the first trader entering the market can immediately trade. Otherwise, he would arrive at an empty queue and have to wait for others to enter and trade against him so that his orders will be executed.

When a new market is set up, the market maker's presence is obvious from the regular pattern of seeding. Figure 2.1 provides an example of a seeding schedule. If a trader wants to buy 150 shares, he will have to pay the price of $\$ 0.5$ each for the first 100 shares and $\$ 0.5167$ each for the next 50 shares. 
Figure 2.1: An example of buy and sell offers in iPredict

\begin{tabular}{|c|c|}
\hline \multicolumn{2}{|c|}{$\begin{array}{c}\text { Current Top } 10 \\
\text { Buy Orders }\end{array}$} \\
\hline Quantity (Shares) & Price Per Share \\
\hline 100 & $\$ 0.4833$ \\
\hline 100 & $\$ 0.4667$ \\
\hline 100 & $\$ 0.4502$ \\
\hline 100 & $\$ 0.4337$ \\
\hline 100 & $\$ 0.4174$ \\
\hline 100 & $\$ 0.4013$ \\
\hline 100 & $\$ 0.3854$ \\
\hline 100 & $\$ 0.3697$ \\
\hline 100 & $\$ 0.3543$ \\
\hline 100 & \\
\hline
\end{tabular}

Current Top 10 Sell Orders

\begin{tabular}{|c|c|}
\hline Quantity (Shares) & Price Per Share \\
\hline 100 & $\$ 0.5000$ \\
\hline 100 & $\$ 0.5167$ \\
\hline 100 & $\$ 0.5333$ \\
\hline 100 & $\$ 0.5498$ \\
\hline 100 & $\$ 0.5663$ \\
\hline 100 & $\$ 0.5826$ \\
\hline 100 & $\$ 0.5987$ \\
100 & $\$ 0.6146$ \\
100 & $\$ 0.6303$ \\
\hline 100 & $\$ 0.6457$ \\
\hline
\end{tabular}

The market maker is treated as a trader in the system. Each contract listed on iPredict has one market maker automatically associated with it. The market maker is given a budget, and that budget is consumed as the market maker buys and sells stocks. If the budget is exhausted, then the market maker will stop seeding (or very substantially thin its offers) on the side of the market that additional trading will cause erosion of its funds. For instance, if the market maker low on funds and is long on its stock, it will thin or eliminate entirely more offers to buy. The market maker loses money over the time ${ }^{3}$.

The market maker's seeding operates according to three settings determined by the iPredict's administrator at the time a new contract is launched: an initial price defining the price at which buy orders and sell orders begin, the market maker sensitivity determining the steepness of the S-curve and the batch size which is the number of stocks offered at each price point.

The market maker prices all buy and sell offers using an S-curve (see Figure 2.2). The formula for this S-curve is:

\footnotetext{
${ }^{3}$ On average, the market maker loses $\$ 186.50$ in binary contracts, $\$ 25.15$ on index contracts, and $\$ 154.64$ per market overall.
} 


$$
\text { price }_{i}=\frac{1}{1+e^{\frac{i}{\text { sensitivity }}}}
$$

where $i$ is an integer that varies between $-n$ to $n$, where $n$ is defined by the value that produces a price that is within 0.0001 of 0 and 1 , the minimum and maximum prices. In Figure 2.2, $i$ varies along the horizontal axis. The sensitivity is within the range $(0,99]$. The higher the sensitivity, the flatter the S-curve and the smaller the price gap between each step in $i$.

Figure 2.2: Market maker price setting sensitivity

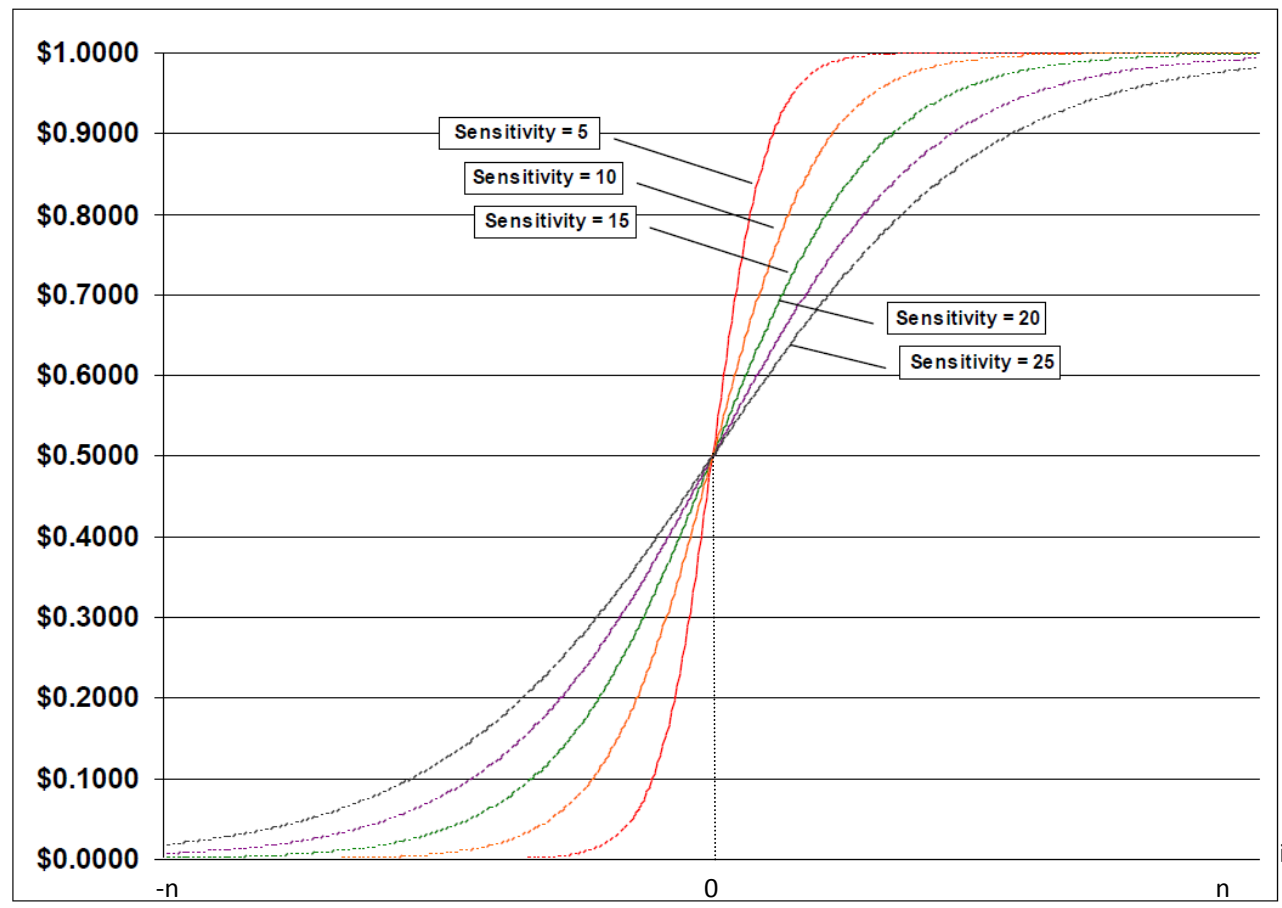

Starting from an index $i$ of 0 , the system will increase $i$ in steps of 1 , at each step price $_{i}$ is calculated and permanently stored in an array. The integer $i$ will increase until price $_{i}$ is within 0.0001 of 0 . The process is then repeated, starting from 0 , this time decrementing the index by 1 at each step until price ${ }_{i}$ is within 0.0001 of 1 . At this point, an entire price schedule for this market maker is calculated, and all offers to buy and sell (unless 
market maker setting is changed) will be at prices defined by this schedule.

At all price $_{i}$ above the start price, the offer will be on the sell side of the market, otherwise the buy side. Once trading commences, the market maker seeds the market by replacing completely-filled buy or sell offers with sell or buy offers at the same time. For instance, a trader decides to accept in its entirety a market maker's offer to buy 100 shares at price $\$ 0.5$. Once the buy offer is filled, the market marker will immediately place a new sell offer at $\$ 0.5$. The effect of this is to move the market equilibrium price downwards. Market maker never trades with itself because at no time its buy and sell offers overlap. All trades with the market maker have human traders on the other side. About $75 \%$ of all trades on iPredict are between market maker and human and the remainder is between two human traders. The market maker starts with zero stocks. This means the market maker's funds are depleted whichever way the market moves. When a stock launches, sell orders offered by the market maker mean that the market maker takes a short position on that stock when those orders are filled.

\subsection{The 2011 New Zealand Vote Share Prediction Market}

The vote share market in iPredict provided forecasts of the proportion of total share of votes a party would receive in the General Election in New Zealand in 2011. This market had eight index contracts ${ }^{4}$, each paying 1 cent for each $1 \%$ of the total vote received by the underlying party. The actual vote share determined the contract payout value. Typically, a contract had a payout equal to 1 cent times the proportion of the total vote received by the associated party. Details of the eight contracts are summarized in Table 2.1.

\footnotetext{
${ }^{4}$ Index contracts have pay-off depending on a number that rises or falls thus varies in a continuous way (Wolfers and Zitzewitz, 2004). The price for such contract represents the mean value that the market assigns to the outcome.
} 
Table 2.1: Summary of the vote share market's contracts

\begin{tabular}{|l|l|l|}
\hline Contract name & Contract's predictive goal (Contract's question) & Payout (cents) \\
\hline VOTE.2011.NAT & $\begin{array}{l}\text { What share of the party vote will the National Party win } \\
\text { at the } 2011 \text { election? }\end{array}$ & 47.31 \\
\hline VOTE.2011.LAB & $\begin{array}{l}\text { What share of the party vote will the Labour Party win } \\
\text { at the } 2011 \text { election? }\end{array}$ & 27.48 \\
\hline VOTE.2011.GREEN & $\begin{array}{l}\text { What share of the party vote will the Green Party win } \\
\text { at the } 2011 \text { election? }\end{array}$ & 11.06 \\
\hline VOTE.2011.NZF & $\begin{array}{l}\text { What share of the party vote will the New Zealand First } \\
\text { Party win at the } 2011 \text { election? }\end{array}$ & 6.59 \\
\hline VOTE.2011.ACT & $\begin{array}{l}\text { What share of the party vote will the ACT Party win at } \\
\text { the } 2011 \text { election? }\end{array}$ & 1.07 \\
\hline VOTE.2011.Māori & $\begin{array}{l}\text { What share of the party vote will the Māori Party win } \\
\text { at the } 2011 \text { election? }\end{array}$ & 1.43 \\
\hline VOTE.2011.UNF & $\begin{array}{l}\text { What share of the party vote will the United Future Party } \\
\text { win at the } 2011 \text { election? }\end{array}$ & 0.6 \\
\hline VOTE.2011.OTHER & $\begin{array}{l}\text { What share of the party vote will all other parties win at } \\
\text { the } 2011 \text { election? }\end{array}$ & $4.46^{1}$ \\
\hline
\end{tabular}

${ }^{1}$ This contract pays $\$ 1$ less the sum of payouts from VOTE.2011.NAT, VOTE.2011.LAB, VOTE.2011.GREEN, VOTE.2011.NZF, VOTE.2011.ACT VOTE.2011.Māori and VOTE.2011.UNF.

In this market, prices are interpreted as the forecast of a party's vote share (Wolfers and Zitzewitz, 2006a). For instance, at 20:16:12pm on June 19, 2011 the (last traded) price of contract VOTE.2011.NAT is 44.03 cents. This implies that the market expected National Party would receive $44.03 \%$ of the total party vote at the 2011 General Election. Any traders who believed that National Party would win more (or less) than $44.03 \%$ would buy (or sell) shares until the contract price coincided with their expected level. The official election results released on December 10, 2011 revealed that the National party received $47.31 \%$ of the total party vote thus the contract VOTE.2011.NAT paid out 47.31 cents to every share held on its close date.

The vote share market was launched on November 2, 2010 and closed on December 10, 2011 after the official election results were released on the same day. The Election Day was November 23, 2011; this means that trading continued operating after the Election Day until the release of the official results. The market was running for 404 days. This was a very liquid market compared to other markets run by iPredict; there were 33,258 transactions and 561,739 shares traded within its lifetime and 82 transactions and 1,390 
shares per day on average. The total amount invested was $\$ 134,116.8$ much higher than that in the 2008 Election $(\$ 22,800$ according to McGirr and Salmond (2010)). The summary of transactions and shares traded in each contract over the period of the contract are given in Table 2.2 .

Table 2.2: Summary of trading activity in the vote share market

\begin{tabular}{|l|l|l|l|l|l|l|l|l|l|}
\hline Contract & National & Labour & Green & $\begin{array}{l}\text { NZ } \\
\text { First }\end{array}$ & ACT & Māori & $\begin{array}{l}\text { United } \\
\text { Future }\end{array}$ & Others & Overall \\
\hline Transactions & 3,217 & 3,711 & 3,081 & 9,876 & 4,475 & 2,642 & 3,634 & 2,626 & 33,258 \\
\hline Shares traded & 39,250 & 48,389 & 38,884 & 201,638 & 64,410 & 34,736 & 99,695 & 34,737 & 561,739 \\
\hline $\begin{array}{l}\text { Transactions } \\
\text { per day }\end{array}$ & 8 & 9 & 8 & 24 & 11 & 6 & 9 & 7 & 82 \\
\hline $\begin{array}{l}\text { Shares per } \\
\text { day }\end{array}$ & 97 & 112 & 96 & 500 & 160 & 86 & 247 & 86 & 1,390 \\
\hline $\begin{array}{l}\text { Amount } \\
(\mathrm{NZ} \$)\end{array}$ & 19,140 & 20,164 & 9,340 & 41,799 & 15,753 & 5,326 & 6.687 & 15.903 & 134,116 \\
\hline
\end{tabular}

Because the trading fee of 0.35 cents per share trader was only introduced in August 2011, any transactions occurring before this were not subject to any trading fee. The application of this fee does not appear to have any effect on the trading activity, more specifically it did not discourage trading or reduce the amount of trades. Figure 2.3 shows no change in the number of transactions and shares traded after the trading fee is applied. In fact, the trading volume increases significantly two months prior to the Election's results and this essentially is the result of an increase in the attention to the Election ${ }^{5}$.

\footnotetext{
${ }^{5}$ There is a possibility that without the trading fee, trading would have been higher but there is noway to prove or disprove it.
} 
Figure 2.3: The effect of transaction fee on trading activity

\section{Daily volume of transactions}

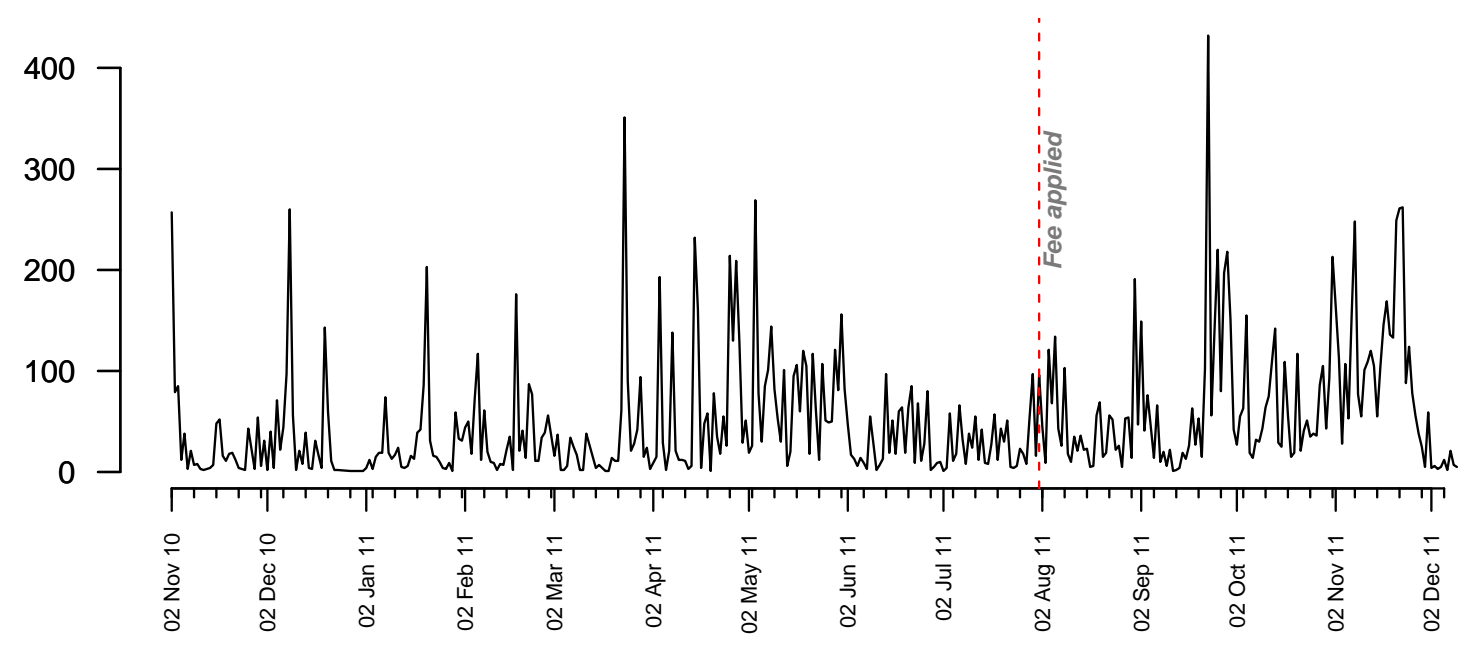

\section{Daily volume of traded shares}

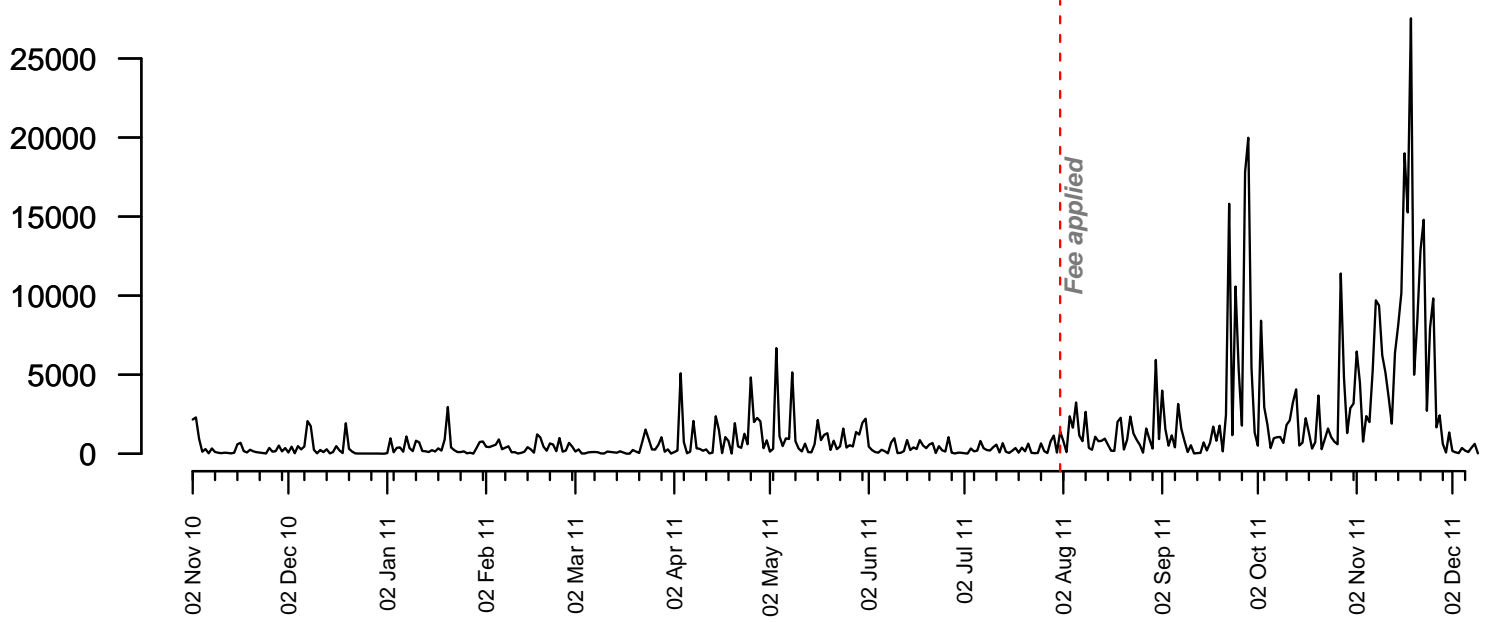

The vote share market was set up to have greater liquidity (the sensitivity of 50 and the batch size of 1) than other markets in iPredict. For instance, the markets predicting OCR announcements ${ }^{6}$ are set up with the sensitivity of 15 (making for a steeper S-curve) and the batch size at 10 . Increasing the sensitivity of the S-curve reduces the difference of two adjacent seeding prices. The smaller the difference, the more liquid the market is. Each seeding price is associated with 10 shares, i.e. it requires purchase or sale at least

\footnotetext{
${ }^{6}$ iPredict has provided contracts for predicting the Official Cash Rate set by Reserve Bank of New Zealand since December 2008.
} 
one share to move the market price from one seeding level to the other.

Apparently, the New Zealand First contract is mostly traded in terms of the number of transactions and shares traded. The uncertainty around low prices is relatively greater and the great uncertainty tends to create the volatility in prices which offers opportunities of arbitrage and speculation. As a result, it attracts more trading. However, this is proved to not be the case as the Variance-to-Mean ratio of the New Zealand First contract is low among other contracts. The final outcome seems to be a surprise to the market: the market underestimated New Zealand First's vote share for most of the time. The high trading volume might also be an indicator of constant arrival of new information related to the New Zealand First's performance during the election. New Zealand First party is one of other minor parties but receives considerable attention. Their share of party vote is almost as much as the aggregation of shares received by the rest of minor parties. It has been considered as a "kingmaker" who has an important influence on the formation of the Coalition of the government. The special attention received by their important role in the election outcomes may have resulted in a substantial interest which is consequently reflected in the high trading volume. 


\section{Chapter 3}

\section{Efficiency in Prediction markets}

\subsection{Theoretical foundation}

An efficient prediction market is claimed to be the best tool to aggregate information because it provides incentives for information discovery and truthful revelation of beliefs (Hall, 2010; Wolfers and Zitzewitz, 2006b). Information perceived and assessed by individuals is likely to be correlated with actual information. Prediction markets can serve as a simple mechanism for aggregating each individual's information by weighting the forecasts possessed by different individuals. They can also ensure that forecast will reflect the true beliefs of the market's participants by providing trading incentives. The underlying intuition is that when trader "puts his money where his mouth is", he has greater incentives to trade honestly with this belief than when he does not (Abramowicz, 2007).

The claim that prediction markets can efficiently aggregate information is based on the Efficient Market Hypothesis. Market efficiency is formally defined by Fama (1969) as a circumstance when "prices fully reflect all relevant information" to the security. He also describes the three levels of efficiency based on the extent to which the information is incorporated into market prices. In the weak form of efficiency, only historical prices 
are incorporated; in the semi-strong form prices also incorporate publicly and recently available information; and in the strong form all relevant information including that only available to insiders is incorporated. Fama's weak and semi-strong form of market efficiency are consistent with Tobin (1958)'s identifying feature of market efficiency in which there exists no risk-free opportunity to exploit. In other words, no-arbitrage is a necessary condition of market efficiency.

Hayek (1945) identifies the problem of limited information during the process of making decisions; that is information does not exist in a "concentrated and integrated form, but solely as the dispersed bits of incomplete and frequently contradictory knowledge which all the separate individuals possess". Thus, one might benefit from the unique information that he possesses if he can be involved in the decision making process. Hayek vaguely hypothesizes that in a commonplace acting as a market, limited information possessed by individuals is communicated sufficiently through many intermediaries and it was prices that acted as subjective values to help the individual to deliver his plans and coordinate the separate actions of various individuals. Following Hayek's theory, Fama (1969) provides both theoretical reason and empirical evidence to prove that stock prices "at a time fully reflect all available information". Grossman and Stiglitz (1976) document a set of sufficient conditions for the equilibrium price to summarize private information perfectly assuming that every trader has Constant Relative Risk Aversion utility function and each receives independent draws from a normal distribution about the true value of the asset.

As in other financial markets, potential trading profit is an incentive of information discovery. Grossman and Stiglitz (1976) challenge the validity of EMH by introducing the impossibility of prices being fully efficient. They argue that if prices fully reflect information, then there is no incentive for any trader to gather information("No-trade theorem"). Instead, they consider the case where information is expensive to garner and prices never fully reflect all available information. In equilibrium the inefficiency in pricing is sufficient 
to induce a proportion of traders to become informed.

Prediction markets provide financial or non-financial for traders to trade honestly and reveal truthfully their beliefs. In some circumstances, when prediction markets are to be used as inputs into future decisions, trading dishonestly and manipulating prices may be beneficial to some traders. However, a number of studies have provided empirical evidence that such manipulation would typically lead the manipulator to lose money. These losses increase the rewards for informed trading, which may ultimately increase the accuracy of prediction markets (Hanson and Oprea, 2009).

In certain cases, existing theories regarding efficient capital markets can be applied directly to prediction markets thanks to the sharing of operating mechanism. At least one theoretical reason to believe that prediction markets should help diminish cognitive biases is that individuals who have a more sophisticated model for assessing the probability generally have greater confidence and willingness to place bets in prediction markets when the current prices are inaccurate as suggested by their model.

A possible explanation for the information aggregation in prediction markets derives from a theory called "Marginal Trader Hypothesis" proposed by Forsythe et al. (1992). The theory claims that the information aggregation is determined by a small group of wellinformed traders called "marginal traders". The official definition of "marginal traders" refers to those who are "correctly informed" (Oi, 1974; Viscusi, 1979, 1983). However, it is unlikely in practice that any individual would have complete information, therefore the equilibrium price is hard to define. Alternatively, marginal traders can be defined by characteristics of their trading activities. They are arbitrageurs who trade to exploit riskfree profit opportunities or speculators who trade when market prices differ from their forecasts. They trade rationally and suffer no judgement bias and interpret information about the underlying events more accurately than less well informed traders. In other 
words, their mere trading motivation is profits and they trade accordingly no matter what their preference is. Theoretically, this would require those traders to have sufficient information about bias of other traders who are less informed in the markets.

Forsythe et al. (1992) propose a measure of trading activity that serves to identify marginal traders. They are those who submit limit orders (offers to buy or sell that are entered into the queues without resulting in immediate trades) at prices close to the market prices. They trade more actively (measured by the number of days that trades occur) and invest more. Marginal traders earn higher returns. The authors find that the median return rate for non-marginal traders was $0 \%$ but for marginal traders it was $9.6 \%$ in the 1988 US presidential election prediction markets (Iowa Electronic Market).

Marginal traders are believed to drive prices to their efficient level and keep them there. The theory is supported by empirical findings regarding the Iowa Electronic Market (Forsythe et al., 1992, 1999; Berg et al., 2001). Even though they find evidence of biased trading, the aggregate market prices produce highly accurate predictions. The theory also implies the importance of including non-marginal traders in the market. Although non-marginal traders tend to drive prices away from the efficient level, the divergence provides incentives for marginal traders to enter the market, exploit the mispricing by trading against non-marginal traders and eventually drive prices to their efficient level. Traders in Iowa Electronic Market do not appear to be fully rational. It is evident that a large proportion of market participants conduct trade based on their personal preferences and are therefore subject to judgement bias (Forsythe et al., 1992; Berg and Rietz, 2006). In addition, traders frequently trade in a manner that does not exploit the availability of prices (Oliven and Rietz, 2004): they submit offers to buy or sell that higher or lower than currently available offers in the market. In contrast, a relatively small group of traders shows no indication of judgement bias in their trading activities in keeping with the hypothesized marginal traders. The difference between the average 
net purchase of shares in the two major candidates is small and statistically insignificant in the 1988 presidential election markets (IEM) (Forsythe et al., 1992). Marginal traders also appear to recognize when relevant news occurs and when it does not. They can be experts or those who invest time and effort acquiring and interpreting information.

The "Marginal Trader Hypothesis" provides evidence favourable to the famous "Hayek Hypothesis" by Smith (1982). Smith (1982) defines the Hayek Hypothesis as: "Strict privacy [of information] together with the trading rules of a market institution are sufficient to produce competitive market outcomes at or near 100\% efficiency". By implication the Hayek Hypothesis also claims that markets aggregate information efficiently despite a large proportion of biased trading.

However, the "Marginal Trader Hypothesis" is challenged by other theories and empirical findings. Beckmann and Werding (1996); Bruggelambert (2004) find no evidence of the presence of unbiased traders in prediction markets. Surowiecki (2004) also raises doubts on the power of a small group of "marginal traders" to offset the majority. Market prices are set by large trades, unless those "marginal traders" have generous budgets, they cannot outweigh the rest of the market and consequently the information aggregation cannot be achieved. In other words, budget constraints limits the ability of those traders to drive prices to the level that matches their forecast ${ }^{1}$. He argues that there exists no single trader or even a small group of traders who can ensure prices are at the efficient level due to budget constraints.

Some studies of the "Hayek hypothesis" actually provide evidence against the "Marginal Trader Hypothesis" when taken to an extreme. (Gode and Sunder, 1993; Othman, 2008) conduct computational studies where markets are set up with "zero-intelligence agents" in which it is claimed that the predictive performance of markets composed of robots are

\footnotetext{
${ }^{1}$ iPredict set a deposit limit to $\$ 2500$ per 6 months per account, subject to a lifetime net contribution limit $\$ 10,000$ in total.
} 
as good as those with human traders. This claim denies the role of marginal traders in the divergence of prices to their efficient allocation.

\subsection{Empirical evidence}

Wolfers and Zitzewitz (2006b) studying the IEM and Tradesports markets, find that relevant news is incorporated into market prices quickly. Prices of the President Bush contract in the 2004 re-election dropped immediately as the polls suggesting a winning chance of Kerry were leaked at 3pm of the Election Day (Figure 3.1). As time passed by, the previous polls were realized to be wrong and the market prices went up sharply as a correction. The price movement in the election market matched with a similar pattern in $\mathrm{S} \& \mathrm{P}$ equity market.

Figure 3.1: 2004 U.S Presidential Election

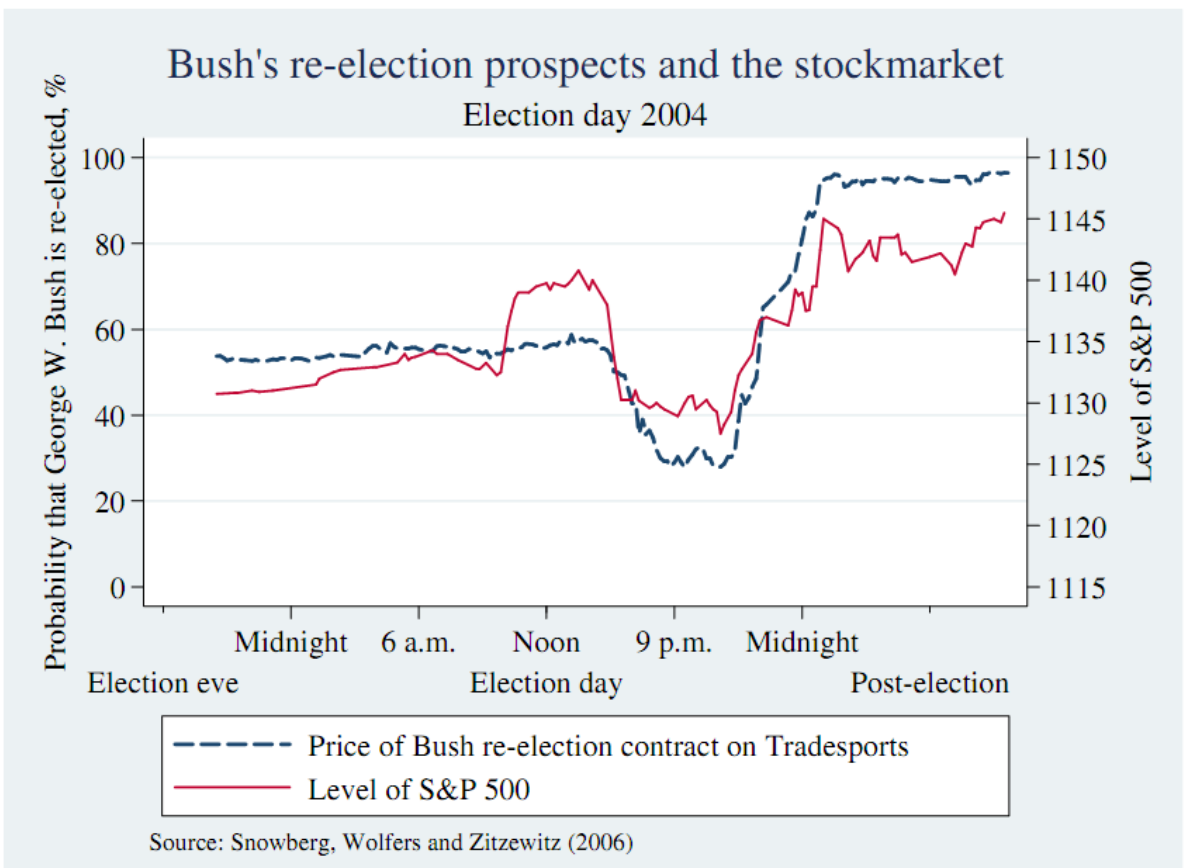


Prediction markets meet at least the weak-form efficiency: prices follow the random walk and any trading strategies based on public information do not produce abnormal returns. This is demonstrated in a Tradesports contract betting whether Saddam Hussein were removed from power by the end of June 2003 (Leigh et al., 2003). The contract price did not follow a predictable pattern. No simple trading strategies based on historical prices produces abnormal returns. A study conducted by Bondarenko and Bossaerts (2000) using the data of the IEM suggests the same conclusion that market participants respond rationally to new information. Although market participants have been shown to display a certain level of bias in their trading decisions, it is not sufficient to create a trading strategy that can beat the market and produce abnormal returns. In the IEM and Tradesports markets, arbitrage opportunities are present but do not produce abnormal profits (Wolfers and Zitzewitz, 2006b). Tetlock (2004) studying Tradesports finds that the financial contracts are largely efficiently priced and thus few arbitrage opportunities are detected. Tetlock (2004) compares the analogy of markets betting on sports versus on financial events in Tradesport. Mispricing in sports game contracts is significantly greater than mispricing in financial markets: the reverse favourite-longshot bias and the tendency of overreaction are present in the contracts on sports games but no such bias is found in the financial contracts. The efficiency of financial markets is remarkable even though they share the same liquidity, volume and structure with the contracts on sports games.

Leigh and Wolfers (2006) study the performance of various prediction markets relative to that of opinion polls and that produced by econometric models using recent economic data in the 2004 Australian election and find evidence supporting the efficiency of prediction markets. First, they find only one arbitrage opportunity by trading across two prediction markets and it yielded an expected profit margin of $2 \%$. Second, prices appear to respond quickly to relevant campaign news. Last, Leigh and Wolfers (2006) note that prices exhibit a sensible degree of volatility when compared with opinion polls. The ran- 
dom walk hypothesis on the price level cannot be rejected while the stationary behaviour is not clear; no predictable pattern in price changes is evident and in one market prices efficiently incorporate information while in the other market there exist some lag in the incorporation of polling data but the correlation between market prices and poll results is too small to yield profitable opportunities.

Forsythe et al. (1992) builds a theoretical framework studying the causality between market prices and opinion polls and finds weak evidence of a random walk in market prices and that there is a small group of traders producing correct prices. Plus, in the comparison with opinion polls, the market works well and the availability of polls' information has little effect on prices. 


\section{Chapter 4}

\section{A study of Arbitrage}

\subsection{Theoretical Background}

\subsubsection{The role of Arbitrage in Market Efficiency}

Fama (1969) defines market efficiency as circumstances in which prices fully reflect all available information, and formally as a martingale property of prices. LeRoy (1973) and Lucas (1978) are among the first to clarify that, with risk aversion, only discounted, risk-adjusted prices could have the martingale property. Whereas Malkiel (2003) uses the non-existence of trading strategies that produce positive, expected, risk-adjusted excess returns as the definition of market efficiency.

The definition of market efficiency in the literature has two main features: (1) prices fully reflect all available information, and (2) there are no trading strategies that produce positive, expected, risk-adjusted excess returns. The Efficient Market Hypothesis asserts that in an efficient market prices reflect information as soon as the information arrives. News spreads very quickly and is incorporated into the prices without delay (Fama, 1969). An implication is that no trading rules relying on either technical analysis, which is the 
study of past stock prices in an attempt to predict future prices, or fundamental analysis ${ }^{1}$, which is the analysis of financial information, would enable an investor to obtain returns that are higher than those that could be obtained from holding a random portfolio with comparably equal risk.

In other words, if prices fully reflect all available information, then it is generally true that there exists no trading strategy that produces risk-free positive expected (risk-adjusted) excess returns. The response of investors to new information is rapid and rational, bidding prices up or down until they eliminate any advantages to trading on the new information.

Thus, according to the EMH, the existence of arbitrage is a signal of market inefficiency. In principle, arbitrage is defined as "the simultaneous purchase and sale of the same or essential similar security in two different markets for advantageously different prices" (Sharpe and Alexander, 1990). Arbitrage involves no negative cash flow at any probabilistic state and a positive cashflow in at least one state. In simple terms; it generates a non-zero probability of a risk-free profit. The existence of an arbitrage opportunity is considered information that is publicly available to all market participants. Traders detect an arbitrage opportunity as soon as it arises and take advantage of it in order to obtain risk free profits. An efficient market (at least in the semi-strong state) should expect arbitrage to be eliminated very quickly because a sufficient number of traders will trade in order to take advantage of it by bidding prices toward its arbitrage-free level. In other words, the existence of arbitrage itself might not nullify a claim of market inefficiency if the arbitrage opportunity is quickly driven away by the pursuit of profits. However, a persistent arbitrage opportunity may indicate the inability of a market to eliminate the mispricing. And this can be caused by the obstacles to the process of eliminating mispricing in the market which is referred as limits to arbitrage.

\footnotetext{
${ }^{1}$ While new financial information may give rise to a change in the fundamentals of a company and hence analyst's expectation of its stock price, once that information is incorporated into prices, it no longer has any ability to generate additional excess returns.
} 
There exists no benchmark of determining how fast an arbitrage opportunity is to be eliminated so that it does not indicate market inefficiency. The speed of elimination of arbitrage varies and determined by many factors including characteristics of individual markets itself, and of traders trading in the market. Those factors include transaction costs, market liquidity, traders' attitude toward risk and their preferred trading strategy, traders' price assessment, traders' search strategies, the allocation of relevant information among market participants and traders' budget constraints. Transaction costs add to the costs of buying and selling assets and consequently affect the optimizing behavior of traders, thus it must be taken into account. Naturally traders only engage in trading at a market price if it promises a (expected) profit, that is, the expected profit is sufficient to cover the transaction costs. Thus the presence of transaction costs in disequilibrium markets is expected to discourage trading by reducing expected profits and restrain the price movement toward its equilibrium level. Consequently, transaction costs are believed to reduce the speed of price convergence to equilibrium.

A liquid market should expect that arbitrage is detected and driven away very quickly because it has a large number of active traders watching the market closely. Another measure of market liquidity is the bid and ask spread. Because arbitraging typically includes crossing the spread, a narrow spread presents arbitrageurs with less of a cost than a wide spread. A large bid and ask spread, in the other hand, reduces trading profits as it plays a role has an effect similar to that of transaction costs and as a result, discourages arbitrageurs to trade.

The speed at which mispricing is corrected is also affected by traders' characteristics. Trader' attitude toward risk, preferences over trading of certain commodities, the price search strategy and rationality have impact on traders' utility optimizing behavior and how they trade and eventually influence how prices are set. Budget constraints also play a 
role in incomplete markets; traders who detect arbitrage opportunities but are restrained by budgets might not be able to drive a market price to the point at which they think it should be. Last, information is dispersed among traders in the market and may not be possessed entirely by one individual. The allocation of relevant information among groups of market participants may determine how fast information is incorporated into market prices and eventually affect how quick mispricing is detected. If relevant information is held mostly by a group with tight budget constraints, traders in that group may not be able to take advantage of their information possession into trade against the market in order to remove the mispricing.

An alternative approach to study the role of arbitrage is in the context of trading out of equilibrium. Market efficiency requires market prices to reflect all relevant information. This only can happen in frictionless markets where there exists no constraints to arbitrage and new information is held by all interested parties. In an efficient market, as soon as new information arises, the market will move instantaneously from the current equilibrium position to a new one. From the view of Rational Expectations theory, any disequilibrium will disappear very quickly if not instantaneously and competitive equilibria will be reached quickly and maintained thereafter until the arrival of new information. The First Theorem of Welfare Economics states that equilibrium in competitive markets without externalities and frictions are Pareto efficient. This means that a market in equilibrium is also trading at an efficient allocation. Generally, every market has certain frictions that reduce the speed by which market prices reach a new equilibrium. There will always be trading out of equilibrium required to move to a new equilibrium. Therefore, during the convergence process, there are trades taking places at out of equilibrium prices and this is where the arbitrage opportunities arise. However, these arbitrage opportunities are a result of information and price changes, and in fact, reflect the incorporation of new information into prices. Thus arbitrage arising from the process of moving to a new equilibrium is temporary and is thus not indicative of market inefficiency. Plus, the speed 
of convergence to equilibrium represents the speed of new information being incorporated in market prices and is a measure of market efficiency.

Once a market is trading at equilibrium, it is efficient. However, what is more interesting is market being out of equilibrium will converge to an efficient allocation under specific conditions. There have been intensive studies on this subject, including Goldman and Starr (1982) in which they characterize the conditions required for a disequilibrium to converge to a Pareto optimal allocation in an exchange market in which traders undertake multiple transactions in small groups and trade directly with each other instead of using an intermediary.

Fisher (1981) develops a model of equilibrium stability which gives insight into how the economy converges to a new equilibrium with different set of allocations and prices after a temporary shock. In the model set up, he allows for the awareness of disequilibrium. Traders are aware that they are trading at out-of-equilibrium prices and prices are expected to change continuously. They are also aware of the risk that they may not be able to complete their transactions at the desirable prices due to the constant price changes. This is an advance on previous studies in which traders are assumed to trade naively. This new awareness will consequently change the trading behavior, as now they optimize their utility by taking into account the price changes, the disequilibrium status of market prices and the risk of transaction failure. The model shows that as soon as information arrives, the equilibrium allocation will move to a new level. Simultaneously at the current price arise arbitrage opportunities. Those opportunities will be arbitraged away quickly by the pursuit of profits and the market will eventually converge to the new equilibrium. This finding indeed supports the Rational Expectations theory which argues that there exists no arbitrage at equilibrium. In a dynamic economy in which it is expected to have new information arriving continuously, equilibrium allocations are not unique and fixed. Arbitrage will cease as soon as the equilibrium allocation is reached. Accordingly, 
arbitrage plays an essential role in the convergence to equilibrium - it is the mechanism of driving mispricing away and moving the economy to new equilibrium corresponding with new information.

Ghosal and Porter (2013)'s study shows similar findings to Fisher (1981)'s. They study whether out-of-equilibrium trading converges to an efficient allocation in a pure exchange economy where there are only two traders (pairwise) and orders are matched randomly. They also allow disequilibrium awareness. In their model set up, trader' preferences are presented by a Cobb-Douglass utility function. Traders trade cautiously acknowledging that their prediction may turn out to be wrong and their knowledge about the preference of their trading partner is limited. They only engage in trading if it increases their utility. As a result, the trading process is path dependent. Ghosal and Porter (2013) confirm Fisher (1981)'s findings about the sources of instability, the certain convergence to optimal allocation and how it is achieved. The authors agree that if there is no arrival of new information or no new perception of opportunities, the economy will stop moving and stay at its equilibrium i.e. being stable. The mechanism of how the economy reaches new equilibrium after a shock explained in their study is similar with that of Fisher (1981). The authors also recognize that arbitrage assists to the convergence to a new equilibrium by driving away old profitable trading opportunities. Their study provides numerical evidence that the trading process in their model converges with probability to pairwise optimal allocations. These allocations are Pareto efficient subject to specific conditions.

In summary, the convergence of out-of-equilibrium trading to efficient allocations provides further insight into the role of arbitrage. Most trading in a market is out of equilibrium and out-of-equilibrium trading converges to efficient allocations under some specific assumptions. Arbitrage opportunities arise as the market is trading out of equilibrium, or in other words, arbitrage is a result of price changes. In frictionless markets, as soon as those opportunities arise, traders will arbitrage them away. Arbitrage contributes to the 
convergence process by removing mispricing in the market and driving market prices to their equilibrium level. The speed at which it does so is a measure of market efficiency.

Therefore, the question is no longer whether arbitrage opportunities exist but how fast they are eliminated so that the market converges to equilibrium. As mentioned earlier, it is very difficult to specify the exact dynamic process of the adjustment to equilibrium and its speed because it depends on the properties of individual markets. The most relevant finding is in study of Ghosal and Porter (2013) in which they use a numerical approach to study the average speed of convergence for a Cobb Douglas utility function. They look mainly at the estimated convergence in average global utility and assess the performance of cautious trading. Their study shows that "the speed of convergence remains exponential with Cobb-Douglass utility functions" for a range of sizes (both in terms of number of goods and number of agents) of economy.

In order to illustrate the role of arbitrage in market equilibrium, Foley (1999) develops an example of statistical equilibrium in a simplified asset market where there is a single financial asset and traders only trade on one side of the market (they either own the asset to sell or own money to buy the asset). He finds that the statistical equilibrium in this market fails to achieve Pareto efficiency because some potential profitable transactions fail to be executed, and there is a dispersion in actual market prices. Thus, there are opportunities for arbitrage (which cannot be exploited by the primitive buyers and sellers because each can transact only on one side of the market). He then allows arbitrageurs to trade on either side of the market and shows that if there is a significant number of arbitrageurs in the market, arbitrage will lead the market to efficiency. The process will continue until the excess demand is eliminated. In this respect, arbitrageurs play the role of an auctioneer whose function is to adjust the auction price according to traders' orders. However, while auctioneer simply plays a role of a coordinator of supply and demand and is exposed to no risks, arbitrageurs face budget constraints and the liquidity risk. 
In summary, the relationship between arbitrage and efficiency is not a black and white story; their mutual interaction is not a simple causation. As investigating market efficiency with regards to arbitrage, the question is not so much about the existence of arbitrage; instead, it is rather about its persistence and significance and more importantly, how long it takes for the market to arbitrage those opportunities away. Arbitrage only indicates market inefficiency when it yields significant profits compared with alternative risk-free investments which are persistent over a long period of time. Alternatively, market instability and the resulting price changes may also elicit arbitrage. Arbitrage, by its nature as a mechanism to remove the price divergence from the efficient level, prompts the convergence of out-of-equilibrium trading to efficient allocations.

\subsubsection{Arbitrage in Prediction Markets}

In principle, arbitrage is risk-free; however, it involves transaction risks in practice. Arbitrage transactions in financial markets involve three main risks. These risk factors and other considerations is often referred to as the limits of arbitrage (Shleifer and Vishny, 1997; Xiong, 2001; Kondor, 2009).

The first is execution risk. Arbitrage is not simply the act of buying a product in one market and selling it in another market for a higher price at some later time. The transactions must occur simultaneously to avoid the exposure to market risk: the risk that prices may change in one market before both transactions are complete. In other words, execution risk arises where it is impossible to close two or more transactions at the same instant. Therefore, there is a possibility that one part of the deal is closed, and there is a quick shift in prices that makes it impossible to close the other at a price that produces an arbitrage profit. 
Second, mismatch risk occurs if the items being sold and bought are not identical and the arbitrage is conducted under the assumption that the prices of the items are correlated and predictable. This can be narrowly referred to as a convergence trade: Arbitrage tends to reduce price discrimination by encouraging people to buy the item when the price is low and sell where price is high. Thus arbitrage has the effect of causing prices in different markets to converge when the items are sufficiently similar. The speed of price convergence is a measure of market efficiency: an efficient market should expect a quick price convergence. Transaction costs, taxes, and other costs provide an impediment to this kind of arbitrage, particularly between different markets.

Last, counterparty risk occurs due to the possibility that a counterparty fails to fulfill their side of a transaction. It might be the failure in making payment to the seller or in delivering the underlying assets to the buyer.

Arbitrage typically refers to the act of exploiting price differences between two or more markets. One possible arbitrage strategy in prediction markets is to exploit the inconsistent pricing of contracts predicting outcomes of the same event. This particular arbitrage strategy fits in the definition of arbitrage because such it is risk-free and produces positive profit. This arbitrage practice is the focus of this chapter and how it is conducted will be discussed in more detail in the next section.

Arbitrage in the iPredict's prediction markets is free from counterparty risk. Any transaction has a human trader on one side and the other side will be either another human trader or the market maker. Trading with the market maker has no counterparty risk. The market maker never fails to fulfill its obligation of the trade because it can create as many shares as it needs to (when it is on the short position) and it is most unlikely for a market maker not to have sufficient funds to complete the trade (when it is on the long position). Trading against a human trader is also free from the counterparty risk. The 
market operator ensures that the long side of the trade has sufficient funds to execute the purchase. iPredict buyers trade on their deposit so transactions will not be executed if they do not have sufficient fund in their deposit to fulfill their purchase. The short side has to pay upfront to insure against the maximum loss before a sale is executed. For instance a trader short-selling a stock (which will close at $\$ 1$ ) at 60 cents does not receive 60 cents immediately once the sale takes place. Instead he has to pay upfront 40 cents to the market maker. This is because in the worst case that the contract closes at $\$ 1$, he has to buy the stock at $\$ 1$ to cover for his precedent short position. The maximum loss of the short sell in this example is 40 cents.

Trading in iPredict is also free from mismatch risk because stocks being traded are identical across contracts in the same event within a prediction market. To the extent that other prediction markets utilise a market maker and deposits, these risks would not be present. Arbitrage in iPredict is exposed only to the execution risk. There may be the case that having closed one side of the deal, a shift in price occurs at the time of closing of the other side. However, this risk is not a serious concern in most prediction markets where traders can observe a schedule of prices to buy or to sell beforehand. Therefore, a shift in market prices may be unavoidable but the new level of market prices, if there is a shift in price, is observable according to the price schedule. In other words, a shift may occur but there is a degree of certainty over the likely new prices.

I do not consider arbitrage across events or across prediction markets in this chapter. Arbitrage across events is not feasible because there is unlikely to exist two (or more) different events that are entirely related and more importantly, share the same attributes especially set of possible outcomes and their associated likelihood.

Arbitrage across prediction markets is possible and actually has been observed in practice overseas. It is quite common that various prediction markets develop contracts predicting 
exactly the same event and it is quite possible that contracts offered by those prediction markets are of the same type (binary, index or spreading contracts) and have the same payout structure. However, conducting this trading practice requires a more complex technique and arguably a great deal more effort spent on watching the markets. The opportunity cost of arbitrage across prediction markets, therefore, will be much higher and consequently make it less profitable for arbitrageurs. There were no other local prediction markets offering index contracts on party vote share for the New Zealand 2011 General Election. While it is possible that there were overseas markets, arbitrage across border obviously introduces further complexity that would reduce the profitability of arbitrage.

\subsection{Theoretical Framework}

\subsubsection{Arbitrage Framework: Without bid and ask Spread}

The most straightforward arbitrage opportunity in prediction markets is to exploit any divergence of the aggregate price of contracts predicting the same event from the contract's payout. The eight index contracts in the vote share market share the same payout value: paying 1 cent for each percentage of the total party vote received by the underlying party. The set of eight contract predicting the same event forms a contract bundle. The bundle price is the aggregate price of all contracts in the same bundle at any point in time.

Because the actual vote share is within 0 and $100 \%$, the contract price varies within $\$ 0$ and $\$ 1$. As the price is assumed to coincide with the estimate of the underlying outcome, i.e. market prices are unbiased, the prices of all contracts predicting the same event must sum up to $\$ 1$, i.e. the bundle price should be equal to $\$ 1$. The aggregate price of $\$ 1$ is a necessary but not sufficient condition of the unbiasedness of market prices. This will be discussed at the end of this section. 
First, I assume that transactions are cost-free. Let $p_{i}(t)$ be the transacted price of contract $i(i=1, \ldots, 8)$ at time $t$ predicting the event whose maturity time is $T$. At time $T$, the actual outcome is realized and all contracts are closed and pay out. All contracts $i$ are launched at the same time $(t=0)$ and closed at the same maturity time $T$.

Let

$$
p(t)=\sum_{i=1}^{8} p_{i}(t)
$$

be the aggregate price of all contracts $i$ at time $t$.

At maturity $T$, because the total vote sums up to $100 \%$, the aggregate price of all contracts is exactly $\$ 1$ so is the total payout.

$$
p(T)=\sum_{i=1}^{8} p_{i}(T)=\$ 1
$$

At any time $t$, the aggregate price $p(t)$ should be $\$ 1$ otherwise arbitrage will arise by exploiting the divergence of $p(t)$ from $\$ 1$. Arbitrage exploiting the mispricing of the bundle price arises in two scenarios, each requiring a different strategy but both bear no risk. First, if $p(t)<\$ 1$, there is at least one underpriced contract. Arbitrage requires purchasing the entire bundle i.e. holding one share of each contract and holding it until the close time $T$. At maturity $T$, the bundle will pay out $\$ 1$. Arbitrage profit is $\$ 1-p(t)$. Second, if $p(t)>\$ 1$, there is at least one overpriced contract. Arbitrage requires short-selling the entire bundle (i.e. sell one share of each contract) and hold it until time $T$. At time $T$, the bundle is worth $\$ 1$, and he will buy the bundle which costs $\$ 1$ to cover his precedent short position. Arbitrage profit in this case is $p(t)-\$ 1$.

Let $y(t)$ be the difference between $p(t)$ and $\$ 1$. Arbitrage arises whenever 


$$
y(t)=p(t)-\$ 1 \neq 0
$$

Accordingly, arbitrage profit is

$$
\pi(t)=|y(t)|=|p(t)-\$ 1|
$$

In practice, there may exist situations of measured $y \neq 0$ that arise because the price level is in the process of change (trading out of equilibrium). This might show up as serial correlation in $y(t)$; arbitrage profit is higher when prices change in response to the arrival of new information. The efficient market hypothesis says that in a complete or fully efficient market $y(t)$ should not be serially correlated. If serial correlation appears because of the adjustment in price level changes to the arrival of new information, it is unlikely to be persistent. This is due to trading out of equilibrium and these market level price changes will presumably happen quickly.

Next, the assumption of cost-free transactions is relaxed, the condition for an arbitrage to be profitable in Equation (4.3) no longer holds. Instead, arbitrage is only profitable if the gain from arbitrage is sufficient to cover transaction costs, otherwise there is no incentive to arbitrage.

Transaction cost varies in prediction markets. iPredict charges three different types of fees. A trading fee of $\$ 0.0035$ per share traded (35 cents per 100 shares traded) was introduced in August 2011. Also, a 1.75\% fee on credit card deposits is paid to the bank. This cost can be easily avoided by a manual deposit into iPredict's bank account. Last, a withdrawal fee of $2 \%$ or $\$ 2$ (whichever is greater) is incurred only if the trader has positive earnings on iPredict. Only the trading fee of $\$ 0.0035$ per share traded should be included as transaction cost in this framework because it is incurred as soon as the 
transaction occurs. The fee on credit card deposit is avoidable (by a manual deposit) and the withdrawal fees incurs only when a withdrawal of funds is made into cash.

In the presence of transaction costs, arbitrage also arises in two scenarios as mentioned above. However, in order to ensure that the arbitrage is profitable, arbitrage arises whenever $p(t)$ is greater than $\$ 1+\$ 0.028=\$ 1.028$ or less than $\$ 1-\$ 0.028=\$ 0.972^{2}$. The two conditions are explained as follows. First, if $p(t)<\$ 0.972$, arbitrage requires purchasing the entire bundle ( 8 transactions to be made), and holding it until the close time $T$. The purchase costs $p(t)+\$ 0.028$. At maturity $T$, the trader will be paid $\$ 1$. The arbitrage profit is thus $\$ 1-p(t)-\$ 0.028=\$ 0.972-p(t)>0$.

Second, if $p(t)>\$ 1.028$, an arbitrageur will short-sell the entire bundle and receive $p(t)-\$ 0.028$ from the sale. At time $T$, he will have to buy the bundle to cover his precedent short position. At $T$, the bundle price is $\$ 1$. The purchase costs him $\$ 1.028$. Arbitrage profit is $p(t)-\$ 1-2 \times \$ 0.028$. This implies that the short-sell-and-cover strategy would cost more than the buy-now-and-hold strategy. However, iPredict offers a feature to eliminate the cost disadvantage of short-selling practice and encourage arbitrage. The feature called Buy-a-Bundle allows purchasing a contract bundle at $\$ 1$; this means that purchasing an entire bundle is not subject to the trading fee. So whenever $p(t)>\$ 1.028$, arbitrage strategy is as follows: Use Buy-a-Bundle feature to buy the entire bundle at $\$ 1$ and right after the purchase sell it for $p(t)$, the purchase will incur transaction cost $\$ 0.028$. Adopting this strategy, arbitrage profit will be $p(t)-\$ 1.028>0$.

In summary, arbitrage profit when there exists a transaction cost equals:

\footnotetext{
${ }^{2}$ The cost of trading a bundle of eight contracts is $8 \times \$ 0.0035=\$ 0.028$.
} 


$$
\begin{gathered}
\pi(t)=\max (0,|p(t)-\$ 1|-\$ 0.028) \\
\quad \text { or equivalently } \\
\pi(t)=\max (0,|y(t)|-\$ 0.028)
\end{gathered}
$$

The above arbitrage strategies fit in the definition of arbitrage because they are exposed to no risk and produce guaranteed positive profits. The term "no risk" simply relates to the fact that traders do not speculate on the movement of the market price. This trading practice does not require the possession of superior information in order to beat the market. Arbitrage in iPredict is exposed to the execution risk but this is not a serious issue. Even though there still exists the risk that their orders are not to executed at the desirable price, traders would not be totally surprised by the shift in price because they can observe the price schedule of offers to buy and to sell beforehand. Arbitrage according to this framework does not suffer mismatch risk because it does not involve trading items across different prediction markets. Counterparty risk should not be a concern either. The market maker is always able to fulfill its obligation to a trade therefore the counterparty risk as trading against market maker is almost zero because in iPredict, the contract payout on contracts is financed mostly by traders' funds. Traders' funds are held in a trust account separate from iPredict's account; iPredict's creditors do not have access to that trust account. If one trades against another trader, his long position is secure because market maker requires short-sellers to pay upfront for the maximum loss. If he takes short position, market maker will ensure that the other side of the trade has sufficient fund otherwise the transaction will not be executed.

There are a few issues with this framework which need to be addressed. First, the derivation of arbitrage profit in Equation (4.4) and (4.5) requires an underlying assumption that at any time $t$, trader can buy and sell shares at the same price, i.e the price order to buy coincides with the price offer to sell. In order words, there is no price discrimination between sell and buy orders. In practice, the offer prices to buy and sell never coincide. 
From the perspective of traders, price offer to buy is always higher than that to sell. This assumption will be relaxed in Section 4.2.2.

The second issue is that the framework ignores the fact that arbitrage at any time $t$ has to be based on the current offers in the market at time $t$, not the last traded price. This price is historical and may be no longer available for trading at the current time. Arbitrage based on this last traded price may mislead the possibility and significance of arbitrage in the market. For instance, suppose at time $t$, a purchase occurs at the price 40 cents. If the volume of the this trade is sufficient to move up the market price above 40 cents then any traders coming to the market wish to buy the stock will have to pay a higher price than 40 cents (assume other things remain constant). This issue will be addressed in Section 4.2.2.

Third, if more than one unit of a bundle is traded at a time, it is not guaranteed that the second unit will be traded at the same price as the first unit or not all units may be acquirable or saleable at the same price. Recall the table listing buy and sell offers in a market of iPredict (Figure 2.1), if a trader attempts to buy 200 shares, he will have to pay 50 cents per share for the first 100 shares and 51.67 cents for the last 100 shares. The framework does not capture this price discrimination associated with the size of trading orders. In order to keep this simple, I examine arbitrage on the basis of one share traded at a time. This means that every transaction is either to buy or sell a unit of share.

The fourth issue comes from the fact that the framework does not capture a cost associated with the timing of transaction. As capital is invested to buy shares, until the close day of the contract that capital is tied up in the form of shares. The foregone returns from reinvesting the capital is considered as an opportunity cost. Of the two arbitrage strategies described above, only the buy-now-and-hold strategy exploiting the $p(t)$ being smaller than $\$ 1$ incurs this cost. This strategy requires the trader to invest capital to buy shares now and hold them until the contract is closed. This opportunity cost gets 
larger as the purchase of shares occurs at earlier time to the maturity $T$. For instance, arbitrage occurring one week before the close day of contract bears less cost than that occurring one month before.

The fifth issue is that the derivation of arbitrage profit ignores the discount factor. The payoff of an arbitrage received at maturity should be discounted at an appropriate discounting rate. Accordingly, arbitrage profit will be the absolute value of the difference between the present value of the payoff $(\$ 1)$ and $y(t)$ instead. As a result, ignoring the discount factor arbitrage profit calculated by this framework is expected to be overestimated. This issue will be addressed and fixed in Section 4.3 when the arbitrage returns is discounted in order to be in the comparison with risk-free rates.

Sixth, the framework also ignores the cap on trading fee. The trading fee is capped at $5 \%$ of any trade's gross cash value, and capped at $\$ 5$ per month per user. Obviously, to traders who conduct trades large value, the trading fee per share to be paid by him is less than the standard 0.35 cents per share. It is difficult to take this limit in trading fee into account because it depends on each individual's total trading value.

The last issue involves the relationship of the unbiasedness of prediction market prices Assume that prediction market prices coincide exactly with the market's aggregate belief. i.e. the market prices are unbiased and an accurate predictor of the event. Then the condition for an arbitrage to arise provided in the framework holds: the aggregate price of contracts predicting the same event diverges from $\$ 1$. However, the framework is also able to detect arbitrage even when prediction market prices are not unbiased. Consider an event with two possible and mutually exclusive outcomes whose market prices are called $p_{1}$ and $p_{2}(i=1,2)$. Arbitrage arises whenever $p_{1}+p_{2} \neq \$ 1$ (assume no transaction cost). This condition does not require the unbiasedness of market prices. For instance, the market believes that the probabilities that the outcome 1 and 2 occurs are $30 \%$ and $70 \%$ but 
their contracts' market prices are 50 cents and 60 cents, respectively. This means that the market price of contract 1 is overpriced and that of contract 2 is underpriced. The market prices are biased but their aggregate price is greater than $\$ 1$ (\$1.1). According to the framework, arbitrage is detected which requires short selling a bundle consisting of one share of each contract for $\$ 1.1$. When the outcomes are realized and contracts are closed, arbitrager pays $\$ 1$ to cover their precedent short position and realizes the profit of 10 cents. Besides, there exists another strategy to exploit the mispricing in contract 1 and contract 2: short sell the overpriced $p_{1}$ and buy the underpriced $p_{2}$. However, this trading practice which relies on the mispricing in individual contracts is not considered arbitrage even though it produces positive profit. This is because this profit is not a risk-free. In order to take advantage of this mispricing, a trader is required to have information as to which contract is underprice and overpriced. This sort of information can never be obtained with $100 \%$ of certainty until the outcome of the event is realized. This practice fits in better the definition of speculation than arbitrage and thus is not considered in this study.

Efficiency reflects the extent to which information is incorporated into market prices. To the extent that this precludes irrelevant information (that does not influence the underlying value of asset) then prices in a truly efficient market should be influenced only by information that affects the asset and should be unaffected by extraneous factors such as traders' biases. However, the issue is not whether prediction markets are completely efficient but rather the extent to which any inefficiencies influence the market pricing. Thus in my examination of efficiency I do not look for unbiased prices for each and every contract. Instead, this thesis limits itself to examining whether the pricing of the bundle of contracts is indicative of inefficiency. It is entirely possible that trading in a particular contract is biased. However, if that bias is offset by an equal but opposite bias in the other contracts then the price of the resulting bundle is unlikely to be significantly different from $\$ 1$. Accordingly, if prices are unbiased, there will be no arbitrage in the market. 
However, the argument in the opposite direction is not necessarily true. The existence of no arbitrage does not guarantee that the market prices are unbiased. Consider the above example, the market prices $p_{1}$ and $p_{2}$ are 40 cents and 60 cents instead. According to the framework, no arbitrage opportunity is detected but the market obviously misprices the probability of the occurrence of the two outcomes, i.e. the market prices are biased. In short, the existence of arbitrage is an indicator of market inefficiency but the existence of no-arbitrage is a necessary but not sufficient condition of market efficiency.

Further, the deviation of market prices from the mean of market expectation may be a result of out-of-equilibrium trading. When the unbiasedness of prediction market prices creates arbitrage opportunities as in one of the examples above, it does not imply market inefficiency as long as traders, in the pursuit of profits, drive away those opportunities quickly. The act of arbitrage constitutes the process which brings the unbiased market prices to their fundamental level and simultaneously contributes to the process of converging out-of-equilibrium trading to efficient allocations.

\subsubsection{Arbitrage Framework: With bid and ask Spread}

The analysis in the previous section investigates the possibility of arbitrage based on prices at which the last transaction occurs. This implicitly ignores the fact that as transaction prices are historical and anyone coming to trade in the market has to accept the currently available offers. If he wants to buy (sell) stocks, he will have to trade at the lowest (highest) available ask (bid) order in the market. The previous framework in Section 4.2.1 ignored the effect of bid and ask spread on arbitrage in prediction markets. At any single point in time the bid order has to be smaller than the ask order.

Let $p_{i}^{b}(t)$ and $p_{i}^{a}(t)$ be the bid and ask offers of contract $i$ at time $t$ respectively. Any trader who wants to sell (or buy) shares of contract $i$ at time $t$ has to accept $p_{i}^{b}(t)$ (or $\left.p_{i}^{a}(t)\right)$. 
Let $p^{b}(t)$ and $p^{a}(t)$ be the aggregate bid and ask order of all contracts $i$ at time $t$ respectively.

$$
\begin{aligned}
& p^{b}(t)=\sum_{i=1}^{8} p_{i}^{b}(t) \\
& p^{a}(t)=\sum_{i=1}^{8} p_{i}^{a}(t)
\end{aligned}
$$

Let $y^{b}(t)$ and $y^{a}(t)$ be the difference between the aggregate bid and ask order of all contracts $i$ and the contract payout $\$ 1$ at time $t$ respectively.

$$
\begin{aligned}
& y^{b}(t)=p^{b}(t)-\$ 1 \\
& y^{a}(t)=p^{a}(t)-\$ 1
\end{aligned}
$$

First I assume that transactions do not incur costs. In the presence of bid and ask spread, it is no longer true that arbitrage is profitable whenever the aggregate price of the last transaction diverges from its efficient level (i.e. $\$ 1$ ). Instead, arbitrage only arises whenever one of the following conditions is satisfied. First, the aggregate ask order of all contracts in the same market at any time t before the announcement is less than $\$ 1$. Arbitrage in this case requires buying a unit of contract bundle, paying $p^{a}(t)$ in total. The portfolio is held until the contract's maturity. The total payout is $\$ 1$. Arbitrage profit is thus the difference between $\$ 1$ and $p^{a}(t)$. It can be written as:

Condition: $p^{a}(t)<\$ 1$ i.e. $y^{a}(t)<0$

Arbitrage profit: $\pi(t)$ (buy and hold) $=\$ 1-p^{a}(t)=-y^{a}(t)$

Second, the aggregate bid order of all contracts in the same market is greater than $\$ 1$. Arbitrage opportunity requires short-selling a unit of contract bundle for $p^{b}(t)$. On the maturity date, the payoff from the bundle is $\$ 1$ and trader will pay $\$ 1$ to cover for his 
precedent short position. It can be written as:

Condition: $p^{b}(t)>\$ 1$ i.e. $y^{b}(t)>0$

Arbitrage profit: $\pi(t)$ (short and cover) $=\$ 1-p^{b}(t)=y^{b}(t)$

In sum, in the absence of transaction costs, the arbitrage profit at any time $t$ is:

$$
\pi(t)= \begin{cases}-y^{a}(t) & \text { if } y^{a}(t)<0 \\ y^{b}(t) & \text { if } y^{b}(t)>0 \\ 0 & \text { otherwise }\end{cases}
$$

The conditions of $y^{a}(t)<0$ and $y^{b}(t)>0$ are mutually exclusive because $y^{b}(t)<y^{a}(t)$ is always true. Thus $\pi(t)$ can be written as:

$$
\pi(t)=\max \left(-y^{a}(t), y^{b}(t), 0\right)
$$

In the presence of transaction costs, buying and selling stocks incur costs. The only relevant cost associated with trading in iPredict is the transaction fee of $\$ 0.0035$ per share traded or $\$ 0.028$ per bundle. Taking this transaction fee into the analysis, arbitrage arises whenever:

$$
\begin{aligned}
& -y^{a}(t)-\$ 0.028>0(\text { buy and hold }), \text { or } \\
& y^{b}(t)-\$ 0.028>0(\text { short sell and cover })
\end{aligned}
$$

Arbitrage profit in the presence of transaction costs thus equals: 


$$
\pi(t)= \begin{cases}-y^{a}(t)-\$ 0.028 & \text { if }-y^{a}(t)>\$ 0.028 \\ y^{b}(t)-\$ 0.028 & \text { if } y^{b}(t)>\$ 0.028 \\ 0 & \text { otherwise }\end{cases}
$$

or equivalently,

$$
\pi(t)=\max \left\{-y^{a}(t)-\$ 0.028, y^{b}(t)-\$ 0.028,0\right\}
$$

Empirical analysis requires designing a scheme to derive bid and ask offers at a single point in time. When a trade takes place in iPredict, the system only records prices and other information relevant to the transaction. In other words, historical bid and ask offers are not available. Figure 4.1 shows an example of the price schedule. The contract's last traded price is $\$ 0.9116$. In addition, traders would see a schedule of buy and sell orders available at this specific time. Any trader who wants to buy stocks knows that he would have to pay $\$ 0.9116$ per share for the first 10 shares and $\$ 0.9168$ for the next 10 shares and etc. Similarly, whoever wants to sell stocks knows that he would be able to sell the first 10 shares he owns at $\$ 0.9061$ per share and the next 10 shares at for $\$ 0.9116$ per share. The last traded price of this contract pi(t) is $\$ 0.9116$, the bid order $p_{i}^{b}(t)$ is $\$ 0.9061$ and the ask order $p_{i}^{a}(t)$ is $\$ 0.9116$. The last traded price and the ask order happen to coincide in this case but this is merely coincidence and is not necessarily true all the time. 
Figure 4.1: An example of a price schedule

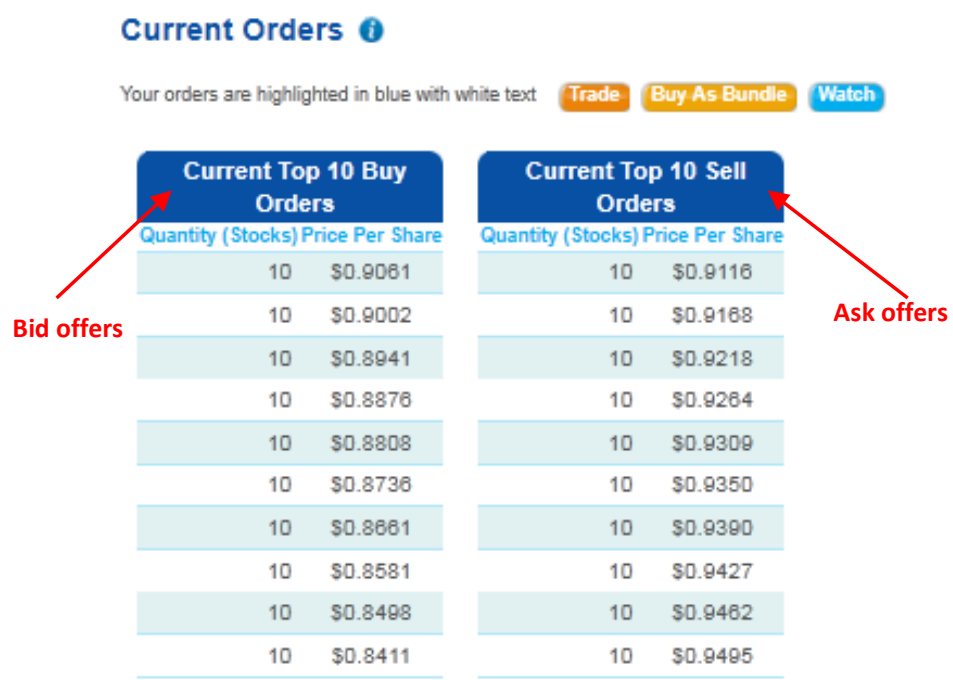

While in practice the schedule of bid and ask offers has multiple units at each price level, for simplicity I assume that only one unit is offered for purchase or sale at each order price. Thus, if a purchase (or sale) of a share of a stock occurs at price $p_{i}(t)$, it will remove the ask (or bid) order on the top of the pricing schedule and the market maker will fill it with a new buy (or sell) order. Any trader coming to the market after a successful transaction has to trade at the new ask (or bid) order. Given the assumption that all bid and ask offers are made by only the market maker, I derive bid and ask offers at each traded price by imitating the mechanism applied by the market maker (S-curve and the formula in Section 2.2. This assumption implicitly ignores the fact that human traders can submit their own bid and ask offers to the market. The mechanism of deriving bid and ask offers are manually constructed assuming that the sensitivity of the S-curve is fixed during the contract's lifetime. In practice, there occurs cases in which market maker adjusts the sensitivity of the S-curve in order to ensure the subsidy loss is within the allowed level and this accordingly affects the bid and ask spread and the liquidity of the market. 


\subsection{Empirical Results}

The eight contracts in the vote share market are bundled in that the sum of their payouts equals $\$ 1$, as should the aggregate price of the bundle at any given time. Arbitrage in the vote share market is analyzed by using the framework constructed in Section 4.2. In the absence of the bid and ask spread, the necessary and sufficient condition for a profitable arbitrage is that the aggregate price of the bundle differs from $\$ 1$ where the divergence is greater than 2.8 cents $^{3}$ when trading fee is in place after August 2011 otherwise zero. If the aggregate price is less than $\$ 1$, arbitrageurs can buy the entire bundle and hold it until the close date of the contracts. If the aggregate price is greater than $\$ 1$, arbitrageurs can short the bundle and cover their precedent short position at the close date by buying the bundle for $\$ 1$. In both cases, the arbitrage profit is the absolute value of the difference of $\$ 1$ and the aggregate price at a given time.

When the bid and ask spread is taken into account, arbitrage arises only when either the cost of buying the bundle (i.e. the aggregate bid orders of all contracts) is greater than $\$ 1$ or the cost of shorting the bundle (i.e. the aggregate ask orders) is less than $\$ 1$ and then only if the difference is greater than the trading cost of 2.8 cents. In both cases, the arbitrage profit is the absolute value of the difference of the aggregate bid (or ask) order and $\$ 1$. The trading fee of 2.8 cents per bundle traded is only applied to transactions occurring after August 2011.

The empirical analysis has resulted in some observations as follows. First, without considering the bid and ask spread, the (unconditional) mean of arbitrage profit is 0.5 cents and the probability of arbitrage is $50 \%$ out of the total number of transactions when taking into account the bid and ask, they drop to 0.21 cents and $21.8 \%$. Second, in order to determine whether an arbitrage is profitable compared to the alternative, I compare

\footnotetext{
${ }^{3}$ The trading fee of buying or selling a bundle containing a share of each contract equals $8 \times 0.35$ cents $=2.8$ cents.
} 
its rate of return with the contemporaneous risk-free rate. The return on arbitrage in the absence of the bid and ask spread is calculated as the ratio of the arbitrage profit $\left(\pi_{t}\right)$ to its cost which is the sum of the aggregate last-traded price $\left(p_{t}\right)$ and the trading fee of 2.8 cents at any given time $t$. In the presence of the bid and ask spread, the last-traded price is replaced by the ask order $\left(p_{t}^{a}\right)$ where arbitrage involves buy and hold or the bid order $\left(p_{t}^{b}\right)$ where arbitrage involves short sell and cover.

Without the bid and ask spread: $R O R_{t}=\frac{\pi_{t}}{p_{t}+\$ 0.028}$

With the bid and ask spread: $R O R_{t}=\frac{\pi_{t}}{p_{t}^{a}+\$ 0.028}$ (buy and hold)

$$
R O R_{t}=\frac{\pi_{t}}{p_{t}^{b}+\$ 0.028} \text { (short and cover) }
$$

The average $R O R$ without the bid and ask spread is $4.8 \%$ while that in the presence of the bid and ask spread is $0.2 \%$; their maximum values are $4 \%$ and $3 \%$, respectively. I use the one-year secondary market government bond yield as the benchmark risk-free rate because the vote share market was running for approximately one year (404 days). Within November 2, 2010 to December 10, 2011, the average of the New Zealand government bond yield are $2.88^{4}$. From Figure 4.2 , the daily average arbitrage return in the vote share market is considerably below the contemporaneous risk-free rate during most of its lifetime, except for a strong rise on March 24, 2011 (explained below). Any investment yielding a return less than the risk-free rate should not be undertaken because its return is not sufficient to cover the opportunity cost. If the extreme arbitrage on March 24, 2011 is considered as an outlier, arbitrage in the vote share market never yielded a higher return than the bond yield. If the non-existence of arbitrage is a necessary condition of market efficiency then it is satisfied in the vote share market.

\footnotetext{
${ }^{4}$ Source: Reserve Bank of New Zealand, Reuters http://www.rbnz.govt.nz/statistics/exandint/b2/hb2-daily.xls No daily data was available for the period of August to December 2011.
} 
Figure 4.2: Daily average arbitrage returns vs. risk free rate

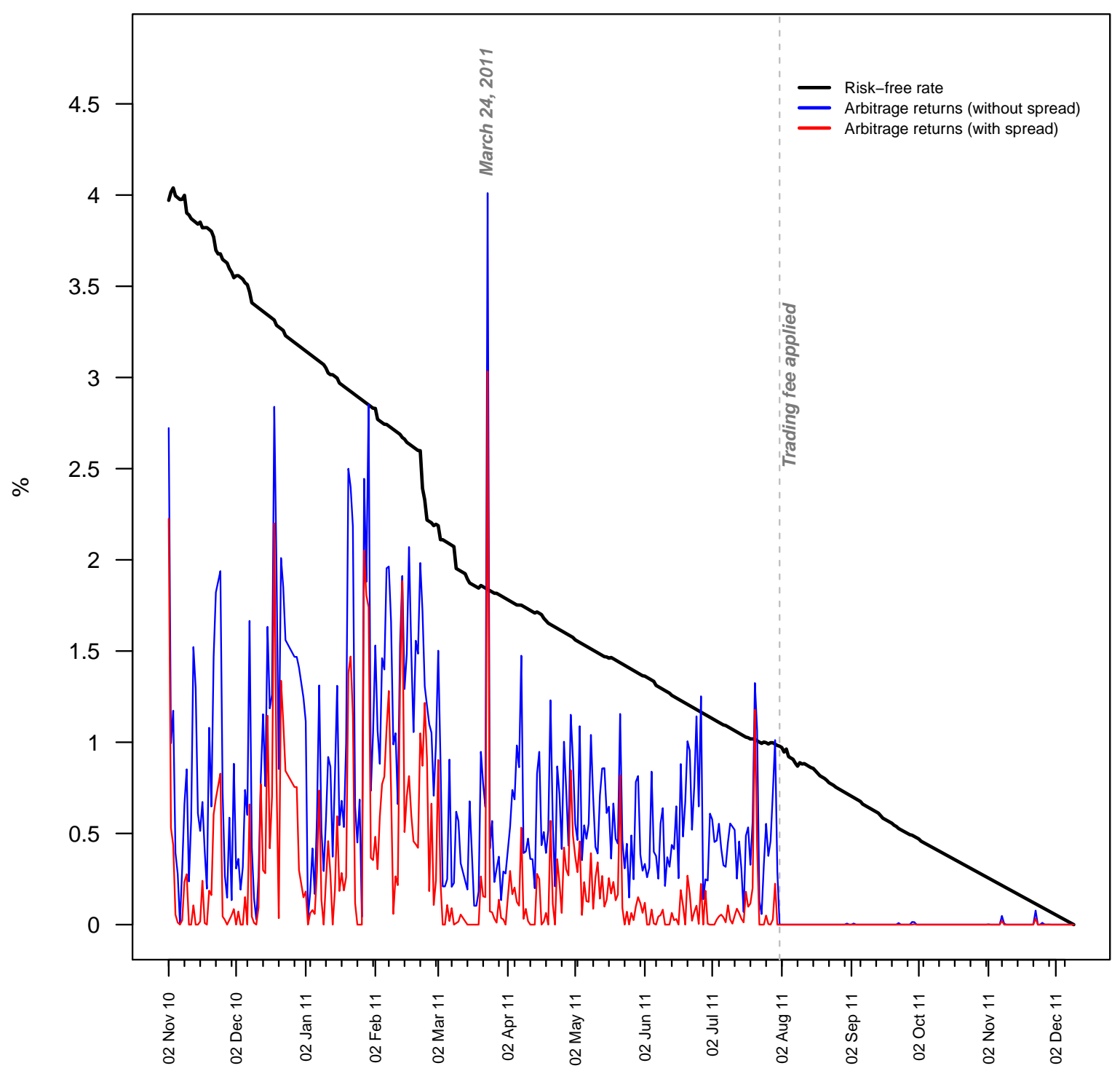

Note: The risk-free rates are adjusted to match the time to maturity with arbitrage ROR.

The daily average is computed as the mean return across all transactions for all contracts.

Figure 4.3 gives further insight into how arbitrage opportunities compete with a riskfree investment. Showing that the arbitrage opportunities are not persistent, they are eliminated very quickly. The top graph plots the proportion of intra-day arbitrage returns that are greater than the risk-free rate on the same day. Apart from the exception on March 24, 2011, there are three occurrences when arbitrage seems to be obvious. The 
occurrence in January 2011 can be explained as a result of low trading day ${ }^{5}$ which can be seen in the bottom plot showing the daily number of transactions.

\footnotetext{
${ }^{5}$ Of all transactions:

- January 30, 2011: Proportion without spread $=42 \%$ and with spread $=22 \%$. Number of transactions $=45$.

- June 27, 2011: Proportion without spread $=65 \%$ and with spread $=0 \%$. Number of transactions $=60$.

- July 21, 2011: Proportion without spread $=78 \%$ and with spread $=27 \%$. Number of transactions $=27$
}

Overall market: Mean (daily transactions) $=51$. Median (daily transactions $)=29$. 
Figure 4.3: Positive arbitrage returns as a proportion of total transactions per day
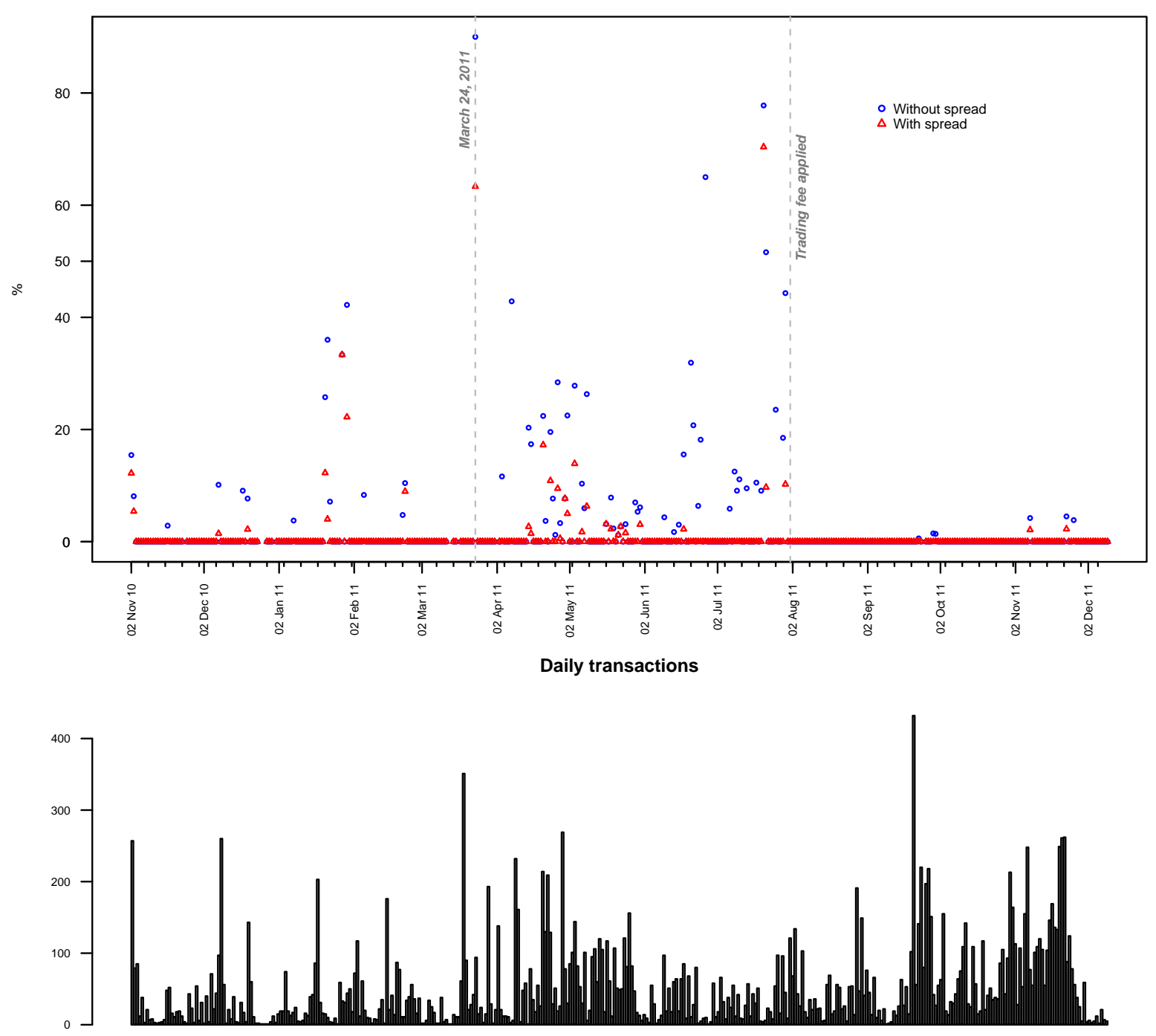

Note: There are 69 and 33 out of 404 days in which arbitrage returns in the absence and presence of bid and ask spread, respectively are greater than the risk-free rate.

Last, one might intuitively expect a negative correlation of the arbitrage possibility $(y(t))$ and the time to maturity as a result of the arrival of new information. As the final outcome draws closer, more information is revealed and that helps to correct mispricings. However, this phenomena is not observed in the vote share market. Figure 4.4 shows no obvious pattern in both $y$ and $|y|$ over the time. The spike on the launching date of the 
market was the result of a surge in the purchase of Green shares to push its price from the initial price of 7.24 cents up to 36.6 cents. The initial price is subjectively set by iPredict's administrator. However, it was quickly driven back within 10 minutes to the initial level by a number of sales.

Figure 4.4: Arbitrage possibility in the vote share market over the whole contract period

Plot of $y$

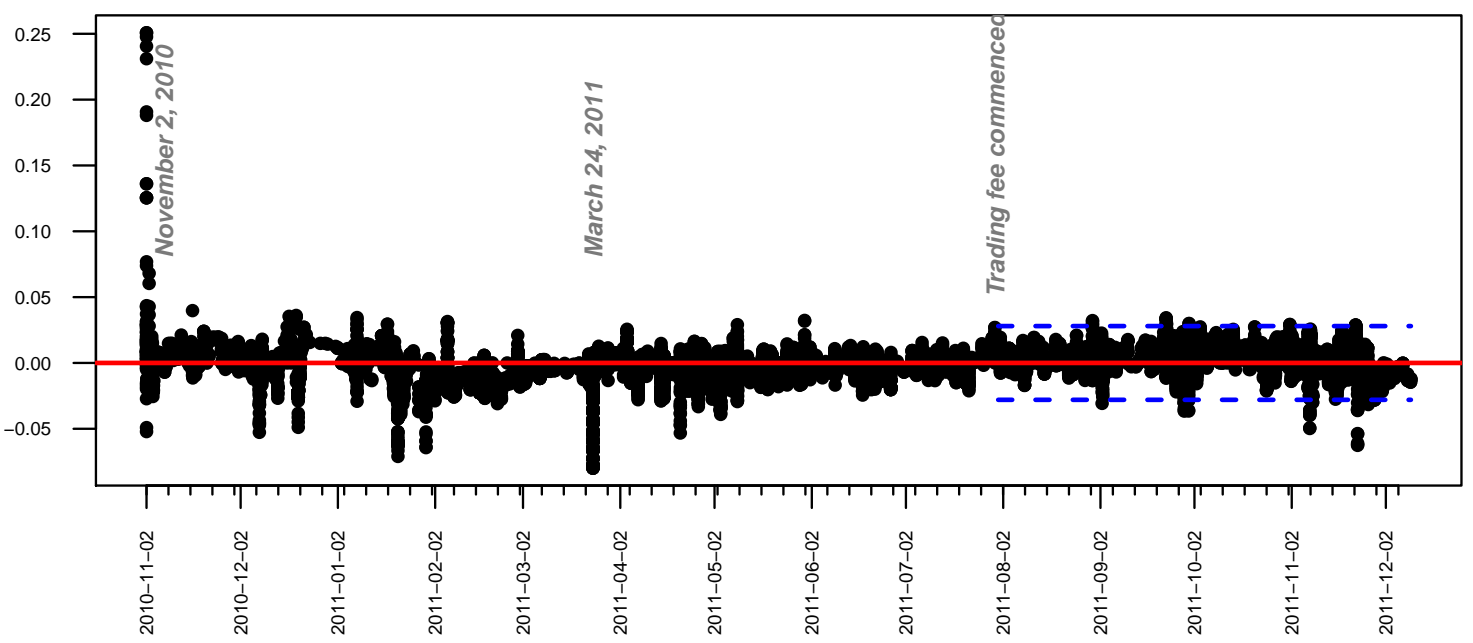

Plot of $|\mathbf{y}|$

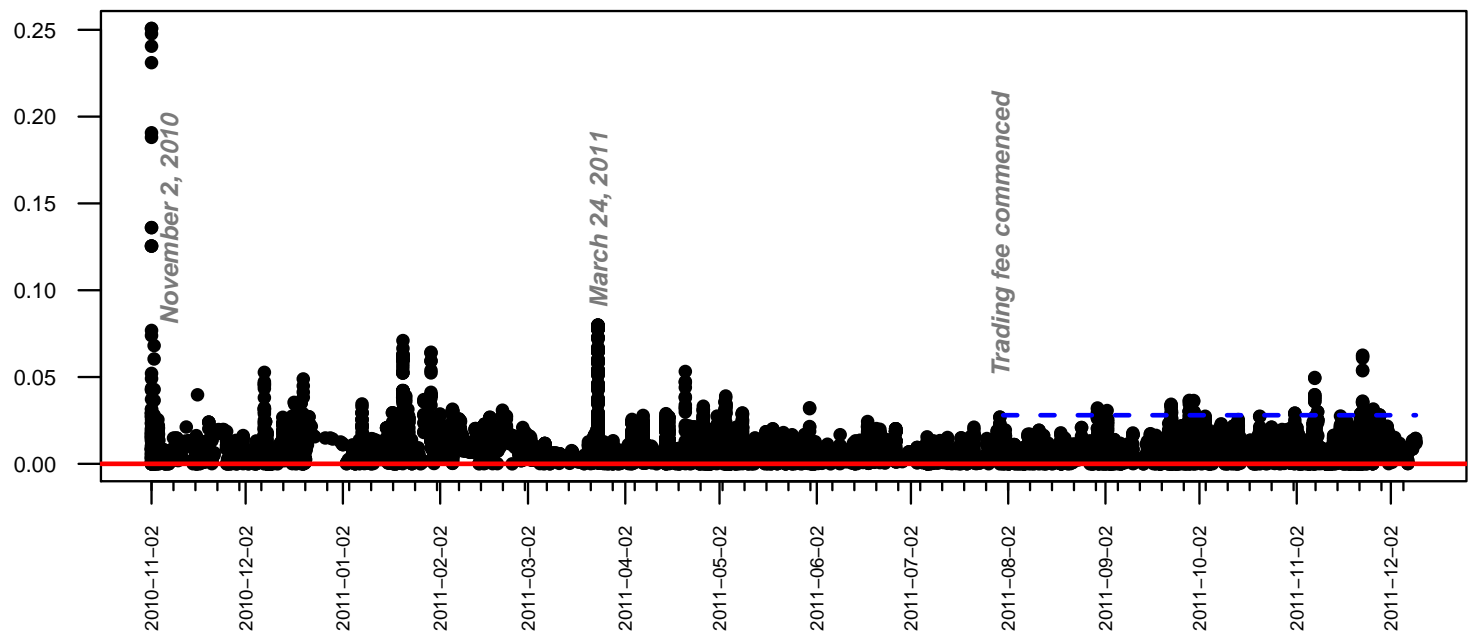

Note: The dash line represents the trading fee of 0.028 cents per bundle.

As the variable $y(t)$ reflects arbitrage possibility and $|y(t)|$ is a measure of arbitrage profit, 
a sharp drop in $y$ (and associated sharp rise in $|y(t)|$ ) at 21.00pm on March 24, 2011 as seen in Figure 4.2 - 4.4 indicates an unusually profitable arbitrage opportunity. The value of $|y|$ rose to $\$ 0.08$ and gradually fell back to $\$ 0$ on March 25,2011 . This was caused by a strong sale of 200 National shares and 200 Green shares which resulted in a sharp drop in both contract prices: National dropped from 46.51 cents to 40 cents and Green 7.45 cents down to 5.12 cents without being accompanied by any increases in other contracts' prices. However, this opportunity did not last for long. Realizing this sudden change in the National and Green contract, a trader almost instantly (within few minutes) started to trade against the sale. He bought a large and different amount of shares of all contracts. As the result, prices of all these contracts rose: the National contract from 40 cents to 43.05 cents, the Labour contract from 31 cents to 32.7 cents, the Green contract from 5.12 cents to 5.95 cents, the ACT contract from 3.99 cents to 4.65 cents, the United Future contract from 2.28 cents to 3.9 cents, the New Zealand First contract 3.5 cents to 1.5 cents and the Other contract 2.56 cents to 2.87 cents. This trader also bought a small amount of Māori contract shares but insufficient to bid up its price. The strong purchase in all the contracts offset the negativity in $y$, it eventually drove $y$ from -0.08 to -0.012 before $10.30 \mathrm{pm}$, within 1.30 hours. The negativity in $y$ was not offset entirely until early morning on March 25, 2011 when a third trader entered the market and bought more National shares and pushed its price back to its prior-the-shock level. The level of $y$ was driven back to 0 by $7.00 \mathrm{am}$ on that day.

The trading behaviour of the second trader is more of interest. His purchases of shares of all contracts to exploit the mispricing in $y$ illustrates the arbitrage practice as discussed previously. He may have seen the drop in National and Green prices as an indication of a shift of support toward other parties and National or Green being underpriced. However, his trading does not entirely fit arbitrage for two reasons. First, the trader did not hold shares until the close day, instead he sold them shortly after the purchase. One possible explanation for this "early" liquidation is that he would not need to wait until the close 
day to receive the payout if he could sell those shares at any point in time prior as long as the aggregate price went above at least $\$ 1$. It might have been his intention to regain the portfolio's liquidity and sell ahead of the close. Second, he did not buy the same amount of shares of each contract, i.e. fix the bundle. The arbitrage on my assumption requires buying multiple bundles in which each contains one share of each contract. However, this may be due to the position of his existing portfolio in which he already owned shares of some contracts.

A similar arbitrage strategy was studied by Luckner et al. (2012) and applied to STOCCER - an experimental market set up to predict outcomes of the FIFA World Cup in 2006 using virtual currency. After taking into account the bid and ask spread, they unsurprisingly showed that the occurrence and persistence of profitable arbitrage opportunities reduced significantly when they increased an arbitrary cut-off point for identifying arbitrage opportunities from one percent of the payout to ten percent. The study simply counts the number of occasions where arbitrage occurs and produces returns that are greater than the present cut-off point. It is not clear whether they considered transactions costs. 


\section{Chapter 5}

\section{Properties of Prices in an Efficient}

\section{Market}

The specification of price change time series has an implication of information reflected in the market prices which consequently indicates the degree of market efficiency. In the context of the EMH, tests of weak form efficiency come from the random walk model. In essence, a random walk means that it is not possible to earn abnormal risk-free returns by trading according to an expected trend.

Furthermore, a random walk process is a non-stationary process whether or not it has a constant drift (See Proof in Footnote ${ }^{1}$ ). A stochastic process is said to be stationary if its mean, variance and covariance (in general, its distribution) are constant over time. A weakly stationary process whose mean and variance are constant will have a tendency to return to its mean (mean reversion) and any fluctuations around its mean will have

\footnotetext{
${ }^{1}$ Given a white noise process: $u_{t} \sim N\left(0, \sigma^{2}\right)$ Random walk model without drift can be written: $P_{t}=P_{t-1}+u_{t}$ such that $P_{t}=P_{0}+\sum u_{t}$. Therefore $E\left(P_{t}\right)=P_{0}=$ constant since errors have zero expectation. Similarly, $\operatorname{Var}\left(P_{t}\right)=t \sigma^{2}$, i.e. it is dependent on time. Hence, random walk model without a drift is a non-stationary process. Although its mean is constant over time, its variance increases over time. In this model, shock persist as the current value is equal to the initial plus a series of random shocks over time.

A random walk model with a drift can be written: $P_{t}=\alpha+P_{t-1}+u_{t}$ such that $P_{t}=t \alpha+P_{0}+\sum u_{t}$. Therefore $E\left(P_{t}\right)=t \alpha+P_{0}$. Similarly, $\operatorname{Var}\left(P_{t}\right)=t \alpha^{2}$. Hence a random walk model with a drift is a non-stationary process because both its mean and variance increase over time.
} 
broadly constant magnitude. Alternatively, the constant variance property will ensure that the process will not drift too far from its mean. In contrast, the mean or variance or both of a non-stationary process will vary over time.

The weak-form EMH states that stock prices in efficient markets follow a random walk therefore the time series of efficient stock prices is a non-stationary process, more importantly without a constant drift so that there is no opportunity for profitable speculation in the market. Essentially, the change in stock price from one period to another is random and unpredictable ${ }^{2}$. The drift is essentially zero otherwise price in the next period is bounded to change by a constant level which eventually creates a certain pattern in the price change process. Furthermore, if a variable follows a random walk model both with or without the constant drift then its first differences are stationary ${ }^{3}$. In sum, the random walk and the (non-) stationary process have mutual implication of the market efficient which can be summarized as follow: Prices in a (weakly) efficient market follow a random walk model and therefore have a non-stationary process without a constant drift. Thus, the one-period price change series is a stationary process.

As stated earlier, the regression between the market price changes and the change in poll results produces meaningful results only when the two time series are both stationary processes. The stationary property of the price change time series can be induced from the fact that the price level follows a random walk model.

The stationary property of market price changes is also necessary for a valid regression test for the relationship between market prices and opinion polls conducted in Chapter 6. A regression in which at least one time series is non-stationary may produce invalid

\footnotetext{
${ }^{2}$ A random walk model without drift has $P_{t+1}-P_{t}=P_{0}+\sum u_{t+1}-\left(P_{0}+\sum u_{t}\right)=u_{t+1}$ while random walk model with drift has $P_{t+1}-P_{t}=\sum \alpha+P_{0}+\sum u_{t+1}-\left(\sum \alpha+P_{0}+\sum u_{t}\right)=\alpha+u_{t+1}$.

${ }^{3} \mathrm{~A}$ random walk model without drift has one-period change written: $\Delta P_{t+1}=P_{t+1}-P_{t}=u_{t+1}$ then $E\left(\Delta P_{t+1}\right)=0$ and $\operatorname{Var}\left(\Delta P_{t+1}\right)=\sigma^{2}$.

A random walk model with drift has one-period change $\Delta P_{t+1}=\alpha+u_{t+1}$ then $E\left(P_{t+1}-P_{t}\right)=\alpha$ and $\operatorname{Var}\left(\Delta P_{t+1}\right)=\sigma^{2}$.
} 
results due to spurious regression problem. It is pointed by Granger and Newbold (1974) that if the two series are integrated and used in a regression model then a high value of $R^{2}$ is likely to arise even when the two series are unrelated.

\subsection{Literature Review}

\subsubsection{Stationarity in stock markets}

Evidence of stock prices being non-stationary have been found in previous studies. In an attempt to look for an explanation of the departure of the change in stock prices from normality, Fama (1965a) tests the stationary process hypothesis by looking at only the change in mean of the one-period change in the daily log price over different periods of time. The distribution of daily changes in log prices has long tails in which the observed extreme values are much more extreme than would be predicted by the normality assumption. In a stationary process, if a significant change in mean persists for any length of time, it must be small. According to this study, the visual examination of stock price changes during the sampling period to look for trends shows a large change in the mean that persists for a long period of time. However, the empirical tests show that the extreme values in the distribution can not be adequately explained by shifts in the mean.

The time series of some economic indices are shown to be non-stationary, such as industrial production, consumer prices and stock prices (Kwiatkowski et al., 1992). Nelson and Plosser (1982) studying various economic time series find that they are unable to reject the non-stationary process without a time trend. However, there are others where no general agreement is reached. For instance, Perron (1989) can not reject the unit root hypothesis for the nominal interest rate. In the same direction, Chan et al. (1992) point out that the mean reversion for the U.S. interest rate is very weak, which is a sign of a possible unit root. However, Dahlquist (1996) finds some mean reversion effects for 
interest rates in Denmark, Germany, Sweden and the UK.

As stated earlier, if a time series follows a random walk model, it is a non-stationary process. However, this is only true if the variable is not bounded by an upper or lower finite limit. Such processes are not possible to follow a random walk because random walk is limitless with probability one. This issue has been addressed by Ait-Sahalia (1996) as in his study of the 7-day Eurodollar deposit rate. He finds a tendency of mean reversion in the spot rate as it goes beyond a certain range. Moreover, the drift is approximately zero when the rate is within the range. Thus, within the range from 4 to $17 \%$ the process behaves like a random walk (as the drift is zero) but shows reversion effects whenever some high or low levels are reached. To such processes, the usual test of stationarity is not able to reject the unit root because the process behave like a random walk within certain ranges. However, the bounded property will show reversionary effects at high or low levels which eventually leads to stationarity and mean reversion.

There is a considerable amount of evidences of bounded time series not having unit roots, for instance the purchasing power parity in various countries (Rogoff, 1996). In the same direction, Nicolau (1999) argues that the DEM/USD exchange rate is not a random walk despite the conclusions of the Dickey-Fuller test (the Dickey-Fuller unit root test is discussed in detail in Section 5.3. In general, there is evidence that the real exchange rate is bounded in probability and converges to a long-run values. With regards to nominal exchange rate, it is bounded by implicit target monetary policies. That is, the DEM/USD behaves like a random walk but can not be a true random walk.

These studies suggest that some economic and financial time series can behave just like a random walk but bounded in probability due to economic reasons. In an attempt to simulate such process, Nicolau (2002) builds a model satisfying the features that allows random walk behavior most of the time but forces mean reversions whenever the process 
tries to escape from some intervals. He shows that the power of the Dick-Fuller test to reject the alternative hypothesis of stationarity is extremely low when the random walk process is bounded. He concludes that such bounded processes follow a random walk and can be, in effect, stationary. Also, he describes three properties of the bounded random walk as follow. First, if a process is an unbounded random walk, the function $E\left[\Delta p_{t} \mid p_{t-1}=x\right]=0$ for all $x$ where $\Delta p_{t}=p_{t}-p_{t-1}$. On the other hand, if a process is bounded and mean-reverting to $\Phi$, the function $E\left[\Delta p_{t} \mid p_{t-1}=x\right]>0$ if $x<\Phi$ and $<0$

if $x>\Phi$. Secondly, the function $E\left[\Delta p_{t} \mid p_{t-1}=x\right]$ must satisfy following condition: (i) must be zero in some interval; (ii) must be positive (negative) when $x$ goes below (above) some intervals; (iii) the reversion effect should be strong if $x$ is far from the interval and should be weak in the opposite case; and (iv) is differentiable to assure a smooth effect of reversion. And last, the stationary distribution of a bounded random walk process is flat in the middle interval and outside the interval there are strong reversions, so the tails must not be heavy.

\subsubsection{Stationarity in prediction markets}

There are very few studies on the properties of prices in prediction markets even though this subject has been widely explored in financial markets and for economic indices. In a study of the ex-ante effect of the Iraq war on the US economy, Leigh et al. (2003) look at the correlation of the contracts on the likelihood of ousting Saddam Hussein from power on Tradesports and various economic indices such as oil prices, equity indices and so on. A simple Dickey-Fuller test on the time series of contracts on various dates for the resignation of Saddam cannot reject the null hypothesis of a random walk. The test simply regresses the one-period price changes on its own lags. The coefficients in all contracts are significant at $1 \%$. This result is confirmed by the findings of the Kwiatkowski-PhillipsSchmidt-Shin (KPSS) test where the null hypothesis that the time series is stationary around a deterministic trend is rejected in all contracts. Extending this to study whether price changes are predictable based on historical data, they regress the change in the 
Saddam contracts' prices on their own lags. They find that the change in the price is negatively serial correlated. This can be explained by the bid and ask bounce - the result of the bouncing of transaction prices back and forth from the bid side of the market to the ask side as alternating buy and sell orders arrive. Institutively this happens because the trading price is either ar the bid or ask (Roll, 1984). The prices in these markets are also found to incorporate information from expert's opinions after only short lags. These findings suggest the absence of profitable trading strategies in that market and this is complimentary to earlier work by Wolfers and Leigh (2002) suggesting that prices follow a random walk in the 2001 Australian election markets and adding information contained in polls does not yield profitable trades. Applying the same methodology, Leigh and Wolfers (2006) test for the market efficiency of contracts predicting the 2004 Australian election results in two online betting markets. In both markets, the null hypothesis of a random walk cannot be rejected by the Dickey-Fuller test. Also, there is little evidence of predictable price changes based on historical price patterns and publicly available polling data. These findings are consistent with that found using the Saddam contacts. However, according to the KPSS test, the hypothesis of trend stationarity is only rejected in one market. The random walk hypothesis again cannot be rejected in a study of Forsythe et al. (1992) as the result of a regression of expected market prices on their lagged prices up to lag 2 .

In a study of the properties of prices in prediction markets, Majumder et al. (2009) use data from the US election markets in 2000 and 2004 in the Iowa Electronic Markets and find mixed results in the distribution of returns. With regards to the Democratic in 2000 contract and the Democratic and Republican in 2004 contracts, the distribution of returns "decays in the tail as a power law". However, it decays as "an exponential function with a characteristic decay scale" in the Republican in 2000 contract. Besides, both unconditional and conditional volatility on given price of returns are higher toward maturity date. Finally, the return distribution changes over time becoming wider at later 
days. Most studies on the price behavior are in the context of market efficiency. The most famous bias is the "favourite-longshot bias" which is the tendency of overvaluing the small probability and underestimate the more certain bet. The finding of this bias is mixed. This bias has been documented for race-betting markets and sports betting markets (Thaler and Ziemba, 1988; Gray and Gray, 1997) and in information markets (Ziemba and Hausch, 1986; Jullien and Salanie, 2000). However, in the baseball betting market the reverse longshot bias is found (Woodland and Woodland, 1994, 2001). The second bias is overconfidence where one's subjective evaluation of a commodity price is higher than an objective value. This overconfidence bias is found in the tendency of overreaction to private information in financial markets (Lichtenstein et al., 1982; Daniel et al., 1998).

The two biases are both found in various prediction markets. Prices in the prediction market appear to be biased by overconfidence but the long-shot bias appears in reverse in a study of Berg and Rietz (2006, 2010) using data in IEM: Events that happen with low frequency are underpriced, and vice versa. Initial trading prices appear relatively noisy but unbiased. This is expected because in the initial stage little information is revealed. Prices display an overconfidence bias at the intermediate horizon when some information has come in but considerable uncertainty about the outcome still remains. The bias gradually disappears as the maturity date approaches. Studying sport games contracts in Tradesports, Tetlock (2004) find evidence of significant reverse favourite-longshot bias and overreaction to information. Even though mispricings as a result of these biases have been documented in financial markets, Tetlock argues that these inefficiencies in information markets are not necessarily generalized to financial markets due to essential differences in the structure of the two types of markets. Evidence of long-shot bias overvaluing the support of a candidate is found in a study of Erikson and Wlezien (2008) and as a result, the market compounds its errors. This bias is consistent and is explained by the degree of uncertainty about the event; while reading the information the market 
also incorporates considerable noise.

\subsection{Expected property of prediction market prices}

Empirical test for the stationarity property in prediction market should reflect the effect of two features of prediction market prices. First, prices in prediction market represent probability therefore are bounded within $\$ 0$ and $\$ 1$. This is the distinguishing feature between prediction market prices and stock prices which do not have an upper bound. According to EMH, if prices follow a random walk process, that is an evidence of market efficiency (at least weak form). However, given that prediction market prices are bounded both upward and downward, the random walk process is not feasible in general because random walks are limitless with probability one as time goes to infinity. The process is obviously bounded with reversion effects at upper and lower bounded levels. The lower bound at $\$ 0$ indicates that bad news would have no effect on prices as they are already $\$ 0$ because prices cannot go any lower than $\$ 0$. Similarly is the price at the upper bound of $\$ 1$. According to properties of a bounded random walk process described by Nicolau (2002) as above, prices in prediction markers are expected to show reversions toward some interval when they approach $\$ 0$ and $\$ 1$.

If a random walk process have no limit then it is also a non-stationary process. On the other hand, if it is bounded within a range then it only behaves like a random walk within some intervals and show reversions toward those intervals as it escapes. Such bounded random walk process then can be stationary. Accordingly, due to the limits at $\$ 0$ and $\$ 1$, prices in the vote share market are expected to share the same properties as bounded random walk process as described above and be stationary. However, the nonnegativity condition should not be considered a significant limit because it is broadly common among financial and economic series like stock prices, interest rate, exchange rate and so on which are used in previous studies and there is still ongoing debate on 
their stationary property. In fact, the upper bound at $\$ 1$ should matter more because it is a distinguishable feature of prediction market prices from other financial stock prices. However, graphically examining the time series of prices in all eight contracts in the vote share market, it is shown that prices never approach even close to the upper bound at \$1. National and Labour contract have the higher prices than the rest of contracts at all time but their maxima is $55 \%$ and $38 \%$, respectively. Therefore, the reversion effects at the upper bound will not be significant in those contracts. Even in their presence, my speculation is that they will not be able to dominate the random walk behavior adequately to convert the non-stationarity to stationarity. Prices in the vote share market, therefore, despite being bounded, are expected to follow a random walk model and be a non-stationary process.

Second, the price process is expected to contain no deterministic elements (a constant drift or time trends). A constant drift implies that prices are expected to change by a certain amount in the next period. If prices fully reflect the market expectation then there is no ground for them to do so. Also, there should not exist any trends in efficient prices because they should effectively reflect information which is random and the arrival of good news or bad news is independent of time.

Furthermore, prices ought to be non-stationary because what change is driven is new information which consequently changes the market's expectation of the stock value. There is no reason for information to have constant mean or variance or both over time. In fact, it is generally common in stock markets that good (bad) news is often followed by another good (bad) new. If this is true then prices have a tendency to diverge from its mean at least until the period of optimistic (pessimistic) time is over. Also, the variance of prices is determined by how good or bad new information is. News that either very good or very bad tends to shift prices far away from it previous level and again there is no reason for news to be broadly equally good or bad over a period of time. In general, if prices 
fully reflect new information then they should be a non-stationary process because the arrival of new information is random and does not have constant mean or variance. In prediction markets where prices are a direct interpretation of the likelihood of a future outcome, information plays an important role in forming prices. Therefore, prediction marker prices should also be non-stationary.

\subsection{Testing prices for unit root}

I use the Augmented Dick-Fuller (ADF) test for a unit root in a time series (Said and Dickey, 1984). The ADF test statistic is a negative number. The more negative it is, the stronger the rejection of the null hypothesis that there is a unit root at some level of confidence. If the time series has a unit root then it is not stationary. The full model of the test is as below:

$$
\Delta p_{t}=p_{t}-p_{t-1}=\alpha_{0}+\gamma p_{t-1}+\tau t+\sum_{i=1}^{k} \alpha_{i} \Delta p_{t-i}+\epsilon_{t}
$$

where $p_{1}, p_{2}, \ldots, p_{N}$ is the observed time series, $t$ is the time index, $\alpha_{0}$ is an intercept constant called a drift, $\tau$ represents a trend over time, $\gamma$ is the coefficient presenting process root, and the focus of testing, $k$ is the lag order of the first-differences autoregressive process, and $\epsilon_{t}$ is an independent identically distributed residual term. Accordingly, the null hypothesis of $\gamma=0$ of non-stationarity is tested against the alternative hypothesis $\gamma<0$ of stationarity. The ADF technique applies an Ordinary Least Squares regression. The p-values are interpolated from Table 4.2 in Banerjee et al. (1993).

The significance of $\gamma$ is tested in three versions of Equation (5.1): (i) with the presence of the deterministic elements $\alpha_{0}$ (a drift term) and $\tau t$ (a linear time trend) and $\alpha_{0} \neq 0$ and $\tau \neq 0$; (ii) without a drift $\alpha_{0}=0$; and (iii) without both deterministic elements, 
$\alpha_{0}=\tau=0$.

The ADF test requires that the $\epsilon_{t}$ be serially uncorrelated. Sufficient lags of $\Delta p_{t}$ should be added to ensure $\epsilon$ is white noise. In theory, too few lags will leave autocorrelation in the errors, while too many lags will reduce the power of the test statistic.

In this study, the number of lags $k$ is determined by $\sqrt[3]{(N-1)}=\sqrt[3]{(404-1)} \simeq 7^{4}$ corresponding to the suggested upper bound on the rate at which the number of lags should be made to grow with the sample size for the general ARMA(p,q) setup.

The test procedure runs as follow (Enders, 2004). First, the null hypothesis of $\gamma=0$ is tested against the alternative of $\gamma<0$ using the Equation (5.1). If the null is rejected then the price series is concluded to have no unit root therefore is stationary. Otherwise, nonstationarity cannot be concluded yet because the ADF test has very low power to reject. The power of the test may be reduced due to the inclusion of deterministic elements. Next the null hypothesis needs to be retested without those elements. Second, if the null hypothesis is not rejected in step 1 then Equation (5.1) is rerun in the absence of the time trend by setting $\tau=0$. The null hypothesis becomes $\tau=\gamma=0$ and the alternative $\tau=0$ and $\gamma<0$. If the null hypothesis is rejected then time trend is significant and must be included in the model and the time series is a stationary process with a drift. Otherwise the test is rerun without the drift term. Third, if the null hypothesis in step 2 is not rejected, it means that the time trend is not significant and should be excluded by setting $\tau_{1}=0$. The null hypothesis now becomes $\alpha_{0}=\gamma=0$ and is tested against the alternative of $\alpha_{0}=0$ and $\gamma<0$. If the null is rejected then the drift is significant and the time series is trend stationary process. Otherwise retest without any deterministic elements. Last, if the null hypothesis in step 3 is not rejected then the model has no deterministic elements where its equation looks like that of a random walk process.

\footnotetext{
${ }^{4}$ The data consists of 404 daily prices.
} 


$$
\Delta p_{t}=p_{t}-p_{t-1}=\gamma p_{t-1}+\sum_{i=1}^{k} \alpha_{i} \Delta p_{t-i}+\epsilon_{t}
$$

Test the above model for the null hypothesis of $\gamma=0$ against $\gamma<0$. If the null is rejected then the time series is a stationary process; otherwise is stationary.

\subsection{Empirical Results}

The test procedure for stationarity described in Section 5.3 is applied to each of eight contracts in the vote share market, using daily prices which are the last traded price. Because iPredict operates $24 / 7$, in order to gather daily prices it is treated as being closed at $23.50 \mathrm{pm}$ everyday including weekends. For days in which no transaction occurs, the market is treated as closed and prices are taken from the close of the previous day to ensure no gap in the data set. The vote share market was operated for 404 days so the price time series in each contract has 404 observations. The expected properties of prices in prediction markets discussed in detail in Section 5.3 can be summarized as follows. Prices in prediction markets, on the one hand, should share same properties as those in financial markets. Prices in stock markets have been found to be a non-stationary process in previous empirical studies. On the other hand, while stock prices are not bounded theoretically, especially upward, prices in prediction markers are bounded between $\$ 0$ and $\$ 1$ because they represent the expected probability. Nicolau (2002) shows evidence through a simulation study that a random walk process which is bounded within a certain interval can be stationary. Whether market prices in prediction markets behave like stationary process depends on the effect of mean reversion as a result of the boundary.

There are a number of key features of the results reported in Table 5.1. First, the empirical results of the unit root test in eight contracts in the vote share market show that the non-stationarity cannot be rejected in seven out of eight contracts, except the Māori 
contract. The conclusion is reached in each contract after going through three steps in the unit root test described in Section 5.3. This finding suggests that despite being bounded within $\$ 0$ and $\$ 1$, prices in the vote share market still behave as a non-stationary process. The effect of the mean reversion near the two limits is dominated by the behaviour of the random walk when prices are far from the limits. As long as prices do not approach the limits, the mean reverse effect does not take place. The iPredict contract prices are similar to stock prices and indeed most economic indices in that they have a lower bound of 0 . As in Figure 5.1, in contracts of two major parties prices fluctuate within the middle range (National prices varies within the range $(42,53)$ cents and Labour $(26,38)$ cents) while prices of the rest of contracts vary at small level above zero. This implies that for the National and Labour contracts, the reverse effect caused by the bounds is not strongly present.

Second, in the Māori contract, prices obviously exhibit a pattern: prices have a decreasing tendency over time which implies a negative correlation between prices and the time to maturity (see Figure 5.2). The stationarity property of a constant mean cannot be achieved; instead there exists a tendency of decreasing mean. Unsurprisingly, the formal unit root test cannot reject the varying mean: The trend coefficient is -0.035 at the significance level of $1.5 \%^{5}$. The failure of $\mathrm{ADF}$ test to reject the non-stationarity despite the visual inspection may be the result of the cointegration of all prices in the entire vote share markets: they sum up to $\$ 1$. The Māori price is essentially the difference between $\$ 1$ and the aggregate price of the rest of seven contracts which is non-stationary due to the varying mean. I suspect this additional constraint is a factor driving Māori prices to the stationary side.

Another possible explanation is that the ADF test fails to reject the stationarity because it only can detect varying mean. In other words, non-stationarity contributed by other

\footnotetext{
${ }^{5}$ Detrending by removing linear and exponential trends does not change the test result.
} 
factors such as varying variance is beyond the scope of ADF test. This means that the Māori prices are not an I(1) process but still can br non-stationary. In terms of market efficiency, the stationarity found in the Māori prices implies that trading in this contract is driven by something else other than information and this element dominates the effect of information. It may be the bias in trading or personal political (in)preference toward Māori no matter what the information is.

Third, the trend coefficient $\alpha_{1}$ and its standard error are very small in all contracts therefore are not included. Fourth, time trend and constant drift are statistically insignificant in seven out of eight contracts, except the Māori contract. 


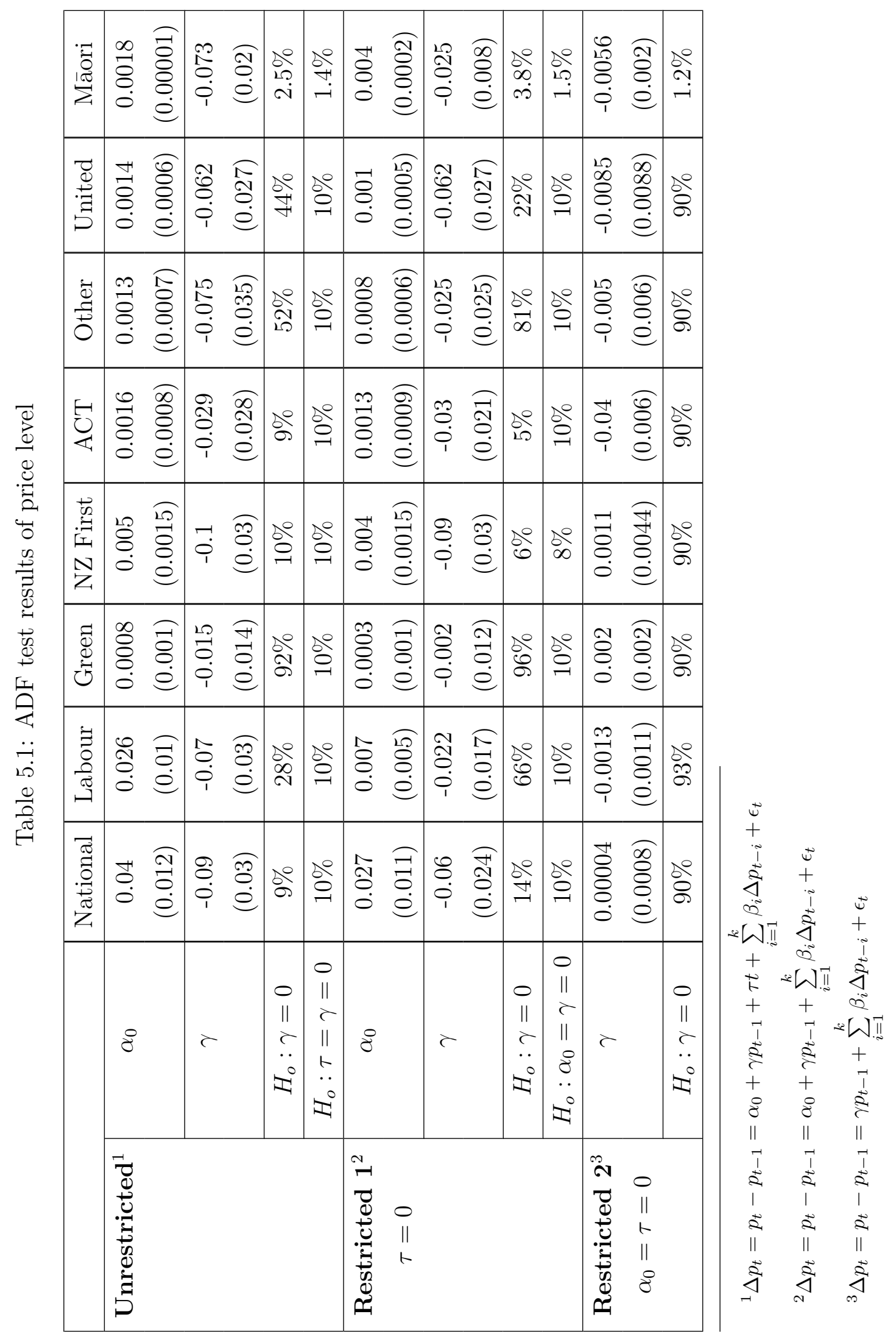


Figure 5.1: iPredict market-based forecast of 2011 General Election vote share

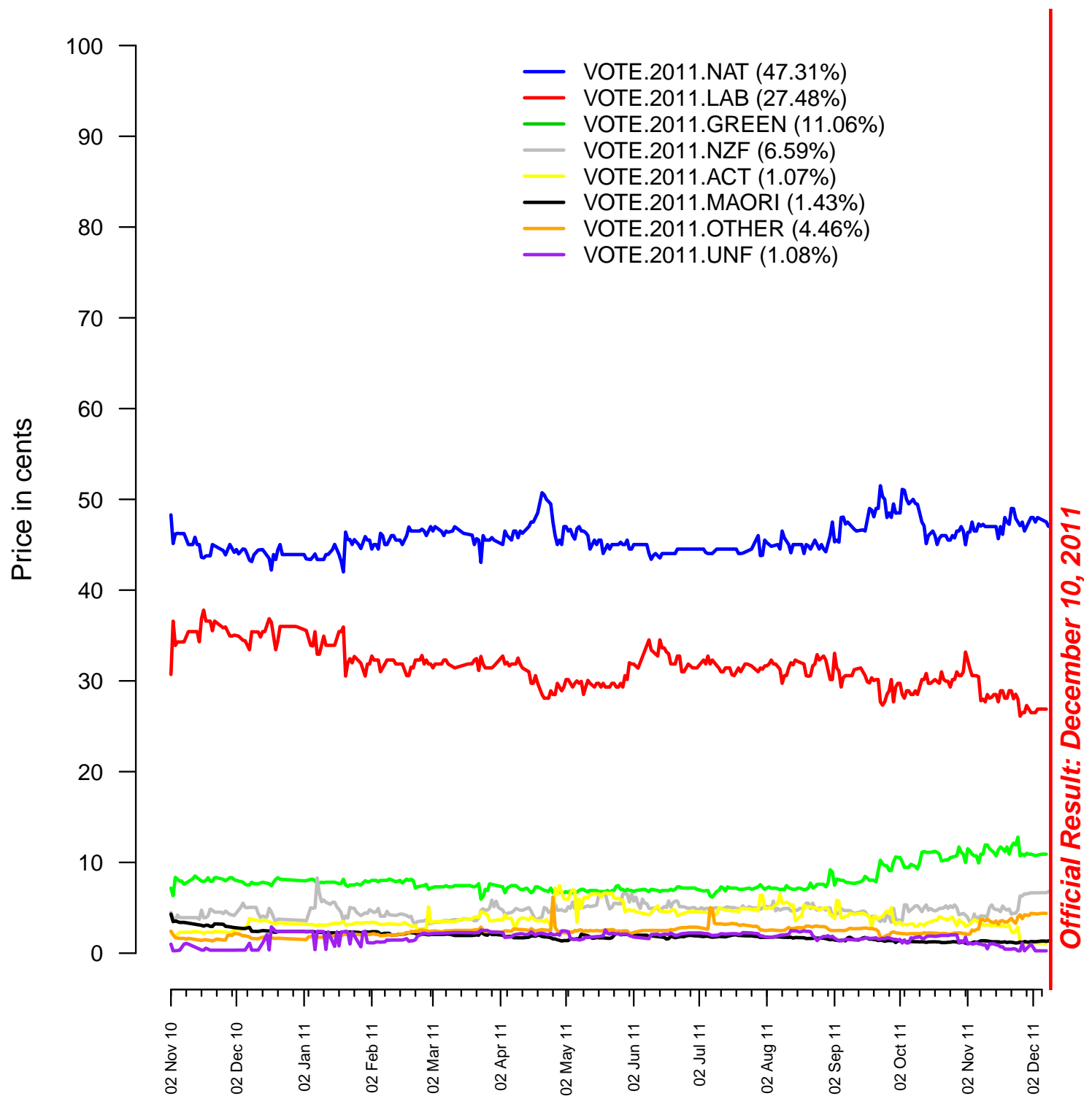

Note: Number in the parentheses are the official election results 
Figure 5.2: iPredict market-based forecast of the Māori contract

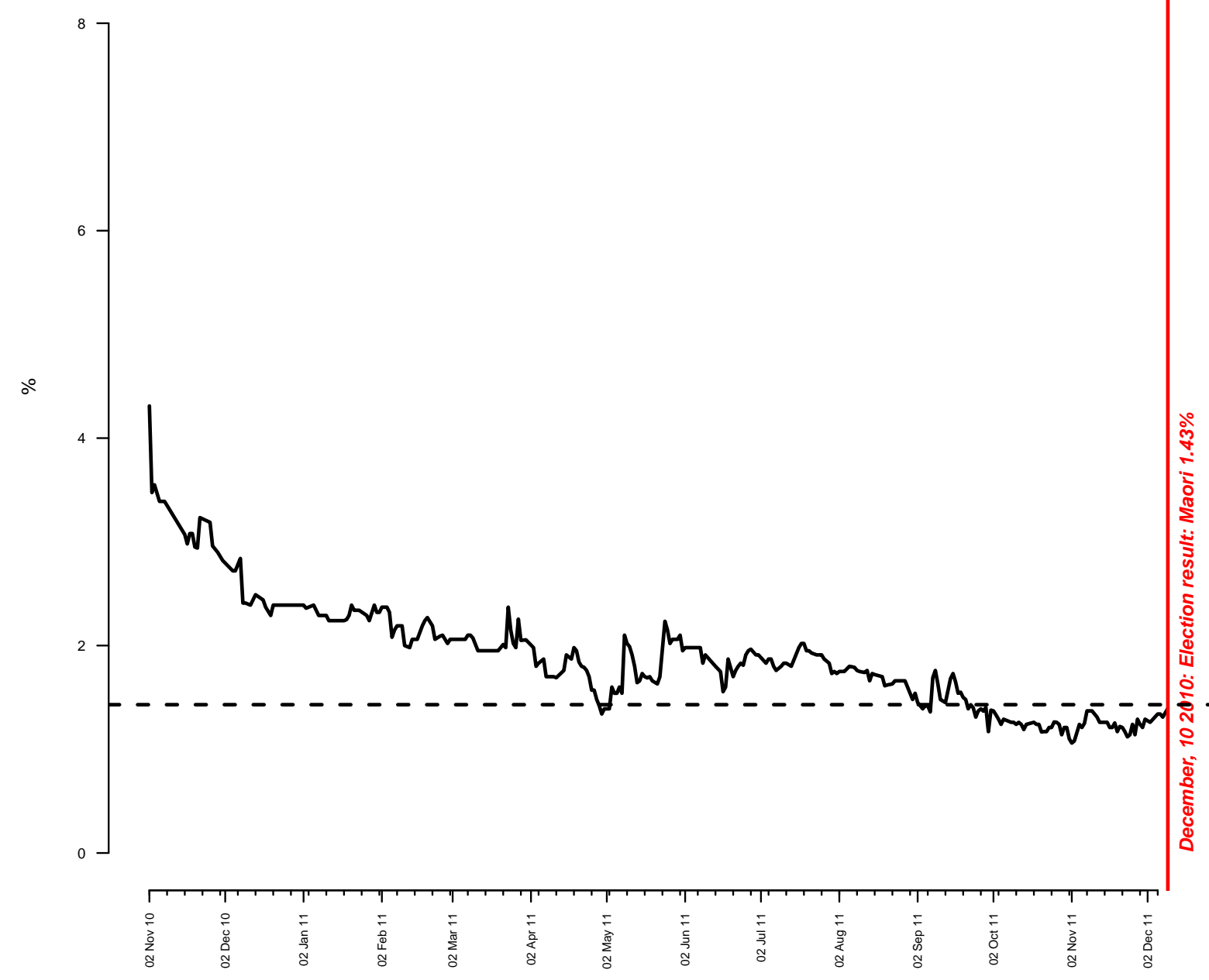




\section{Chapter 6}

\section{Relationship Between Market Prices and Opinion Polls}

The intuition of the causality between the poll results and the prediction market prices is as follows: While participants in prediction markets are provided with an incentive to gather information from many sources to help improve their forecast which subsequently revealed in their trading, respondents in opinion polls are simply expected to reveal their own political preferences without taking into account how others will vote. This is the foundation for the hypothesis that traders may consider information contained in polls and therefore poll results have influence on market prices. According to this hypothesis traders, in an attempt to comprehend the voters' assessment of information, will make trades based on the latest poll results. One should expect reported opinion polls to affect market prices only if they contain news that has not been anticipated or incorporated by traders or convey different interpretation of news by the voting population. In other words, market traders have incorrectly assessed respondents' preferences (as a proxy for the preferences of the electorate as a whole) and their interpretation of information. The release of the opinion poll results allows market traders to correct any incorrect expectation. 
However, it should be noted that while this interpretation is consistent with ascribing inefficiency on the part of prediction market traders, it also relies on an assumption that respondents' preferences are already public information. If poll respondents' preferences are not public information and this is newly revealed in the opinion poll then an efficient prediction market should react to the new information. Arguably this should only matter when a new poll is reported. Ongoing polls, especially where these are polls of the same respondents over time, should be less subject to this being new information. That said, question marks over the consistency and potential bias of polls may indicate that the information in polls cannot be relied upon to reflect a consistent and genuinely representative sample of voters.

Alternatively, if polls do not provide new information at all but only confirm what traders can gather from other sources then there should be no significant reaction to the poll release. In theory, the responses in opinion polls are based on public information. Nonreaction of the prediction market to an opinion poll is consistent with the hypothesis that the public information that influences the information interpretation of poll's respondents is already taken into account by market traders. If this alternative hypothesis is accepted then this would support a finding of the semi-strong form of market efficiency. A lack of reaction by a prediction market to an opinion poll would also be consistent with the market heavily discounting the poll result. Given the questions that have been raised over whether some opinion polls are truly representative, it is also possible that market traders do not trust the poll results and thus ignore them. Technically the market traders are treating polls as if they contain no new information. 


\subsection{Description of Roy Morgan polls}

The main four opinion polls for the 2011 General Election were Television New Zealand, ONE News Colmar Brunton, The New Zealand Herald and Roy Morgan Research. Among them I can only gather sufficient data to support the empirical analysis from Roy Morgan Research because its poll results are available publicly on their website ${ }^{1}$ and newsletters. Other pollsters do not release their poll results on a sufficiently regular basis and also do not provide sufficient details on the results in order for them to be as reliable as a comparator to iPredict. Therefore I will mainly use Roy Morgan's poll results to compare with the forecast of iPredict's vote share market.

Roy Morgan Research is the only Australian-owned independent polling company that is not owned by a media organization. It has been conducting opinion polls on voting intention by telephone with a New Zealand wide cross-section and reporting the result fortnightly since August 18, 2005. Electors are asked a same question: "If a New Zealand Election were held today, which party would receive your party vote?". Although Roy Morgan polls on voting intention have been conducted long before the launching of iPredict's vote share market, I only use the poll results released between November 2, 2010 and December 10, 2011 which is the launching and close date of iPredict's vote share market respectively. Their opinion polls are not conducted on a strict regular basis; the interval between opinion polls varies from 5 days (the last polls before the announcement of the election's results) and 35 days (Christmas and New Year break) and on average is 15 days.

The sample is chosen randomly and interviews are made by telephone. The sample size of the voting intention poll is usually around 1000. Responses not naming a party are excluded from the data to ensure the forecast of vote share received by all parties sums to $100 \%$. The population estimate is the number of votes cast which is $2,237,464^{2}$. The

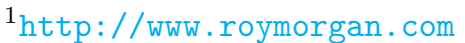

2 http://www.electionresults.govt.nz/electionresults_2011/e9/html/e9_part1.html
} 
samples are weighted based on the latest Census (RoyMorgan, 2011).

The margin of error depends on the sample size (i.e. the number of respondents) and the population size (i.e. the number of eligible votes) (Moon, 1999a). Roy Morgan publishes the margin of error for their estimates as in Table 6.1. This gives $95 \%$ confidence interval expressed as the number of percentage points above or below the actual estimate. The error margin corrected for an estimate of a proportion $(\hat{P o l l})$ is:

$$
\text { Margin of error } \operatorname{ME}(\hat{P o l l})=\text { Critical value } \mathrm{x} \text { Standard error }(\hat{P o l l})
$$

where the critical value for $95 \%$ confidence interval depends on the assumption of the distribution of Poll. The proportion Poll is binomial and due to the independent and large sample, the estimate Poll is normally distributed. Therefore, the critical value corrected for finite population is 1.96. The standard error of Poll is:

$$
S E(\hat{\text { Ooll }})=\sqrt{\frac{N-n}{N-1}} \sqrt{\frac{\hat{\text { ôll }(100-\text { Poll })}}{n}}
$$

where $N$ is the population size $(2,237,464)$ and $n$ is the sample size $(1,000)$.

Table 6.1: The margin of error published by Roy Morgan polls ${ }^{3}$

\begin{tabular}{|c|c|c|c|c|}
\hline Sample size & \multicolumn{4}{|c|}{ Percentage Estimate $\hat{p}$} \\
\hline & $40 \%-60 \%$ & $25 \%$ or $75 \%$ & $10 \%$ or $90 \%$ & $5 \%$ or $95 \%$ \\
\hline 1,000 & \pm 3.4 & \pm 2.7 & \pm 1.9 & \pm 1.4 \\
\hline
\end{tabular}

In order to understand the importance of the error margin to the performance of an forecast, consider an example. Roy Morgan's poll results reported on November 24, 2011 shows National $49.5 \%$ and ACT $1.5 \%$. Reading from the table, the actual margin of error and $95 \%$ confidence interval for National are $3.4 \%$ and $(46.3 \%, 52.7 \%)$. The predicted $1.5 \%$ of $\mathrm{ACT}$ does not fall into any estimate range given in the table so it is calculated manually by the formula ; the actual margin of error and $95 \%$ confidence interval for $\mathrm{ACT}$ are $0.75 \%$ and $(0.75 \%, 2.25 \%)$. The larger the estimate, the larger the error margin

\footnotetext{
${ }^{3}$ http://www.roymorgan.com/news/polls/2011/4724/
} 
all other things being the same.

Leigh and Wolfers (2006) point out an issue with the published poll's error margin in their study of the relative performance of prediction markets and polls for the 2004 Australian election. Looking at the time series of various polls, they found an extreme volatility in the forecasts suggested by polls. They consider the excess volatility as an indicator of an underestimate of the true forecast errors. The extreme volatility raised questions about the predictive accuracy of poll's forecasts and the authors suggest that the pollsters' published margins of error should be at least doubled.

Figure 6.1 shows the Roy Morgan polls' implied forecast within the lifetime of iPredict's vote share market. 
Figure 6.1: Roy Morgan's opinion poll results

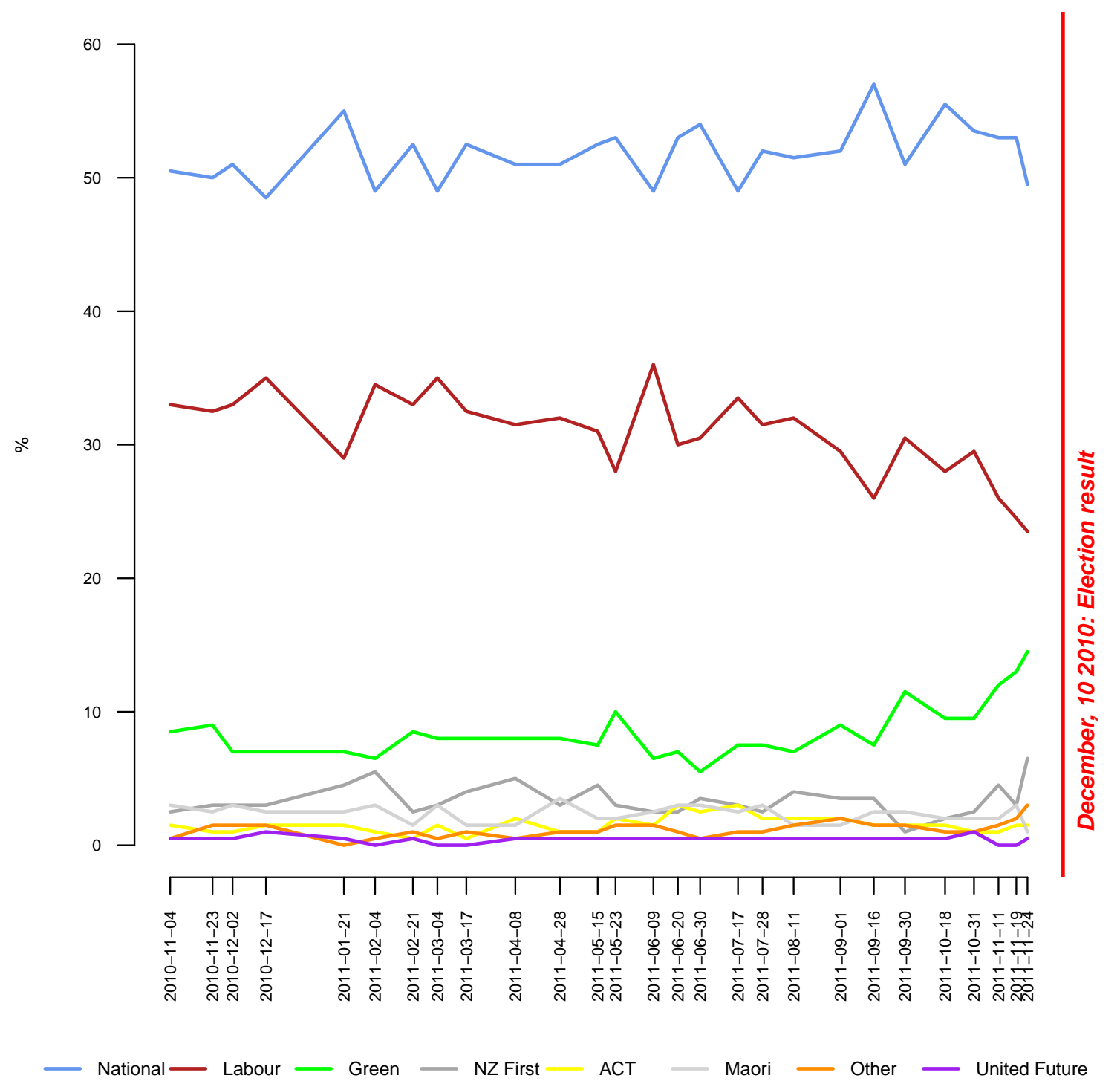

Note: The horizontal axix shows the release date of poll's release date.

A strong surge in the support to the Green party since the poll released on October 31, 2011 is noticed and it continued until the official election results. This increase in support to the Green party came at the cost of the support to the two major parties National and Labour. During that period, supports to the National and Labour parties dropped significantly, especially for the Labour. This can be seen in Figure 6.2 comparing the 
poll results of the Green party and that of the combination of the National and Labour parties. The last few weeks before the official results were announced also observed a strong increase in the support to the New Zealand First party.

Figure 6.2: Comparing the poll results of the Green party and that of the sum of the National and Labour parties

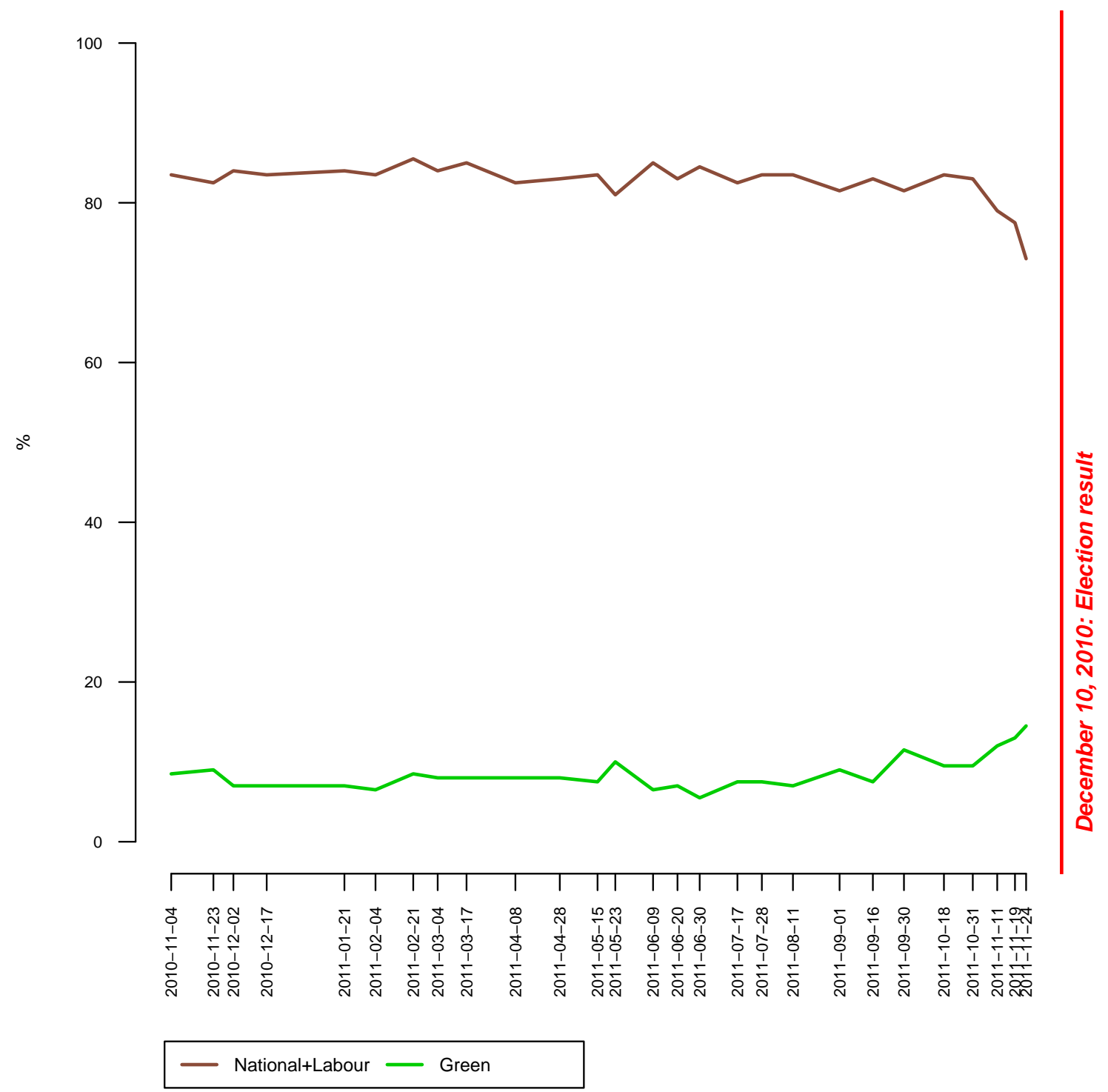

Note: The horizontal axix shows the release date of poll's release date 


\subsection{Differences of forecasts implied by iPredict's prices and opinion polls}

Typically, opinion polls are designed to evaluate public opinion at a single point in time. Even though prediction market prices and opinion polls are in principle comparable as they seek to forecast the same goal - an election result - they are distinguishable in many aspects. Their differences have been discussed in detail in studies of McGirr and Salmond (2010) and Erikson and Wlezien (2008). I review and further develop their discussion as below.

First, what mainly differentiates polls from prediction markets is the form of the questions asked. While prediction markets aim to aggregate what people expect will happen by asking a question in the form of "What share of the party vote will the (name) Party win at the 2011 election?", polls reveal current personal voting preferences by asking the question "If a New Zealand Election were held today, which party would receive your party vote?". The former seeks to aggregate individual investors' knowledge of other people's voting preferences and should not rely on their own personal preference. Whereas an answer to the poll question simply reveals the respondent's party preference without considering what anyone else's preferences are. One may vote for Green and hope Green would win the 2011 election but rationally would not buy Green shares in iPredict at a very high price.

Second, there is a difference in the time frame of the focus between traders in iPredict and respondents in opinion poll results. The market prediction is forward looking and relates to expectations of the voting patterns on a future election day. Prediction markets can look ahead and explicitly project the future outcome. In contrast, the opinion polls are about current voting preference, the pollsters pose a question seeking for the public opinion at the time polls are conducted, not expected opinion at an election in 
the future. They aggregate public opinion for an election at the time of the interview. Polls are not explicitly trying to predict the election results on the election day; instead they are trying to aggregate the public support at a particular point in time. From a point of view of a pollster, a poll should be interpreted as a reading of how the voters would vote if an election was held that day, and not as a forecast of an election sometime in the future. That purpose is reflected in the question asked by pollsters as mentioned earlier: "If a New Zealand Election were held today, which party would receive your party vote?". Nevertheless, this does not eliminate the use of poll results as a forecast and in fact polls have been used widely to help predict what is likely to happen on the election day by media and journalists. Forsythe et al. (1992) argue that even though pollster asks "In the election who do you think you will vote for?", the respondent's answer will be unchanged under the assumption of truthful revelation of preferences. An individual's political preference may change when new information arise and therefore he will vote differently. However, given the information available up to current time, the current preference is the best forecast of the voting behaviour in the future. The chance of changing their preference due to the arrival of new information just reflect the forecast error. In contrast, David and Justin (2012) compare the predictive performance of opinion polls when respondents are asked for their expectation of the election's outcome instead of their personal voting intention and find that the expectation-based questions yield much more accurate predictions of election outcomes.

Furthermore, both poll respondents and market traders will have information regarding future events (for instance, an announcement of a large tax cut). If poll respondents are completely honest about their response, they should reveal the way they would like to vote at the time being asked and not be influenced by their expectations of a policy that has not taken place yet. In practice, those expectations may affect the current voting intention. If the preferences of poll respondents are influenced by expectation about future events then they are using the same information set as market traders. In this case, 
information incorporated in polls should be similar to what in market prices; however, the way in which the information is interpreted may differ between poll respondents and market traders. Obviously, this is highly dependent on the certainty attached to the upcoming event. If little is known about the event or the respondent attaches a very low probability to it, then it may be effectively discounted to the point where it has no influence on current preferences.

Third, iPredict allows 24/7 trading so market prices can reflect new information immediately. Whereas the opinion polls are conducted at discreet time intervals thus there is a potential delay for new information to be reflected in polls. This delay further contributes to the chance poll results may be out of date as mentioned previously. Further, the fact that the interview process of polling takes place over a number of days and the process of analysing the responses may worsen the delay of the incorporation of new information. At the time a poll is reported, its content consists of aggregated information gathered at different time which may produce an inconsistency of time window in the data. This implies a disadvantage of polls in the competition with prediction markets as forecast tools of election results: a chance to report out-of-date forecast due to the time window between the time of interview; i.e. the time associated with the revelation of information and the time of reporting the poll's result. Therefore, there is a chance that public opinion is changing while the poll is taking place so that the pollster's final results may be out of date before they are even reported.

Last, relative to polls, prediction markets rely on very different mechanisms for data collection and aggregation. With an opinion poll, the sample is meant to be broadly representative of the voting population for it to be able to reflect accurately the population's preferences. On that basis, the sample is chosen randomly but within certain constraints in order to achieve the representativeness. This contrasts with prediction markets in which the investors need not be similarly representative of the electors. While the poll 
results are a sample, the iPredict prices are the population and the traders are interested in the population voting shares while the sample is an indicator of this. Traders in prediction markets gather information from many sources including information contained in opinion polls. Prediction markets do not rely on a representative sample or even honest beliefs or rational trade from all market participants. Instead, prices can reach their efficient level if there is a small group of marginal traders who are motivated by profits and invest in accurate prediction and trade accordingly. Indeed, self-selection of investors means that investors are likely to be unrepresentative of the electorate as a whole. According to a survey conducted by iPredict, traders in iPredict are overwhelmingly male (90\% male), well-educated (40\% have an undergraduate university degree or higher), having high income (median personal income is $\mathrm{NZ} \$ 75,000$ ), and young (average age is 35). Also, iPredict does not require traders to be eligible to vote in the election. These stylized facts of traders in iPredict are consistent with Iowa Electronic Market whose traders are also more educated, have higher household income, more often white and male than both US citizens and votes on average. What drives traders' behaviour is not their own preferences but their ability to gather and accurately process information about the preferences of the electors. Thus if investors' information includes all the information held by the poll respondents, their trading behaviour should be consistent with opinion poll responses. However, it is also possible that traders may use polls but make a better interpretation of information revealed in polls. In that case, polls help the market to see how other people interpret information about events and give market participants an opportunity to compare their personal interpretation of information with others'.

The market included 664 traders; however, apparently the movement of prices is determined mainly by a small group of traders who dominate trading trading volume in terms of the number of trades and shares traded. Chart on the left of Figure 6.3 show the proportion of trading volume of individual traders and it is obvious that a group of a dozen traders takes up almost $50 \%$ of the entire market. Indeed, only 6 traders are responsible 
for around half of all transactions. Most notably, a single trader takes up a quarter. The right hand side of Figure 6.3 also shows how the majority of traders are individually very small traders. This feature distinguishes the difference in the mechanism of prediction markets and opinion polls whose predicative accuracy depends crucially on the representativeness of the sample.

Figure 6.3: Trading activity by traders

Proportion of transactions by individual trader

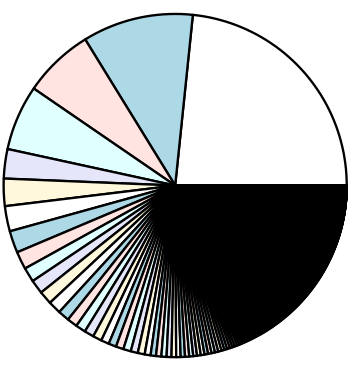

Proportion of shares by individual trader

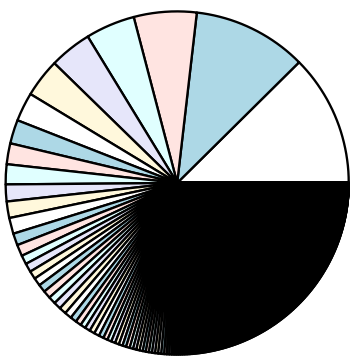

Proportion of values by individual trader

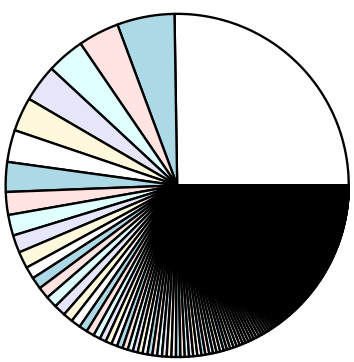

Proportion of traders by transaction

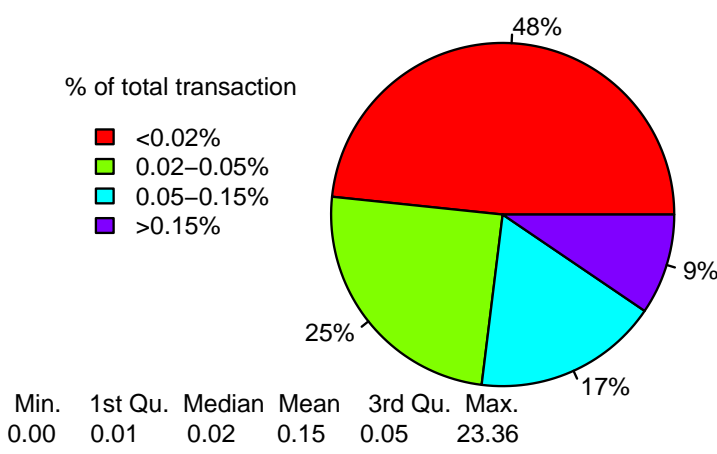

Proportion of traders by share

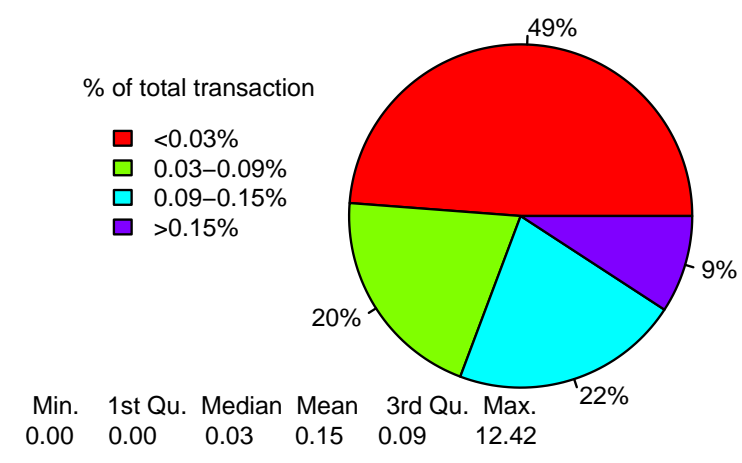

Proportion of traders by value

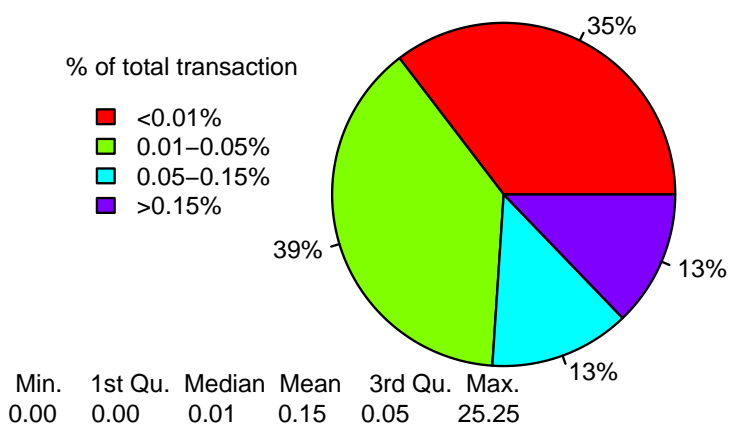


Conceptually, aside from the timeframe difference, polls and markets should be equivalent. In particular, they both operate from the same set of publicly available information. This is also based on the assumption that polls are representative and do not have any inherent bias. To the extent that polls are not truly representative, the bias may well affect the extent to which information is reflected in the poll result. For instance, a poll sample that under-represents a proportion of voters that are adversely affected by a party's policies may overstate its support. Prediction market traders face an incentive to take into account the effect of policies including the proportion of voters likely to be affected.

\subsection{The accuracy of iPredict's election market and Roy Morgan Research's opinion polls}

\subsubsection{Definition of predictive accuracy}

The predictive accuracy represents the extent to which a predictor correctly identifies an actual event. In a wide range of empirical studies, a forecast error measuring the spread between the market price at a specific time and the expiry value has been applied as an estimator of the predictive accuracy. The comparison of absolute forecast error is conducted at various times prior to the settlement date. For a part vote share contract in iPredict, the accuracy is determined by the extent to which the contract price differs from the official result. By definition, the forecast error can only be measured once the actual outcome is revealed. It implies that the accuracy defined by the forecast error does not reflect how close the market forecast is to the current voting preferences of the population which is a random variable and varies over the time prior to the Election Day. The formal definition of forecast error $(\mathrm{FE})$ is as below: 


$$
F E_{t, i}=p_{t, i}-p_{T, i}
$$

where $p_{t, i}$ is the market price at time $t$ in contract $i$ and $p_{T, i}$ is contract $i$ 's payout value. By definition, FE equals 0 at expiry. In order for prediction markets to generate accurate forecast at each point in time FE is optimally low or zero.

The average forecast error (AFE) is used in the comparison across contracts during a period of time (number of transactions $=N$ ).

$$
A F E_{t=[x, y], i}=\frac{\sum_{t=x}^{t=y}\left(p_{t, i}-p_{T, i}\right)}{N}
$$

Efficiency and accuracy are distinct concepts because their definition relate to two different variables. The degree of efficiency in the vote share markets depends on how well prices can incorporate information of the contemporaneous voting preference to the future election of the population which is a random variable, unobservable and varies over the time. For that reason, efficient prices should be a random variable and fluctuate over time to reflect the arrival of new information. Accuracy, on the other hand, is a measurement of how close the contract price matches the actual outcome. There is only one actual outcome which is observed on the expiry day and fixed. Accuracy therefore can only be measured ex-post.

However, if market efficiency is concerned with the extent to which risk-free trading opportunities occur, accuracy and efficiency are related. Efficiency in a frictionless market first requires the non-existence of arbitrage opportunities. In an efficient prediction markets prices reflect all relevant information and then are unbiased and the best predictor of the underlying event. Clearly an inefficient market where the aggregate contract prices are significant different from $\$ 1$ cannot be completely accurate - at least one contract must be incorrectly priced. Conversely, an efficient market needs not be accurate in that 
two contracts may be incorrectly priced (biased) but exactly offset each other so that they still add up to $\$ 1$.

\subsubsection{Literature review}

Campbell (1996) find that polls predicting the vote share of presidential elections in the US during 1948-1992 has the mean of absolute forecast error is 3.52\% five months prior, $2.14 \%$ two months prior and $1.79 \%$ in the last poll. Wolfers and Leigh (2002) calculate Roy Morgan poll's average error during 1987-1998 is 1.4\% on election eve, $2.4 \%$ one moth prior, $1.5 \%$ three months prior, $3.9 \%$ one year prior (based on Australian elections). Wolfers and Zitzewitz (2004) also use the mean absolute error as a measurement of accuracy as comparing market's forecasts with that of surveys in the prediction of economic indices. Kou and Sobel (2004) instead use Mean Square Forecast Error but consider this not to change the assessment of relative performance of alternative forecast tools. They derive a model with an underlying assumption that the poll results are in the information set used by market participants and prove that for every given point in time the market prices produce forecast that is more accurate than opinion polls because the Mean Square Forecast Error of polls comprises of that of market prices plus systematic measurement errors in the polls. Furthermore, they prove by their model that the market exhibits less volatility than polls under the assumption that the preferences are less volatile on Election Day than at any other time. Berg and Rietz (2006) show that the accuracy of IEM election markets for the vote share since 1988 has the average absolute percentage error on the election eve is $1.33 \%$ while polls for election prior to 2014 yield error average of $2 \%$. Diemer and Poblete (2010) compare the relative accuracy of play-money contracts versus real-money contracts in iPredict and find that overall play-money contracts produce more statistically significant accuracy: play-money market's mean of forecast error is $13.9 \%$ while real-money's is $18.7 \%$. However, in a direct comparison of the same events, the real-money markets outperform. The forecast errors are $18 \%$ on average overall and 
show significant skewness: high density for trading activity at low forecast error. The accuracy is found to depend on incentives, specific contracts and volumes. They also find a negative correlation between days to expiry and number of trades: the trading volume is higher as the expiry date draws closer, a negative correlation between the number of order volumes and accuracy: a low number of high-volume trading occurrences are more accurate than a high number of risk-adverse trades involving low volumes and a positive correlation between the mean of forecast errors and the days to expiry.

McGirr and Salmond (2010) study the predictive performance of various opinion polls and two prediction markets (iPredict - using real money and New Zealand Political Stockmarket - using virtual money) in the 2008 New Zealand General Election. They find that pollsters produced conflicting results in two aspects. One is their substantial disagreement about the level of support for the National Party which is explained by the influence sample bias has on their poll results. TVNZ and The New Zealand Herald are suggested by the authors as having a sample bias in favour of the National Party and they both produced the highest level of support for National. The opposite pattern was found in the forecast of Roy Morgan. Second, short-term shifts in major parties' expected vote share did not appear consistently across pollsters. This is explained as a result of sampling error rather than the actual movements in public opinion. Of the two prediction markets it was iPredict, the prediction market with real money which worked better and outperformed polls in picking the correct winners. The performance of the virtual money market was poorest among all forecast channels. These conclusions are drawn from the comparison of the forecast errors on the election eve and for the whole period for 6 months prior. Interestingly, the study also suggests that traders in prediction markets are subject to bias in aggregation. iPredict's observed tendency of overestimating the National Party's support is explained by the fact that real money prediction market attract people with high income. The opposite tendency is observed in NZ Political Stockmarket which overestimates the support for Labour party and is explained by the fact the vir- 
tual money prediction markets tend to attract people with less income. An implication of this phenomenon is an evidence of trading bias in both prediction markets - an individual's income determines his voting preferences and is reflected in his trading behaviour.

The better performance of prediction markets over opinion polls is also evident in the 1988 US presidential election market (IEM) (Forsythe et al., 1992). The same conclusion is drawn in 2001 Australian Federal elections when the prediction market selected the correct winners more often than opinion polls (Wolfers and Leigh, 2002; Leigh and Wolfers, 2006). Berg et al. (2000, 2001) and Berg and Rietz (2006) show that daily prices contain only half the forecast error of the daily polls (IEM). Poll results appear to be more volatile than market prices (Leigh and Wolfers, 2006; Berg and Rietz, 2006; Forsythe et al., 1992), certainly more than can be attributed to sampling error alone. Chen et al. (2005) apply two different methods of aggregating expert's opinions (linear and logarithmic) and compare their forecast on the outcomes of 2003 US National Football League games with that implied by prediction markets and find that the market's forecast is as accurate or more accurate than pooled opinions. Kou and Sobel (2004) propose a theoretical justification for using market prices which is to use the market equilibrium price instead of the actual price as the market-based forecast. They find that even though the market forecast does not dominate that of polls in general, they prove that the market outperforms polls if the information contained in polls is included in the information set possessed by market participants. Other studies agree on the same idea that market beat polls include Caldeira (2004); Sunstein (2005) and Surowiecki (2004).

In contrast, Erikson and Wlezien (2008) show that historically market participants can profit by exploiting information contained in the opinion polls. Interestingly, Erikson and Wlezien (2008); Rhode and Strumpf (2004) use the election eve prices of markets in the period during and before the advent of opinion polls and find that the predictive performance of market is affected by the availability of polls: before polling, the market worked 
remarkably well. However, following the introduction of polls, market prices heavily reflected the polls and did not add information beyond polls (Erikson and Wlezien, 2012).

Erikson and Wlezien (2008) propose an method to transform a poll result which is supposed to reflect the public opinion on the day polls are conducted to a forecast (called projected polls) for what will happen on the election day on the future. While in most other studies, data from poll results are recorded on their release date, Erikson and Wlezien (2008)'s poll data are reported in terms of the beginning and end of the polling period. They lag the poll's projection two days, i.e. they treat each poll as being released two days after the final date in the period of interview and process. They provide no explanation why the use of polls lagging two days from the final date of polling is chosen.

\subsubsection{Comparison of forecast error}

Since market prices vary continuously, the question arises of which price to take as the prediction from the market. Berg et al. (2000) suggest to weight market prices according to their trading volume (i.e. the number of shares associated with each trade). Table 6.2 compares the forecast errors of Roy Morgan's polls and iPredict's volume weighted average price on the release day of the last poll (November 23, 2011). Across all contracts, the average poll error is $12.12 \%$ while that of the market is $6.61 \%$. The market outperforms the opinion polls in major parties (National, Labour, and Green), being similar in small parties except for the New Zealand First and ACT in which polls predict better.

A prediction on a single day is less rich than predictions over the full course of the campaign. Figures $6.4-6.8$ compare the market prediction with that of opinion polls for the individual parties over the course of the campaign. There is a general tendency for the market and the opinion polls to converge to election outcomes over the time but the market prediction appear to be more stable than those of polls. The exception to this 
Table 6.2: Forecast errors of Roy Morgan polls and iPredict's prices on November 24, $2011(\%)$

\begin{tabular}{|c|c|c|c|c|c|c|c|c|c|}
\hline $\begin{array}{ll}\text { General } & \text { Elec- } \\
\text { tion } 2011 & \end{array}$ & National & Labour & Green & $\begin{array}{l}\text { NZ } \\
\text { First }\end{array}$ & ACT & Māori & $\begin{array}{l}\text { United } \\
\text { Future }\end{array}$ & Others & Sum* \\
\hline Official Results $^{1}$ & 47.31 & 27.48 & 11.06 & 6.59 & 1.07 & 1.43 & 0.60 & 4.46 & 100 \\
\hline $\begin{array}{l}\text { Roy } \\
\text { Poll }^{2}\end{array}$ & 49.50 & 23.50 & 14.50 & 6.50 & 1.50 & 1.00 & 0.50 & 3.00 & 100.00 \\
\hline iPredict prices $^{3}$ & 47.16 & 28.35 & 11.92 & 4.22 & 2.37 & 1.21 & 0.75 & 3.77 & 99.75 \\
\hline $\begin{array}{l}\text { Error of Roy } \\
\text { Morgan }^{4}\end{array}$ & 2.19 & -3.98 & 3.44 & -0.09 & 0.43 & -0.43 & -0.10 & -1.46 & 12.12 \\
\hline Error of iPredict ${ }^{5}$ & -0.15 & 0.87 & 0.86 & -2.37 & 1.30 & -0.22 & 0.15 & -0.69 & 6.61 \\
\hline
\end{tabular}

* Sum of absolute values

${ }^{3}$ Volume-weighted prices

${ }^{4}(4)=(3)-(1)$

${ }^{5}(5)=(4)-(1)$

are the ACT and United Future contracts in which the market diverges from the actual outcomes more often and by a greater extent than opinion polls. Also, prices in those markets exhibit significant volatility. Nevertheless, over the full course, the markets are more accurate and stable than polls. This emphasises the value of the markets as long run forecast devices. iPredict outperformed the opinion polls in six out of eight contracts but did poorly especially in the New Zealand First contract when comparing the forecast error over the full course (see Table 6.3). McGirr and Salmond (2010) studying the 2008 NZ Election find that iPredict's average error immediately prior election day is $15.7 \%$ and $25.8 \%$ over the whole campaign. Those of Roy Morgan polls are $20.8 \%$ and $36.8 \%$, respectively. In this study of the 2011 Election, iPredict's error was $1.35 \%$ on the election-eve, and $17.17 \%$ during the full course. Roy Morgan polls' errors were $12.12 \%$ on the last poll and $19.74 \%$ during the entire course. Both iPredict and Roy Morgan have apparently improved their predictive performance since the previous election but iPredict continues to produce better forecast in general.

Table 6.3: Forecast errors of Roy Morgan polls and iPredict's prices over the full course(\%)

\begin{tabular}{|l|l|l|l|l|l|l|l|l|l|}
\hline Error & National & Labour & Green & $\begin{array}{l}\text { NZ } \\
\text { First }\end{array}$ & ACT & Māori & $\begin{array}{l}\text { United } \\
\text { Future }\end{array}$ & Others $^{\text {Sum }}$ \\
\hline Roy Morgan & 4.54 & 3.98 & 3.04 & 0.59 & 0.93 & 0.22 & 3.19 & 3.25 & 19.74 \\
\hline iPredict & 1.88 & 3.93 & 2.97 & 2.85 & 0.60 & 1.08 & 1.97 & 1.89 & 17.17 \\
\hline
\end{tabular}

${ }^{*}$ Sum of absolute errors 
Most studies on predictive power of prediction markets use some form of graphical examination to look for patterns in the time trend of both forecasts. The time trend of two forecasts are used to look for any apparent trend of overestimating or underestimating the support for the underlying party candidate (McGirr and Salmond, 2010; Berg et al., 2001; Forsythe et al., 1992). Leigh and Wolfers (2006) graphically examine the reaction of both opinion polls and market prices to specific events and conclude that prices respond quickly to news and different polls appear to respond in similar ways to market prices. The graphical examination in those studies reach one agreement on the degree of volatility in polls: poll results are more volatile than market prices and are conflicting among various pollsters. They state that this volatility cannot be explained by the sampling error solely.

Visual inspection of Figures 6.4 - 6.11 graphing the forecast implied by iPredict and opinion polls has a number of key suggestions. The poll overpredicted the actual outcome and market prices all the time in the National contract which suggests a bias in poll results. The bias could be resulted from the poll sampling. The poll's sample is ideally to be chosen randomly but at the same time to be a representative of the voting population. The overprediction in the poll results may result from a skew in the sample in National's favour. Furthermore, market prices and polls appear to reveal conflicting information about the change in the support toward the National party in that the two series do not follow each other. This is reflected in the low correlation of 0.23 . The positivity of the correlation of market prices and opinion polls may be flawed due to the small sample ${ }^{4}$. In contrast, the opinion polls and market prices appear to follow the same trend in the Labour, Green and ACT contracts. However, when the polls and market prices for the Labour and Green contracts produce the same predictions, prices in the ACT contract exhibit a considerable difference with poll results. Also, no similar trend is observed in the contract of the New Zealand First, Māori, United Future party and the Other contract. Plus, market prices did a poor job predicting the support to the United Future contract:

\footnotetext{
${ }^{4}$ Due to the difference in time interval, the correlation of market prices and polls is calculated by matching prices and poll results on the poll's release date. As a result, the sample size is only 27 .
} 
overpredicting the actual result all the time. And the similar observation may be made with regards to the ACT contract. In general, the visual inspection shows mixed results of which tools produces the better forecast but market prices experienced less volatility. The correlation of market prices and poll results is positive in all contracts, except for the rest of vote share (negative but very small), and particularly strong in Labour, Green and NZ First.

Figure 6.4: Forecast of the National's vote share by iPredict and opinion polls

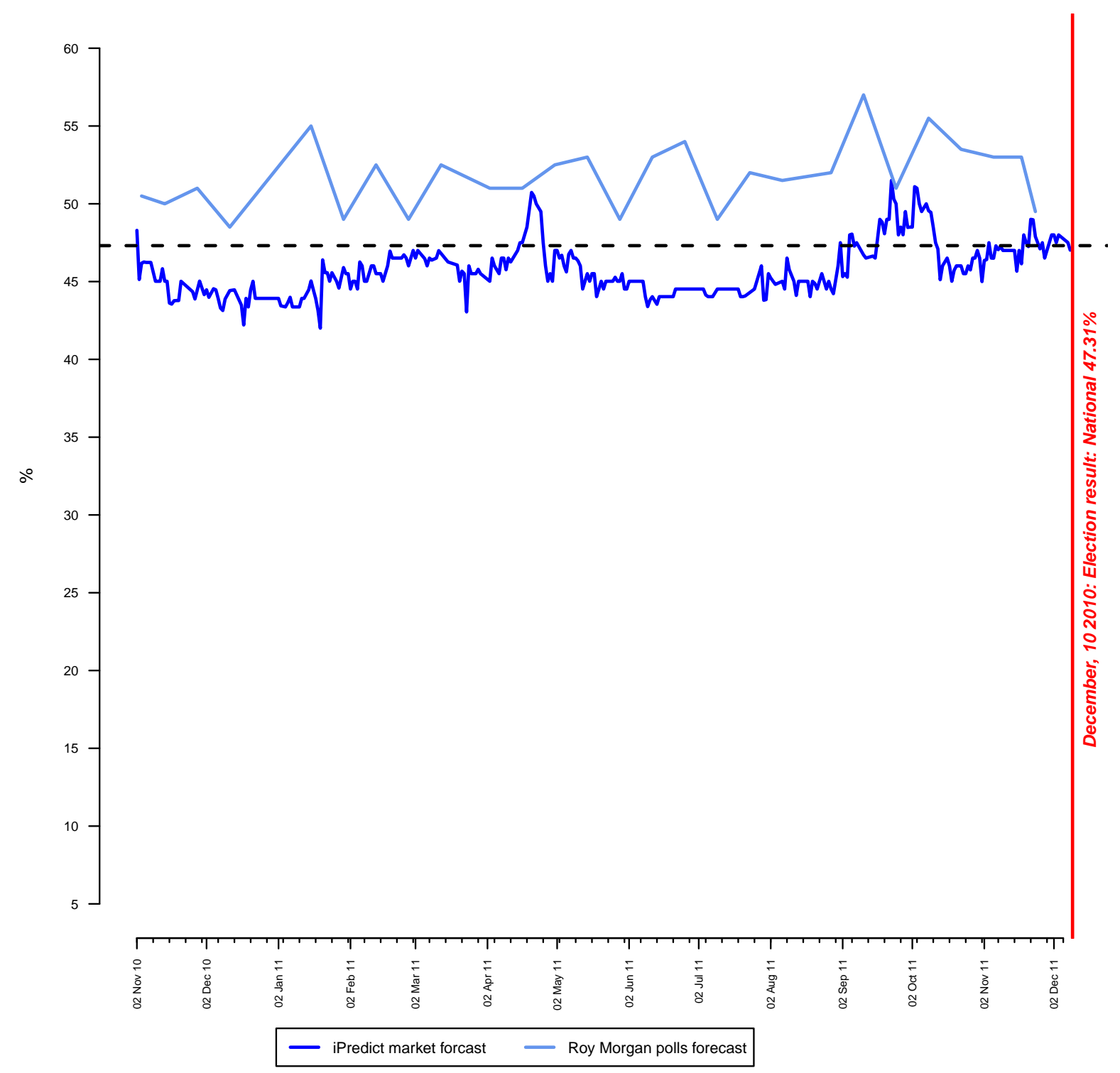

Correlation $=0.23$ 
Figure 6.5: Forecast of the Labour's vote share by iPredict and opinion polls

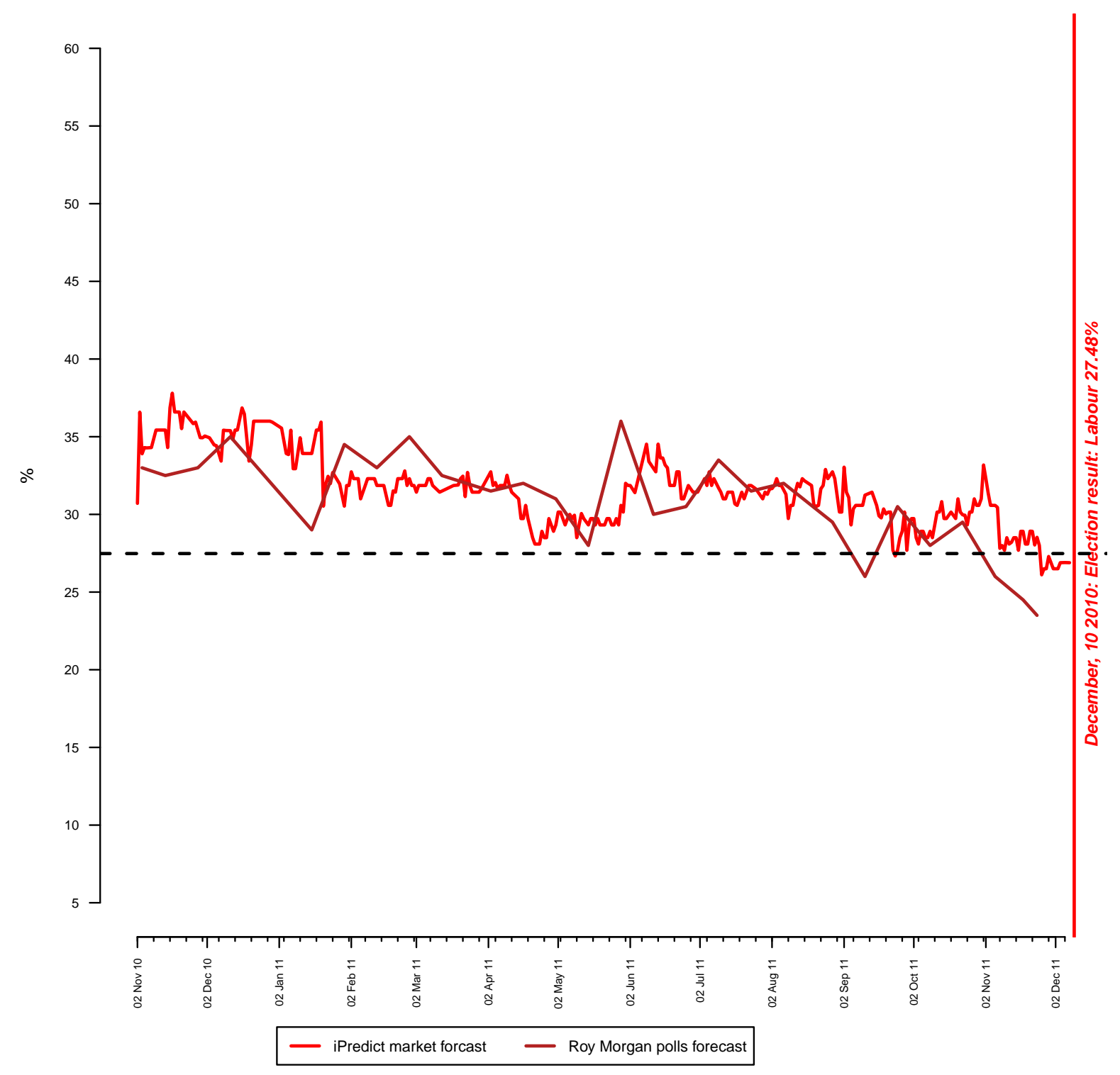

Correlation $=0.7$ 
Figure 6.6: Forecast of the Green's vote share by iPredict and opinion polls

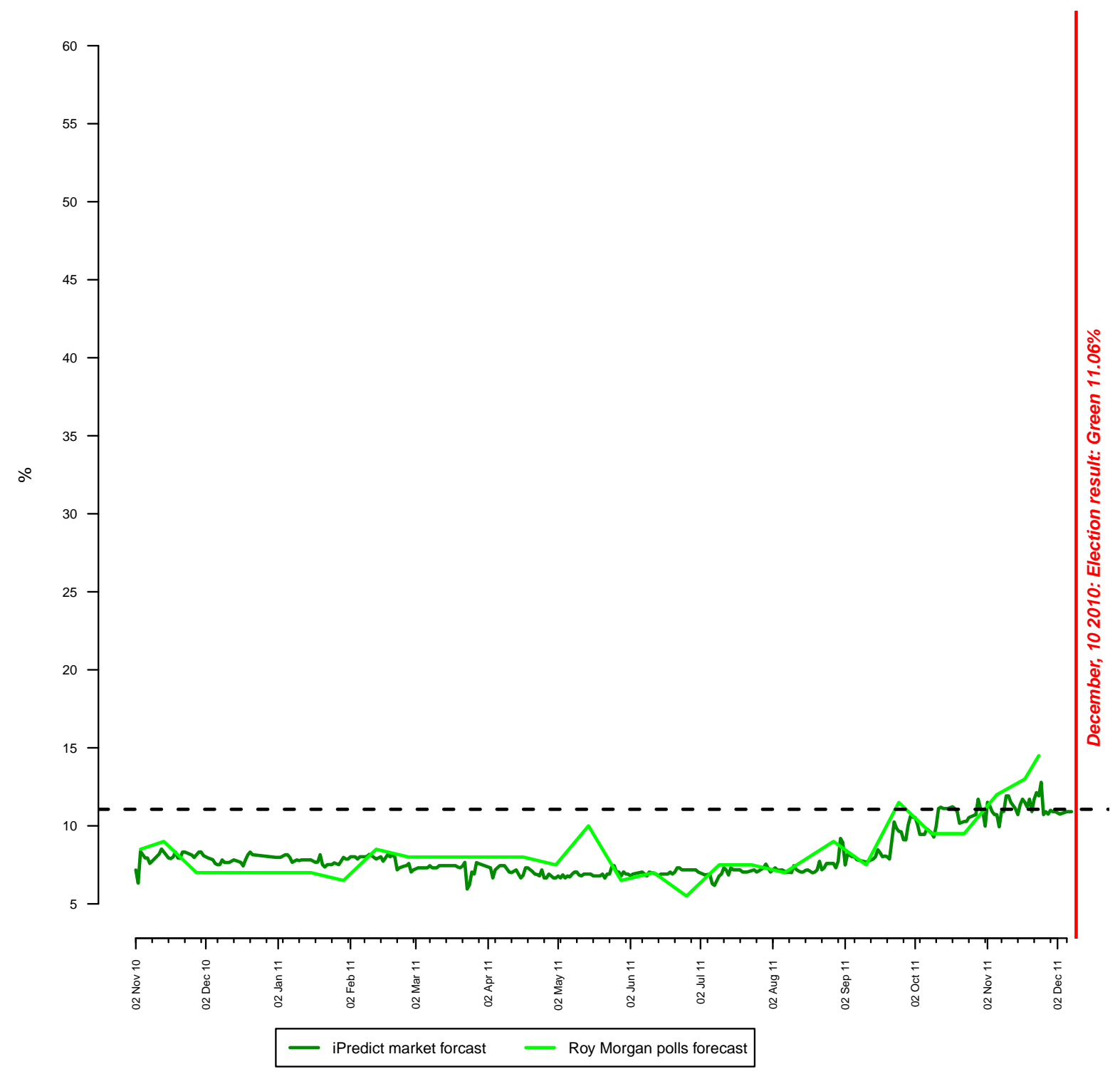

Correlation $=0.83$ 
Figure 6.7: Forecast of the New Zealand First's vote share by iPredict and opinion polls

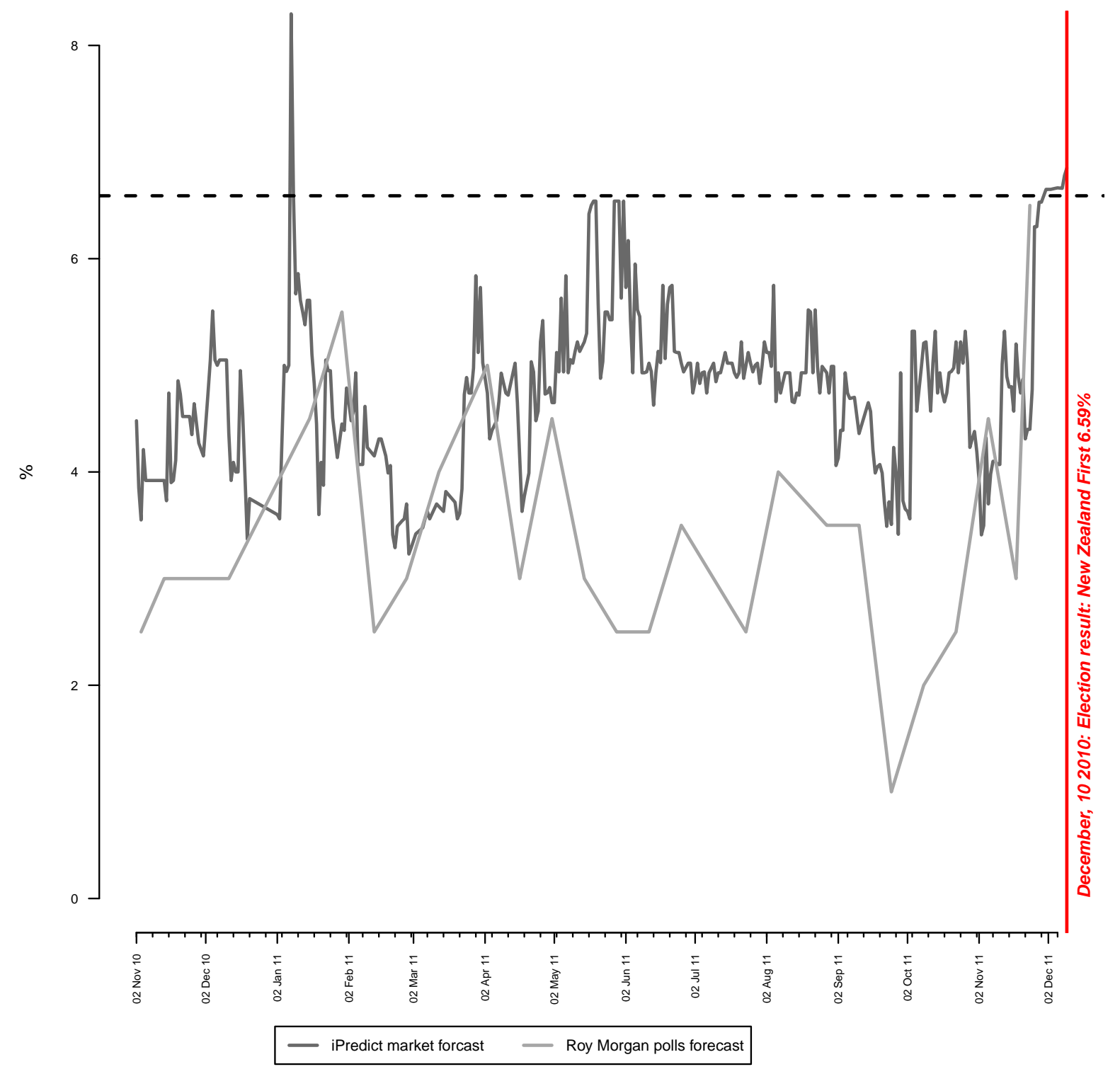

Correlation $=0.75$ 
Figure 6.8: Forecast of the ACT's vote share by iPredict and opinion polls

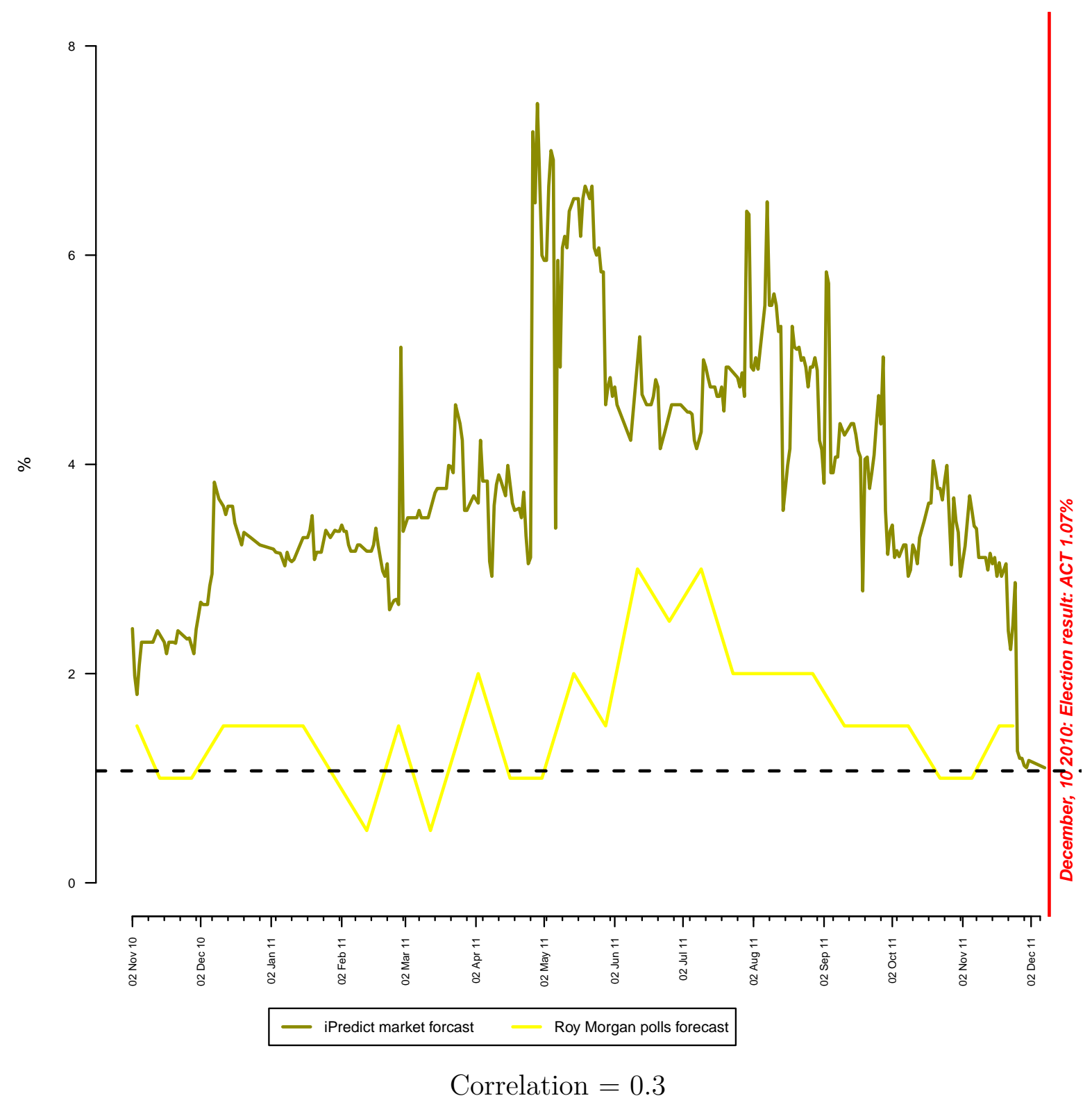


Figure 6.9: Forecast of the Māori's vote share by iPredict and opinion polls

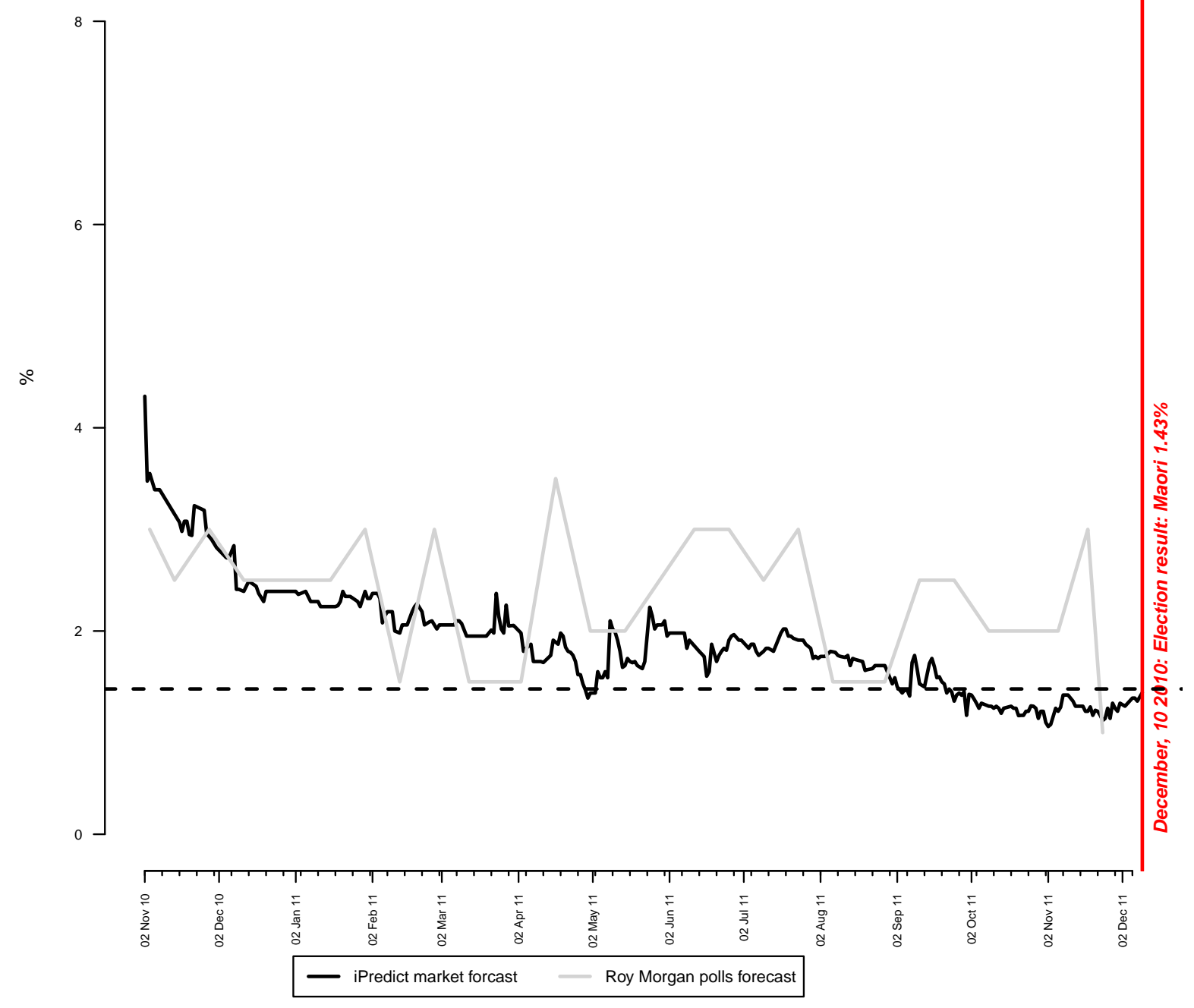

Correlation $=0.345$ 
Figure 6.10: Forecast of the United Future's vote share by iPredict and opinion polls

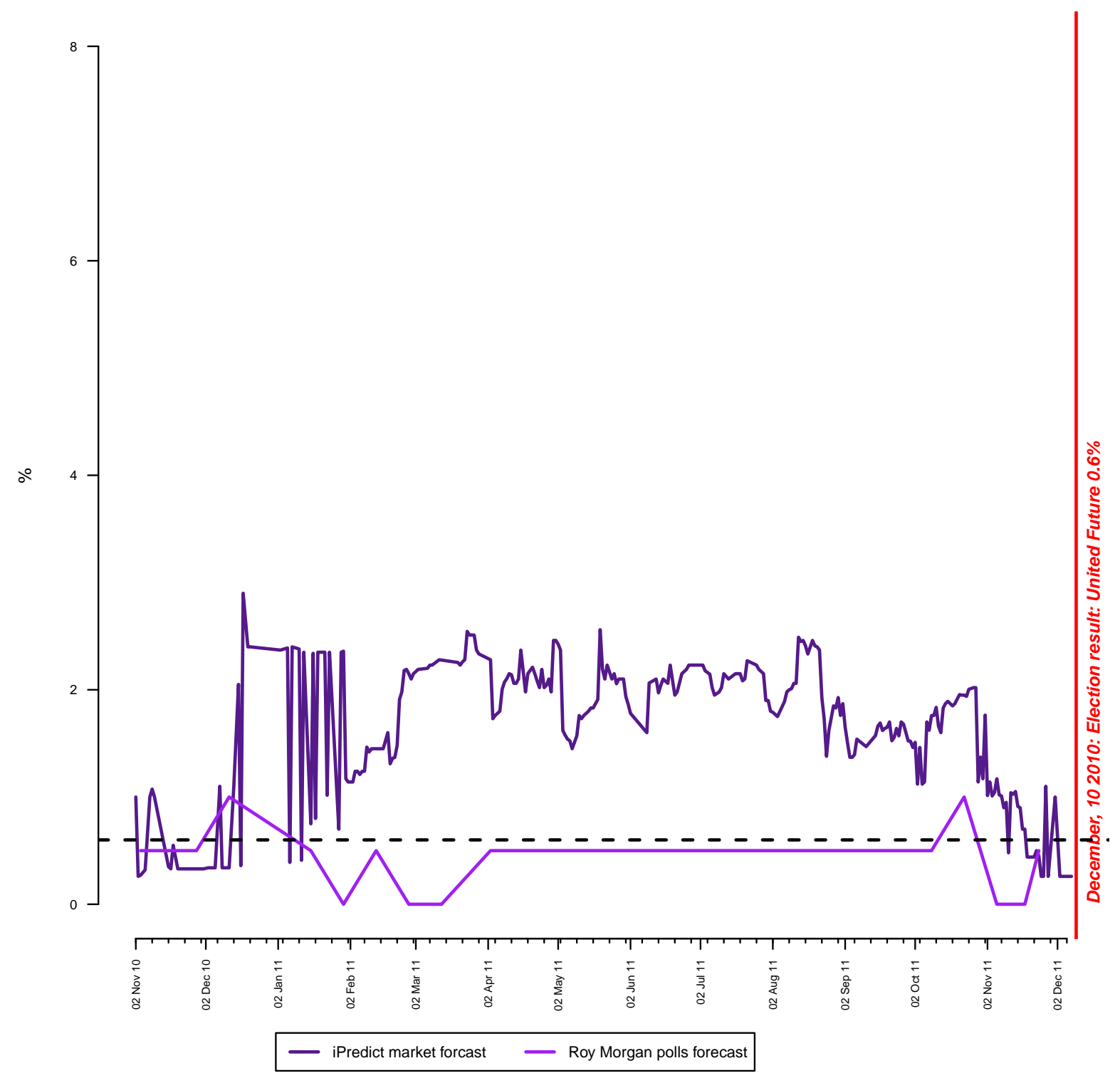

Correlation $=0.35$ 
Figure 6.11: Forecast of the rest of the vote share by iPredict and opinion polls

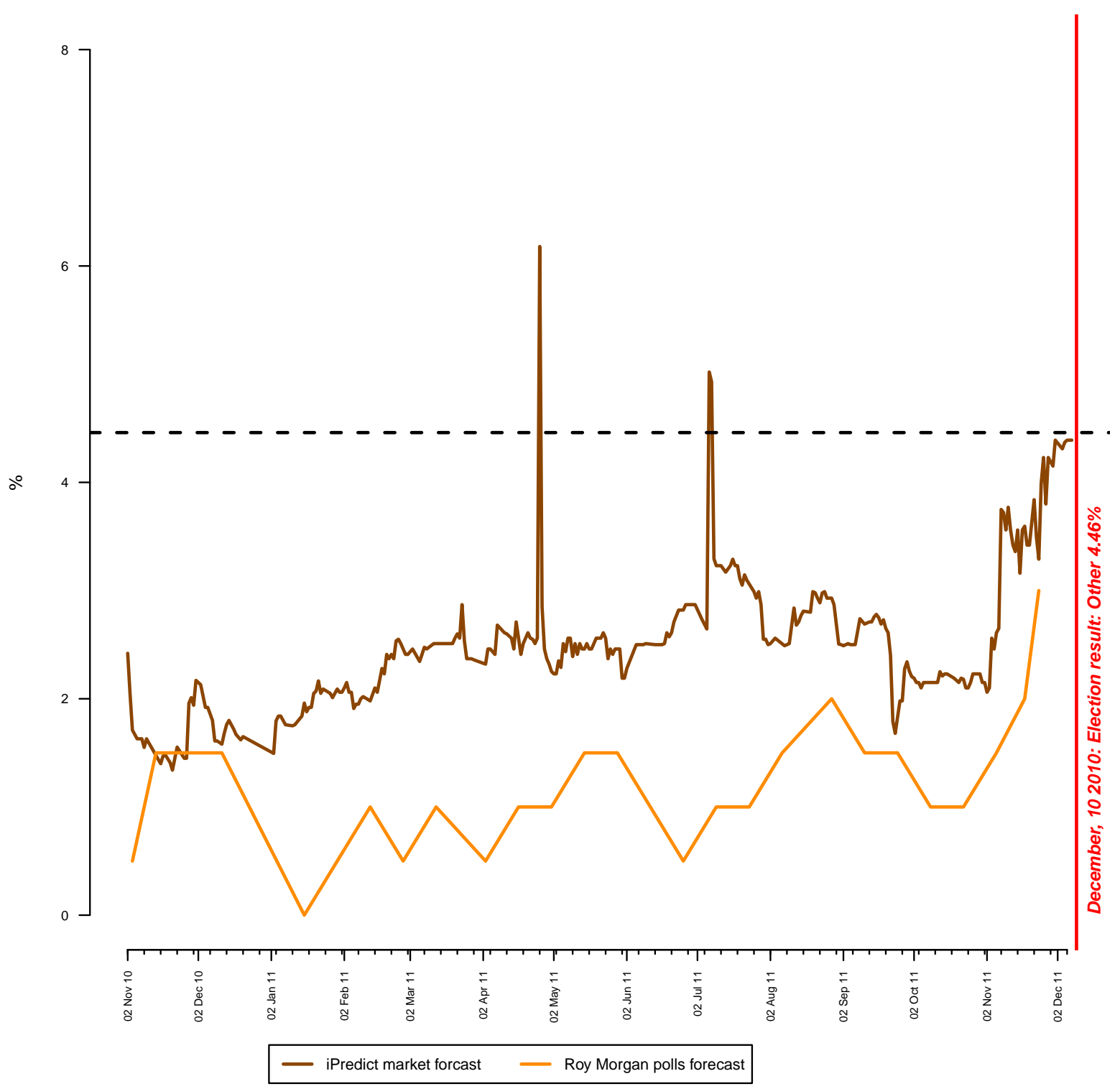

Correlation $=-0.058$ 


\subsection{Literature Review}

Page (2008) propose a theoretical way to transform a poll into a market price of a binary contract $^{5}$ under the assumption that opinion polls are the only available relevant information to the election. The formula yields that the price depends on the probability that the current proportion of votes for the underlying candidate is greater than $50 \%$ and on the volatility of voters' change of mind.

Erikson and Wlezien (2008) set up a hypothetical market whose prices are determined by poll results and a robot trades against the market at offers derived from the actual market prices. If the robot can produce a profit then market prices contain superior information beyond polls and vice versa. They find a $50 \%$ chance of the robot making a profit which implies that market prices do not provide a better forecast than polls.

The relationship between market prices and opinion polls is tested by a formal model in Forsythe et al. (1992). In their model, the market price is determined by its previous values up to lag 2 and the difference of the actual poll result and its expected value conditional on the current information set.

$$
p_{t}=\alpha_{0}+\alpha_{1} p_{t-1}+\alpha_{2} p_{t-2}+\beta\left[\operatorname{Poll}_{t}-E_{t}\left(\operatorname{Poll}_{t} \mid \phi_{t-1}\right)\right] D_{t}+u_{t}
$$

where $p_{t}$ is the market price on day $t, \phi_{t-1}$ is all information available prior to time $t$, Poll $_{t}$ is an opinion poll's result released on day t, $D_{t}$ is a dummy variable which takes on the value 1 or 0 according to whether a new poll is released on day $t$ and $u_{t}$ is white noise. The anticipated poll result is determined by preceding poll results plus the cumulative response of the market to any news that has arrived since the last poll.

$$
E_{t}\left(\operatorname{Poll}_{t} \mid \phi_{t-1}\right)=\gamma_{o}+\gamma_{1} \operatorname{Poll}_{t-s}+\gamma_{2}\left(p_{t-1}-p_{t-s}\right)
$$

\footnotetext{
${ }^{5} \mathrm{~A}$ binary contract pays $\$ 1$ of and only if a specific event occurs and 0 otherwise.
} 
For each contract, the model is estimated in two versions: the constrained model when $\beta=0$ and the unconstrained when $\beta \neq 0$. In the constrained model, poll results are irrelevant to market participants (as the information in the poll is assumed to be already incorporated into the information set available to market participants) and Equation (6.4) collapses to:

$$
p_{t}=\alpha_{0}+\alpha_{1} p_{t-1}+\alpha_{2} p_{t-2}+u_{t}
$$

The estimate of $\gamma_{1}$ represents the extent to which the previous poll result influences the current poll. Thus if $\gamma_{1}$ was close to zero, it would indicate that previous polling has little bearing on the likely outcome of the current poll. In contrast, a significant value would indicate the opposite. As mentioned above, it is unlikely that poll results reflect information contained in prediction market prices. The market prices embody participants' aggregation of information including the voting preferences of non market participants. In contrast, poll respondents are expected to truthfully reveal their personal voting intention without consideration of what other voters may vote. Forsythe et al. (1992) find that the null hypothesis $\beta=0$ implying that the information contained in polls has no effect on market prices is not rejected at any significance level. The hypothesis that correlation coefficients cannot be zero $\alpha_{1}=\alpha_{2}=0$ is rejected and in addition one cannot reject $\alpha_{1}=0$ at $5 \%$; this is a weak evidence that market prices follow a random walk.

There is an issue with Forsythe et al. (1992)'s model and results. The regression analysis appears to be a relatively simple linear regression. However, it ignores the potential complications that arise from regression of non-stationary variables which will affect the significance of the estimates. More important, the non-stationary property is expected to be present in the market price level. Forsythe et al. (1992) do not indicate whether any tests for non-stationarity (including unit root tests) have been undertaken. Indeed, the graph of prices in Bush's contract (Figure 6.12) plotting the market prices and the 
corresponding polling results shows significant upward trends. This is not to say that these trends are not reflective of the same underlying factors, in which case the common trend is reasonable. Nevertheless, there still exists the possibility that the two series are affected by different factors that impart distinct trends: the two series can be correlated if trended by the same factor. This would lead to a spurious regression. Arguably it would be appropriate to transform the series (via, for instance, detrending or differencing) which would eliminate the potential for spurious regression. In fact, the stationary test conducted in this study using iPredict's data of markets predicting the 2011 General Election in New Zealand provides empirical evidences that market prices are indeed nonstationary processes. This implies that the regression equation (6.4) will produce spurious results unless an estimation procedure that recognises that they are stationary is used. For those time series of market prices whose non-stationary property is found as in the vote share market in iPredict, a different approach to analyze the causality must be taken.

Figure 6.12: Graph of Bush' prices in IEM

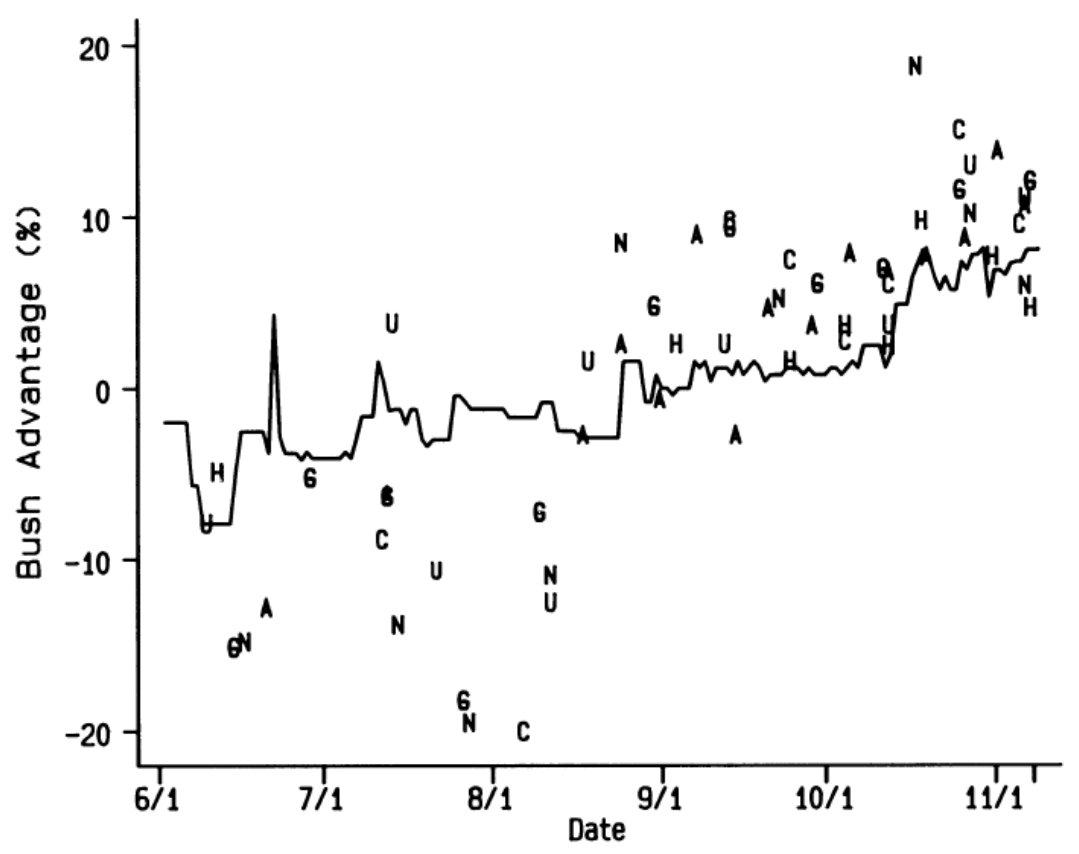

Figure 1. Bush's Lead In Opinion Polls and the IPSM

Key: $\mathrm{A}=\mathrm{ABC} /$ Washington Post, $\mathrm{C}=\mathrm{CBS} /$ New York Times, $\mathrm{G}=$ Gallup, $\mathrm{H}=$ Harris, $\mathrm{N}=\mathrm{NBC} /$ Wall Street Iournal, and $\mathrm{U}=\mathrm{CNN} /$ USA Today. The solid line depicts the IPSM results. 
In the same attempt to study the causality between poll results and market prices, Leigh and Wolfers (2006) use a different approach: a formal test whose hypothesis is that market price changes are predictable on the basis of publicly available polling data. It regresses price changes on the changes of latest poll results. The regression equation is:

$$
\Delta p_{t}=\beta_{1} \Delta \operatorname{Poll}_{t-1}+\beta_{2} \Delta \operatorname{Poll}_{t-2}+\beta_{3} \Delta \operatorname{Poll}_{t-3}
$$

The test is implemented in two prediction markets in Australia and produces different results of the same event. In one market, the coefficients are small and statistically insignificant suggesting that the market incorporates information contained in polls efficiently. In the other, the coefficients are also small but jointly significant suggesting some lags in the information incorporation. However, it is insufficient to create profitable opportunities by exploiting the serial correlation in market prices. Leigh and Wolfers (2006)'s equation has the same issue with that of Forsythe et al. (1992): without a confirmation of the stationary property of price changes, their model is exposed to the risk of the spurious regression problem.

\subsection{Testing Models and Results}

Poll results once reported in media or in a pollster's newsletter become publicly available information. The test for the existence of the causality relationship between market prices and poll results is likely to entail a one-way effect of information contained in polls on the change in market prices. An efficient market, at least at semi-strong form, should expect to find no such effect: if information revealed in opinion polls is anticipated by traders then the release of a poll result will not affect market prices. In other word, polls do not provide information beyond what is already reflected in market prices. 
A formal test of the relationship between opinion polls and market prices requires a model of market price changes. Its first purpose is to examine the degree of market efficiency. Efficiency in the context of a single market usually implies that prices follow a random walk and that the change in prices should not be predictable (otherwise it would be possible to consistently take a speculative positions that earn a supernormal profit). This further implies no pattern in the price changes, i.e. no serial correlation with its own lags or no sources of external information can help to predict the movement of changes in the price. The second purpose is to provide a model to test for the influence of opinion polls on the market prices. In an informationally efficient market, market price changes are independent to opinion polls.

In order to avoid the spurious regression problem, the validity of any models requires that changes in market prices follow a stationary process. Theoretically the change in poll's results is also required to be stationary. However, due to a relatively large interval in the arrival time of poll results and its small sample size (27 observations in this study) and more importantly that poll respondents are theoretically not meant to consider any other information than their own voting preference, it is reasonable to assume poll results to be an exogenous regressor (i.e. poll results are independent to market prices) therefore their stationary property is not essential.

\subsubsection{Property of market price changes}

The unit root test in Section 5.4 shows that market prices in seven contracts, except the Māori contract, are non-stationary and a I(1) process. This result implies that the first-period price changes in these contracts are $\mathrm{I}(0)$ and therefore stationary. Any test which requires a regression of the price changes in these contracts should not be subject to the spurious regression problem. In the Māori contract, the ADF test rules out the possibility that its price level is an I(1) process but it does not imply that it is station- 
ary. The visual inspection in Figure 5.2 suggests a time trend of decreasing mean in the Māori contract prices, which is a signal of a non-stationary process. The time trend is eliminated in the first differeence ${ }^{6}$. The ADF test applied to the first differences of the Māori contract shows that its stationarity cannot be rejected.

\subsubsection{Alternative models of market price changes}

I start with a simple model in which changes in price are determined by solely one factor: the opinion polls. This simple model excludes any other determinants. Assume that $E\left(u_{t} \mid \Delta\right.$ Poll $\left._{t}\right)=0:$

$$
\Delta p_{t}=\alpha_{0}+\beta \Delta \operatorname{Poll}_{t} D_{t}+u_{t}
$$

where $\Delta$ is the one-period difference; for market prices $\Delta p_{t}=p_{t}-p_{t-1}$ is one-day price change while for poll results $\Delta$ Poll $_{t}=$ Poll $_{t}-$ Poll $_{t-s}$ is the difference of two adjacent poll reports. Stationarity tests have no power with polls therefore $\Delta P o l l_{t}$ is treated as exogenous, i.e. $E\left(u_{t}\right) \mid \Delta$ Poll $_{t} D_{t}=0$. Note that while the market price is a continuous daily time series, poll results arrive at discrete and irregular intervals. For Roy Morgan's polls, the time interval are fortnightly on average. This difference in arrival time's window is overcome by the dummy variable $\left(D_{t}\right)$ which takes on the value 1 or 0 according to whether a new poll is released on day $t$. The regression is estimated by OLS method.

Ideally, polls are meant to be a representative of the voting population then market prices are expected to perfectly (and positively) correlate with the opinion polls. In the other words, $\operatorname{plim} \hat{\beta}=1$. However, in reality there always exist measurement errors arising from the sampling therefore $\beta$ is never one. The greater the errors, the further $\beta$ is away from

\footnotetext{
${ }^{6}$ Assume the Māori price is specified by a model $M(p)$ and the linear time trend $p_{t}=M\left(p_{t}\right)+\tau t+u_{t}$. This leads to $\Delta p_{t}=M\left(\Delta p_{t}\right)+\tau[t-(t-1)]+u_{t}-u_{t-1}$ and subsequently $\Delta p_{t}=M\left(\Delta p_{t}\right)+\tau+u_{t}-u_{t-1}$
} 
one. Measurement errors associated with poll results arise in two circumstances. First, it depends on how well a sample represents the population. Ideally, a sample replicates all the key properties of the population and at the same time is chosen randomly. The representativeness comes at the cost of the randomness and the quality of a sample is determined by how this trade-off is balanced. In practice, no sample achieves a perfect representativeness and therefore every poll result is associated with a reported margin of error which depends on the sample size as discussed in Section 6.1. The second source of measurement errors occurs during the sampling and processing procedure when questions are not understood correctly by respondents or the responses are not processed properly. This type of errors is relatively infrequent and can be eliminated by improving the quality of the sampling and processing procedure.

The robustness of this simple model in Equation (6.6) is examined by checking whether its residuals are white noise. The three properties of white noise variables namely zero mean, homoscedasticity and independence (i.e. no serial correlation) are tested by the t-test, Breusch-Pagan and Box-Ljung test (and Box-Pierce to confirm the results), respectively. At the 5\% significance, the simple model in Equation (6.6) violates the white noise's assumptions in all eight contracts, except for the Māori contract. The null hypothesis of homoscedasticity is rejected in two contracts, those for the National and Labour party and the null hypothesis of independence is rejected in all seven contracts. In the Māori contract, the simple model is robust and plausible and both the constant term and coefficient on the change in polls are not significant at any significance level. The polls appear not to have any influence on the movement of market prices in the Māori contract.

The rejection of the white noise hypothesis of residuals in seven out of eight contracts suggests adding regressors to the simple model in Equation (6.6). The second alternative model is the autoregressive process where the number of lags are determined by a paring down process. The ADF test results in Section 5.4 suggests the constant term is small 
and insignificant in all contracts therefore it is excluded in the AR model. The AR(k) model is as follows:

$$
\Delta p_{t}=\beta \Delta \operatorname{Poll}_{t} D_{t}+\sum_{j=1}^{k} \alpha_{j} \Delta p_{t-j}+\epsilon_{t}
$$

A specific $\mathrm{AR}(\mathrm{k})$ process is determined for individual contract as follows ${ }^{7}$ :

National contract: $\operatorname{AR}(3)$

Labour contract: $\mathrm{AR}(4)$

Green contract: $\mathrm{AR}(5)$

New Zealand First contract: $\operatorname{AR}(2)$

ACT contract: $\operatorname{AR}(4)$

Māori contract: $\operatorname{AR}(2)$ Other contract: $\operatorname{AR}(3)$

United Future contract: AR(5)

The robustness of the autoregressive model is improved slightly as compared to that of the simple model in Equation (6.6). Residuals in all contracts satisfy the property of independence while the null hypothesis of homoscedasticity is still rejected strongly.

The third alternative model is a moving average process $\mathrm{MA}(\mathrm{q})$ in which the number of lags is determined by a visual inspection of the autocorrelation graphs. The MA(1) process seems to be appropriate for all contracts, except for the Green and Other contracts which appear to follow a MA(2) process.

\footnotetext{
${ }^{7}$ The number of lags of seven $k=7$ is chosen to start with as in the ADF test. The seven lags are generally large enough to avoid missing significant lags and also consistent with the one week of trading because iPredict is operating continuously $24 / 7$. The paring down process runs the Equation 6.7 starting with $k=7$ to identify insignificant lags and exclude them. The same procedure runs at $k=6,5, \ldots$ until all the lags remaining in the equation are all significant.
} 
In the National, Labour, New Zealand First, ACT, Māori and United Future contracts:

$$
\Delta p_{t}=\alpha_{0}+\beta \Delta \operatorname{Poll}_{t} D_{t}+\lambda_{1} \epsilon_{t-1}+\epsilon_{t}
$$

In the Green and Other contract:

$$
\Delta p_{t}=\alpha_{0}+\beta \Delta \operatorname{Poll}_{t} D_{t}+\lambda_{1} \epsilon_{t-1}+\lambda_{2} \epsilon_{t-2}+\epsilon_{t}
$$

The moving average model produces robustness in no contract. All contracts violate either or both of the assumptions of homoscedasticity and independence. Table 6.4 reports the result of the effect of opinion polls on the movement of market prices examined by the three models. 
Table 6.4: The immediate effect of opinion polls on market prices

\begin{tabular}{|l|l|l|l|l|l|l|l|l|}
\hline Contract & National & Labour & Green & NZ First & ACT & Māori & Other & $\begin{array}{l}\text { United } \\
\text { Future }\end{array}$ \\
\hline \multicolumn{2}{|l|}{ Simple model in Equation (6.6) } \\
\hline$\beta$ & \begin{tabular}{l|l|l|l|l|l|l|l|l|}
$-149^{* * *}$ \\
$(0.043)$
\end{tabular} & $\begin{array}{l}0.243^{* *} \\
(0.05)\end{array}$ & $\begin{array}{l}0.015 \\
(0.042)\end{array}$ & $\begin{array}{l}0.156^{* *} \\
(0.058)\end{array}$ & $\begin{array}{l}-0.011 \\
(0.139)\end{array}$ & $\begin{array}{l}-0.005 \\
(0.02)\end{array}$ & $\begin{array}{l}-0.042 \\
(0.109)\end{array}$ & $\begin{array}{l}-0.148 \\
(0.223)\end{array}$ \\
\hline F-joint & $* *$ & $* * *$ & & $*$ & & & & \\
\hline AIC & -2792.5 & -2697.8 & -3410.5 & -3236.5 & -3147.3 & -4450.4 & -3497.4 & -3321.7 \\
\hline$R^{2}$ & 0.0288 & 0.056 & 0.0003 & 0.023 & 0.00001 & 0.0002 & 0.0004 & 0.001 \\
\hline
\end{tabular}

\begin{tabular}{|c|c|c|c|c|c|c|c|c|}
\hline \multicolumn{9}{|c|}{$\mathbf{A R}(\mathbf{k})$ process in Equation (6.7) } \\
\hline$\beta$ & $\begin{array}{l}0.128^{* *} \\
(0.044)\end{array}$ & $\begin{array}{l}0.215^{* * *} \\
(0.041)\end{array}$ & $\begin{array}{l}0.037 \\
(0.035)\end{array}$ & $\begin{array}{l}0.161^{* *} \\
(0.054)\end{array}$ & $\begin{array}{l}-0.164 \\
(0.121)\end{array}$ & $\begin{array}{c}-0.007 \\
(0.019)\end{array}$ & $\begin{array}{l}0.063 \\
(0.0888)\end{array}$ & $\begin{array}{l}0.13 \\
(0.147)\end{array}$ \\
\hline$\alpha_{1}$ & $\begin{array}{l}-0.258^{* * *} \\
(0.05)\end{array}$ & $\begin{array}{l}-0.381^{* * *} \\
(0.052)\end{array}$ & $\begin{array}{l}-0.265^{* * *} \\
(0.05)\end{array}$ & $\begin{array}{l}-0.279^{* * *} \\
(0.05)\end{array}$ & $\begin{array}{l}-0.353^{* * *} \\
(0.05)\end{array}$ & $\begin{array}{l}-0.162^{*} \\
(0.07)\end{array}$ & $\begin{array}{l}-0.402^{* * *} \\
(0.05)\end{array}$ & $\begin{array}{l}-0.629 * * * \\
(0.05)\end{array}$ \\
\hline$\alpha_{2}$ & $\begin{array}{l}-0.144^{* *} \\
(0.052) \\
\end{array}$ & $\begin{array}{l}-0.218^{* * *} \\
(0.055)\end{array}$ & $\begin{array}{l}-0.267 * * * \\
(0.052)\end{array}$ & $\begin{array}{l}-0.127^{*} \\
(0.05)\end{array}$ & $\begin{array}{l}-0.174^{* * *} \\
(0.052)\end{array}$ & $\begin{array}{l}-0.134 . \\
(0.07)\end{array}$ & $\begin{array}{l}-0.31 * * * \\
(0.051)\end{array}$ & $\begin{array}{l}-0.327 * * * \\
(0.059)\end{array}$ \\
\hline$\alpha_{3}$ & $\begin{array}{l}-0.146^{* *} \\
(0.05)\end{array}$ & $\begin{array}{l}-0.224^{* * *} \\
(0.054)\end{array}$ & $\begin{array}{l}-0.224^{* * *} \\
(0.052)\end{array}$ & & $\begin{array}{l}-0.184^{* * *} \\
(0.052)\end{array}$ & & $\begin{array}{l}0.142^{* *} \\
(0.049)\end{array}$ & $\begin{array}{l}-0.261^{\text {*** }} \\
(0.06)\end{array}$ \\
\hline$\alpha_{4}$ & & $\begin{array}{c}-0.136^{*} \\
(0.053) \\
\end{array}$ & $\begin{array}{l}-0.23^{* * *} \\
(0.052) \\
\end{array}$ & & $\begin{array}{l}-0.141^{* *} \\
(0.049) \\
\end{array}$ & & & $\begin{array}{l}-0.108 . \\
(0.06)\end{array}$ \\
\hline$\alpha_{5}$ & & & $\begin{array}{l}-0.146^{* *} \\
(0.051)\end{array}$ & & & & & $\begin{array}{l}0.974^{*} \\
(0.05)\end{array}$ \\
\hline F-joint & $* * *$ & $* * *$ & $* * *$ & *** & $* * *$ & * & $* * *$ & $* * *$ \\
\hline AIC & -2835.6 & -2779.1 & -3453.6 & -3278.0 & -3197.4 & -4468.7 & -3565.0 & -3471.0 \\
\hline$R^{2}$ & 0.103 & 0.184 & 0.127 & 0.09 & 0.126 & 0.03 & 0.162 & 0.31 \\
\hline$R^{2}(\beta=0)$ & 0.08 & 0.129 & 0.124 & 0.072 & 0.122 & 0.03 & 0.161 & 0.31 \\
\hline
\end{tabular}

\begin{tabular}{|c|c|c|c|c|c|c|c|c|}
\hline \multicolumn{9}{|c|}{ MA(q) in Equation (6.8) } \\
\hline$\beta$ & $\begin{array}{l}0.135^{* * *} \\
(0.04)\end{array}$ & $\begin{array}{l}0.21^{* * *} \\
(0.042)\end{array}$ & $\begin{array}{l}0.041 \\
(0.035)\end{array}$ & $\begin{array}{l}0.157^{* *} \\
(0.053)\end{array}$ & $\begin{array}{l}-0.192 \\
(0.124)\end{array}$ & $\begin{array}{l}-0.005 \\
(0.019)\end{array}$ & $\begin{array}{l}-0.03 \\
(0.083)\end{array}$ & $\begin{array}{l}0.134 \\
(0.153)\end{array}$ \\
\hline$\lambda_{1}$ & $\begin{array}{l}-0.295^{* * *} \\
(0.058)\end{array}$ & $\begin{array}{l}-0.441^{* * *} \\
(0.058)\end{array}$ & $\begin{array}{l}-0.294^{* * *} \\
(0.048)\end{array}$ & $\begin{array}{l}-0.316^{* * *} \\
(0.053)\end{array}$ & $\begin{array}{l}-0.396^{* * *} \\
(0.058)\end{array}$ & $\begin{array}{l}-0.192^{* *} \\
(0.096)\end{array}$ & $\begin{array}{l}-0.429^{* * *} \\
(0.049)\end{array}$ & $\begin{array}{l}-0.598^{* * *} \\
(0.038)\end{array}$ \\
\hline$\lambda_{2}$ & & & $\begin{array}{l}-0.277^{* * *} \\
(0.049)\end{array}$ & & & & $\begin{array}{l}-0.189^{* * *} \\
(0.051)\end{array}$ & \\
\hline F-joint & $* * *$ & $* * *$ & $* * *$ & $* * *$ & $* * *$ & $*$ & $* * *$ & $* * *$ \\
\hline $\mathrm{AIC}$ & -2832.6 & -2774.0 & -3448.5 & -3280.2 & -3193.2 & -4467.3 & -3574.3 & -3462.0 \\
\hline$R^{2}$ & 0.088 & 0.163 & 0.106 & 0.094 & 0.106 & 0.022 & 0.178 & 0.284 \\
\hline$R^{2}(\beta=0)$ & 0.062 & 0.113 & 0.103 & 0.074 & 0.1 & 0.022 & 0.178 & 0.283 \\
\hline
\end{tabular}

Main table entries are regression coefficient estimates, and entries in parentheses are standard errors.

The joint significance is tested by F-test.

The $R^{2}$ value is calculated as the square of the correlation coefficient between the actual and modeled data values.

Significant code: $0{ }^{\prime * * *}, 0.1 \%{ }^{\prime * *}, 1 \%{ }^{\prime} *, 5 \%$ '. $10 \%, ' 100 \%$.

In each case the constant term and its standard errors are tiny and insignificant therefore are excluded. 
There are several important points from the results. First, a significant $\beta$ indicates an effect of poll results on market prices which consequently implies that information revealed in opinion polls is not anticipated by market participants. This also indicates that obtaining information contained in polls helps predict the movement of market prices and one can benefit from exploiting information contained in polls. Consequently, the finding of a significant $\beta$ is a signal against the efficiency of the market. In contrast, if the hypothesis of $\beta=0$ cannot be rejected then information revealed in opinion polls does not surprise market participants and therefore have already been incorporated into market prices. The three alternative models do not produce greatly conflicting conclusions. They agree on the sign and significance of the $\beta$ 's estimate: $\beta$ is significant in three contracts of the National, Labour and New Zealand First contract. The magnitude of $\beta$ 's estimate varies considerably in the contracts of the Green and ACT party; however $\beta$ is insignificant in those cases. The magnitude of $\beta$ can be interpreted as how much explanatory power contributed to the movement of market prices by information revealed in opinion polls, e.g. in the Labour contract, the $\beta$ of $21.5 \%$ in the AR model implies that $21.5 \%$ of the change in prices is driven by the poll's results. Given that opinion polls are the major source of information which directly reveal contemporaneous voting preference, one may expect its effect on market prices to be greater. This result indicates that either most information contained in polls has been anticipated by traders or traders discount the credibility of information revealed by polls due to its bias created during the poll's sampling or the different purposes and mechanism of opinion polls and the market.

Second, in reality, there are other sources of information other than opinion polls. As discussed earlier, if polls are the only source of information relevant to the election and contain no errors then market prices should correlate perfectly with the opinion polls, or in other words $\beta=1$. When the measurement errors naturally associated with opinion polls are recognized, the estimate of $\beta$ remains relatively close to 1 unless the measurement errors are considerably large which eventually raises questions on the credibility of 
opinion poll results. The empirical results show that $\beta$ is in fact very small in magnitude even when it is statistically significant. On the one hand, this can be seen as an evidence that market traders gather information from many other sources therefore the effect of opinion polls is attenuated. On the other hand, this may result from the fact that the measurement error is opinion polls is underestimated or constituted by more than just the sampling errors. Leigh and Wolfers (2006) suggest in their study of the relative performance of various opinion polls predicting 2004 Australian elections that the margin of errors reported by pollsters should be doubled. The sampling error is caused by the fact that the sample interviewed is not the population itself and is dependent on the size of the sample and the randomness of the sample. However, beside the random sampling, samples used in opinion polls ar required to be a representative of the population. The quality of a opinion poll in terms of diminishing the sampling error is determined by how a sample is chosen so that it can meet both the randomness and representativeness. Furthermore, error may occur during the interview: it may result from the interviewer's misinterpreting questions or failures of memory by respondents (Moon, 1999b).

Third, the F-test for joint significance results in a rejection of the null hypothesis in which all coefficients are zero in every case. The market efficiency hypothesis states that the changes in price are random and unpredictable therefore determined by a random noise. This implies that all the coefficients are zero is the market is efficient. However, the rejection of the null hypothesis in the majority of cases, especially when the AR and MA model are in use suggests a degree of predictability.

Fourth, the autoregressive model produces negative coefficients in all contracts at all lags, except for the lag 2 in the Labour contract. This is consistent with previous studies of financial markets. Many previous studies have documented the negative correlation in stock returns over a holding period (DeBondt and Thaler, 1985; Shefrin and Statman, 1985; Long et al., 1990; Bremer and Sweeney, 1991). The predictable trend in stock 
returns is explained by the overreaction of the market which subsequently leads to price reversal. However, all of these studies rely on transaction prices and are thus unable to separate the effects of price reversal caused by the overreaction from these caused by measurement errors in prices. Niederhoffer and Osborne (1966); Roll (1984) show that within a market using a continuous trading mechanism, the observed security returns will be negatively correlated due to transaction prices bouncing between bid and ask prices. Roll (1984) illustrates a simple case where an unobservable "efficient price" follows a random walk and transactions only can occur on bid or ask quotes and the assumption is that the spread is constant and symmetric around the "efficient price". This results in transaction price changes following a MA(1) process with a negative coefficient. Kaul and Nimalendran (1990) confirm the main source of price reversals in the short run is the bid and ask spread and find little evidence of market overreaction. However, in contrast with Roll (1984)'s finding, they find (also using NASDAQ data) a positive correlation in stock returns after removing the effect of the bid and ask spread by using bid-to-bid returns and ask-to-ask returns instead returns derived from transaction prices. Rhee and Wanga (1997) further show that the patterns in stock returns is caused by two types of measurement errors: the bid and ask bounce error and the spread size error. Hascrouck (2007) discusses the Roll's model in great detail and suggest to use mid-point of bid and ask spread as a more precise for price estimate while there are suggestions from Blume and Stambaugh (1983); Keim (1989); Kaul and Nimalendran (1990). This is likely to be the underlying driver of the negative autocorrelation in the first-order price changes as shown in Table 6.4.

Fixth, the MA(1) model applied to the series of price changes is consistent with the theory of "bid and ask bounce" in which the transaction price changes follow a MA(1) process with a negative coefficient if transactions only can occur at bid or ask orders. Even though this is only true under the assumption of a constant and symmetric bid and ask spread around a theoretical "efficient price", the finding of negative coefficients in all 
contracts is consistent with the theory.

Sixth, using AIC as a criteria to find the best fit model, the autoregressive model produces the most negative values of AIC in all contracts, except for the contract of the New Zealand First party and the Other contract in which the lowest AIC is achieved by the moving average model.

Last, $R^{2}$ represents thee fitness of the model. For instance, in the National contract, $R^{2}$ is $2.9 \%$ in the simple model and is improved up to $10.3 \%$ in the AR model; this can be interpreted that $2.9 \%$ of the movement in market price can be explained by the opinion polls and the additional $6.4 \%$ is the result of its own historical price data. The $R^{2}$ mostly achieves its highest value in the AR specification but in general the value of $R^{2}$ is very low (less than $20 \%$ in all cases) and this indicates that all the coefficients that are statistically significant but may not be sufficient to create a pattern in the movement of market prices that can be exploited to be used to produce any profitable trading strategy. Additional information extracted from the $R^{2}$ in order to determine the influence of opinion polls is to compare the $R^{2}$ of the $\mathrm{AR}$ and MA models with and without opinion polls, i.e. $\beta=0$. For instance, $R^{2}$ is improved by $2.3 \%$ when opinion polls are included in the AR models and by $2.6 \%$ in the MA model in the National contract. Across all contracts, $R^{2}$ values goes up by a very small amount; this implies that opinion polls do not add much information to help predict market price changes even in cases where the estimate of $\beta$ is statistically significant.

The effect of opinion polls when it is statistically significant in the contracts of the National, Labour and New Zealand First party is questioned for its permanence. Using an event study, I regress the change on prices from a day before to a day after the poll's release on the change in poll's results to examine whether the effect of a poll's result persist for on more day. Results in the simple and AR models as shown in Table 6.5 agree that 
the persistence is present. It then suggests the incorporation of information revealed in opinion polls remains influential on the price level the day after the poll. The MA model reveals a completely different story by the lack of significance of $\beta$ and a near perfect MA coefficient of 1 . This has an implication for the nature of these contracts. Taking the $\lambda_{1}$ result and putting this in the Equation (6.8) (using $p_{t+1}-p_{t-1}$ as a dependent variable), along with $\beta=0$, means that the price changes for these contracts follow a random walk ${ }^{8}$

The left-hand side: $p_{t+1}-p_{t-1}=\Delta p_{t+1}+\Delta p_{t}$ The right-hand side: $\alpha_{0}+\epsilon_{t}+\epsilon_{t-1}=\alpha_{0}+\Delta \epsilon_{t}$ In sum: $\Delta p_{t+1}=\alpha_{0}-\Delta p_{t}+\Delta \epsilon_{t}$ 
Table 6.5: The permanence of the opinion polls' effect in the National, Labour and NZ First contracts

\begin{tabular}{|l|l|l|l|}
\hline Contract & \multicolumn{1}{|l|}{ National } & Labour & NZ First \\
\hline Simple model: $\Delta^{2} p_{t}=p_{t+1}-p_{t-1}=\alpha_{0}+\beta \Delta$ Poll $_{t} D_{t}+u_{t}$ & \multicolumn{2}{l|}{} \\
\hline$\beta$ & $0.184^{* * *}$ & $0.175^{* *}$ & $0.217^{* *}$ \\
& $(0.053)$ & $(0.059)$ & $(0.07)$ \\
\hline F-joint & $* *$ & $* *$ & $* *$ \\
\hline AIC & -2696 & -2585 & -3080 \\
\hline$R^{2}$ & 0.026 & 0.019 & 0.02 \\
\hline
\end{tabular}

\begin{tabular}{|c|c|c|c|}
\hline \multicolumn{4}{|c|}{ AR model: $\Delta^{2} p_{t}=p_{t+1}-p_{t-1}=\beta \Delta \operatorname{Poll}_{t} D_{t}+\sum_{j=1}^{k} \alpha_{j} \Delta p_{t-j}+\epsilon_{t}$} \\
\hline$\beta$ & $\begin{array}{l}0.163^{* *} \\
(0.051)\end{array}$ & $\begin{array}{l}0.194^{* * *} \\
(0.054)\end{array}$ & $\begin{array}{l}0.186^{* *} \\
(0.07)\end{array}$ \\
\hline$\alpha_{1}$ & $\begin{array}{l}-0.323^{* * *} \\
(0.061)\end{array}$ & $\begin{array}{l}-0.147^{* * *} \\
(0.06)\end{array}$ & $\begin{array}{l}-0.315^{* * *} \\
(0.061)\end{array}$ \\
\hline$\alpha_{2}$ & $\begin{array}{l}-0.277^{* * *} \\
(0.062)\end{array}$ & $\begin{array}{l}-0.345^{* * *} \\
(0.062)\end{array}$ & $\begin{array}{l}-0.157^{*} \\
(0.063)\end{array}$ \\
\hline$\alpha_{3}$ & $\begin{array}{l}-0.18^{* *} \\
(0.06) \\
\end{array}$ & $\begin{array}{l}-0.254^{* * *} \\
(0.062)\end{array}$ & $\begin{array}{l}-0.165^{* *} \\
(0.063)\end{array}$ \\
\hline$\alpha_{4}$ & & $\begin{array}{l}-0.071 \\
(0.056)\end{array}$ & \\
\hline F-joint & $* * *$ & ** & $* * *$ \\
\hline $\mathrm{AIC}$ & -2648 & -2628 & -3072 \\
\hline$R^{2}$ & 0.113 & 0.155 & 0.084 \\
\hline
\end{tabular}

\begin{tabular}{|c|c|c|c|}
\hline \multicolumn{4}{|c|}{ MA model: $\Delta p_{t}=\alpha_{0}+\beta \Delta$ Poll $_{t} D_{t}+\sum_{i=1}^{q} \lambda_{q} \epsilon_{t-1}+\epsilon_{t}$} \\
\hline$\beta$ & $\begin{array}{l}0.0025 \\
(0.004)\end{array}$ & $\begin{array}{l}0.0103 \\
(0.006)\end{array}$ & $\begin{array}{c}-0.0052 \\
(0.007)\end{array}$ \\
\hline$\lambda_{1}$ & $\begin{array}{l}\sim 1^{* * *} \\
(0.0087)\end{array}$ & $\begin{array}{l}-0.58^{* *} \\
(0.057)\end{array}$ & $\begin{array}{l}\sim 1^{* * *} \\
(0.0076)\end{array}$ \\
\hline$\lambda_{2}$ & & $\begin{array}{l}-0.42^{* * *} \\
(0.056)\end{array}$ & \\
\hline F-joint & $* * *$ & $* * *$ & $* * *$ \\
\hline AIC & -2783 & -2738 & -3227 \\
\hline$R^{2}$ & 0.381 & 0.35 & 0.373 \\
\hline \multicolumn{4}{|c|}{$\begin{array}{l}\text { Main table entries are regression coefficient estimates, and entries in parentheses are standard errors. } \\
\text { The joint significance is tested by F-test. } \\
\text { The } R^{2} \text { value is calculated as the square of the correlation coefficient between the actual and modeled data values. } \\
\text { Significant code: } 0{ }^{\prime * * *} 0.1 \%{ }^{* *}, 1 \%{ }^{*}, 5 \%, 10 \%,{ }^{\prime} 100 \% \text {. }\end{array}$} \\
\hline
\end{tabular}


Information is not always incorporated into market prices immediately or as soon as it becomes available. Or it is also possible that the market anticipates the poll's result even before it is reported. This issue is examined in the following test in the conjunction with the three alternative models discussed above (Equation (6.6) - (6.8)):

$$
\Delta p_{t}=\alpha_{0}+\beta \Delta \operatorname{Poll}_{t} D_{t}+\beta_{1} \Delta \operatorname{Poll}_{t} D_{t}^{1}+\beta_{2} \Delta \operatorname{Poll}_{t} D_{t}^{2}+\beta_{-1} \Delta \operatorname{Poll}_{t} D_{t}^{-1}+\text { model }+v_{t}
$$

where $D_{t}^{1}, D_{t}^{2}$ and $D_{t}^{-1}$ take on the value 1 or 0 according to whether a new poll is released a day or two days before day $t$ or a day after day $t$, respectively. A significant estimate of $\beta_{1}$ and $\beta_{2}$ and $\beta=0$ indicates a delay in the incorporation of information contained in polls into market prices, otherwise it is period effect. Whilst inside information of poll's results being traded in the market is hinted if $\beta_{-1}$ is significant. The regression is estimated by OLS method and its result is reported in Table 6.4. The three models produce consistent results. First, the National and Labour contracts show no significant anticipation or lagged response. Second, no delay in the incorporation of information is observed, except for in the New Zealand First contract at lag of two days. And last, trades by anticipating the poll results before they are released publicly is indicated by a consistently significant estimate of $\beta_{-1}$ in contracts of the Green and ACT party. In these two contracts, the $R^{2}$ is improved by the additional inside the AR model is $15 \%$, up from $12.7 \%$, i.e. the inside trading contributes $2.3 \%$ of explanatory power of the movement of the market prices. Similarly in the ACT contract, $1.4 \%$ of $R^{2}$ is added by the inside trading. The overall suggestion is that the market incorporates poll results quickly (on the day).

It is difficult to model robustly and in order to do this, it may require a more complex model beyond the scope of this study. Overall, although none of the models are sufficiently robust to provide confidence that the price change process is adequately modelled, 
there is a degree of consistency in the results with regards to $\beta$. There is mixed evidence as to the effect of opinion polls: the National, Labour and New Zealand First contract prices are affected by polls but to a very small degree while there is no effect of polls on prices of the rest of the contracts. The event studies conflict is that the simple and extended versions point to polls having a permanent effect in those contacts where the immediate effect of polls is found in contrast the MA version suggesting not only is there no permanence effect, but also the MA model collapse to a random walk. 
Table 6.6: The ex-ante and ex-post effect of opinion polls on market prices

\begin{tabular}{|c|c|c|c|c|c|c|c|c|}
\hline Contract & National & Labour & Green & NZ First & ACT & Māori & Other & $\begin{array}{l}\text { United } \\
\text { Future }\end{array}$ \\
\hline \multicolumn{9}{|c|}{ Simple model: Equation (6.6) and Equation (6.9) } \\
\hline$\beta$ & $\begin{array}{l}0.149^{* * *} \\
(0.043)\end{array}$ & $\begin{array}{l}0.242^{* * *} \\
(0.05)\end{array}$ & $\begin{array}{l}0.015 \\
(0.041)\end{array}$ & $\begin{array}{l}0.156^{* *} \\
(0.058)\end{array}$ & $\begin{array}{l}-0.011 \\
(0.139)\end{array}$ & $\begin{array}{l}-0.005 \\
(0.02)\end{array}$ & $\begin{array}{l}-0.043 \\
(0.109)\end{array}$ & $\begin{array}{l}-0.148 \\
(0.223)\end{array}$ \\
\hline$\beta_{1}$ & $\begin{array}{l}0.035 \\
(0.043)\end{array}$ & $\begin{array}{l}-0.067 \\
(0.05)\end{array}$ & $\begin{array}{l}-0.051 \\
(0.041)\end{array}$ & $\begin{array}{l}0.062 \\
(0.058)\end{array}$ & $\begin{array}{l}-0.123 \\
(0.139)\end{array}$ & $\begin{array}{l}-0.020 \\
(0.02)\end{array}$ & $\begin{array}{l}0.064 \\
(0.109)\end{array}$ & $\begin{array}{l}0.333 \\
(0.223)\end{array}$ \\
\hline$\beta_{2}$ & $\begin{array}{l}-0.029 \\
(0.043)\end{array}$ & $\begin{array}{l}-0.037 \\
(0.05)\end{array}$ & $\begin{array}{l}-0.012 \\
(0.041)\end{array}$ & $\begin{array}{l}0.14^{*} \\
(0.058)\end{array}$ & $\begin{array}{l}-0.059 \\
(0.139)\end{array}$ & $\begin{array}{l}-0.016 \\
(0.02)\end{array}$ & $\begin{array}{l}0.022 \\
(0.109)\end{array}$ & $\begin{array}{l}0.184 \\
(0.223)\end{array}$ \\
\hline$\beta_{-1}$ & $\begin{array}{l}-0.068 \\
(0.043)\end{array}$ & $\begin{array}{l}-0.011 \\
(0.05)\end{array}$ & $\begin{array}{l}0.135^{* *} \\
(0.041)\end{array}$ & $\begin{array}{l}-0.095 \\
(0.058)\end{array}$ & $\begin{array}{l}-0.307^{*} \\
(0.139)\end{array}$ & $\begin{array}{l}0.018 \\
(0.02)\end{array}$ & $\begin{array}{l}-0.2901^{* *} \\
(0.109)\end{array}$ & $\begin{array}{l}0.199 \\
(0.223)\end{array}$ \\
\hline F-joint & $* *$ & $* * *$ & $*$ & $* *$ & & & & \\
\hline AIC & -2807.4 & -2725.4 & -3415.8 & -3253.7 & -3151.1 & -4457.3 & -3501.7 & -3328.4 \\
\hline$R^{2}$ & 0.037 & 0.062 & 0.03 & 0.041 & 0.014 & 0.006 & 0.019 & 0.01 \\
\hline
\end{tabular}

\begin{tabular}{|l|l|l|l|l|l|l|l|l|}
\hline \multicolumn{2}{|c|}{ AR(k) process: Equation (6.7) and Equation $(6.9)$} & \multicolumn{1}{l|}{ and } \\
\hline$\beta$ & $0.143^{* * *}$ & $0.244^{* * *}$ & 0.016 & $0.155^{* *}$ & 0.017 & -0.006 & -0.009 & -0.136 \\
& $(0.042)$ & $(0.049)$ & $(0.040)$ & $(0.057)$ & $(0.137)$ & $(0.019)$ & $(0.107)$ & $(0.214)$ \\
\hline$\beta_{1}$ & 0.032 & -0.057 & -0.048 & 0.065 & -0.138 & -0.016 & 0.041 & 0.320 \\
& $(0.042)$ & $(0.05)$ & $(0.039)$ & $(0.057)$ & $(0.136)$ & $(0.02)$ & $(0.107)$ & $(0.215)$ \\
\hline$\beta_{2}$ & -0.035 & -0.039 & -0.022 & $0.129^{*}$ & -0.026 & -0.014 & 0.004 & 0.028 \\
& $(0.041)$ & $(0.046)$ & $(0.038)$ & $(0.055)$ & $(0.129)$ & $(0.019)$ & $(0.099)$ & $(0.182)$ \\
\hline$\beta_{-1}$ & -0.066 & 0.011 & $0.1235^{* *}$ & -0.095. & $-0.305^{*}$ & 0.015 & -0.168. & 0.115 \\
& $(0.041)$ & $(0.046)$ & $(0.039)$ & $(0.055)$ & $(0.129)$ & $(0.019)$ & $(0.10)$ & $(0.182)$ \\
\hline$\alpha_{1}$ & $-0.258^{* * *}$ & $-0.387^{* * *}$ & $-0.27^{* * *}$ & $-0.293^{* * *}$ & $-0.354^{* * *}$ & $-0.155^{* *}$ & $-0.391^{* * *}$ & $-0.628^{* * *}$ \\
& $(0.05)$ & $(0.053)$ & $(0.050)$ & $(0.05)$ & $(0.049)$ & $(0.055)$ & $(0.050)$ & $(0.05)$ \\
\hline$\alpha_{2}$ & $-0.138^{* *}$ & $-0.224^{* * *}$ & $-0.258^{* * *}$ & $-0.12^{*}$ & $-0.179^{* * *}$ & $-0.122^{*}$ & $-0.302^{* * *}$ & $-0.329^{* * *}$ \\
& $(0.052)$ & $(0.055)$ & $(0.052)$ & $(0.050)$ & $(0.052)$ & $(0.055)$ & $(0.052)$ & $(0.059)$ \\
\hline$\alpha_{3}$ & $-0.1452^{* *}$ & $-0.22^{* * *}$ & $-0.22^{* * *}$ & & $-0.181^{* * *}$ & & $-0.137^{* *}$ & $-0.254^{* * *}$ \\
& $(0.051)$ & $(0.055)$ & $(0.052)$ & & $(0.052)$ & & $(0.050)$ & $(0.060)$ \\
\hline$\alpha_{4}$ & & $-0.128^{*}$ & $-0.228^{* * *}$ & & $-0.149^{* *}$ & & & -0.107. \\
& & $(0.054)$ & $(0.052)$ & & $(0.050)$ & & & $(0.059)$ \\
\hline$\alpha_{5}$ & & & $-0.127^{*}$ & & & & & $0.099^{*}$ \\
& & & $(0.052)$ & & & & $(0.050)$ \\
\hline F-joint & $* * *$ & $* * *$ & $* * *$ & $* * *$ & $* * *$ & $*$ & $* * *$ & $* * *$ \\
\hline AIC & -2833.3 & -2776.3 & -3458.4 & -3283.9 & -3199.0 & -4464.6 & -3561.8 & -3468.8 \\
\hline$R^{2}$ & 0.111 & 0.19 & 0.15 & 0.12 & 0.14 & 0.034 & 0.17 & 0.32 \\
\hline
\end{tabular}

\begin{tabular}{|c|c|c|c|c|c|c|c|c|}
\hline \multicolumn{9}{|c|}{ MA(q): Equation (6.8) and Equation (6.9) } \\
\hline$\beta$ & $\begin{array}{l}0.149^{* * *} \\
(0.042)\end{array}$ & $\begin{array}{l}0.248^{* * *} \\
(0.05)\end{array}$ & $\begin{array}{l}0.015 \\
(0.042)\end{array}$ & $\begin{array}{l}0.156^{* *} \\
(0.058)\end{array}$ & $\begin{array}{l}-0.011 \\
(0.140)\end{array}$ & $\begin{array}{l}-0.006 \\
(0.020)\end{array}$ & $\begin{array}{l}-0.043 \\
(0.112)\end{array}$ & $\begin{array}{l}-0.148 \\
(0.218)\end{array}$ \\
\hline$\beta_{1}$ & $\begin{array}{l}0.035 \\
(0.043)\end{array}$ & $\begin{array}{l}-0.068 \\
(0.05)\end{array}$ & $\begin{array}{l}-0.051 \\
(0.042)\end{array}$ & $\begin{array}{l}0.061 \\
(0.058)\end{array}$ & $\begin{array}{l}-0.123 \\
(0.140)\end{array}$ & $\begin{array}{l}-0.017 \\
(0.020)\end{array}$ & $\begin{array}{l}0.065 \\
(0.112)\end{array}$ & $\begin{array}{l}0.334 \\
(0.218)\end{array}$ \\
\hline$\beta_{2}$ & $\begin{array}{l}-0.043 \\
(0.043)\end{array}$ & $\begin{array}{l}-0.033 \\
(0.046)\end{array}$ & $\begin{array}{l}-0.015 \\
(0.040)\end{array}$ & $\begin{array}{l}0.13^{*} \\
(0.055)\end{array}$ & $\begin{array}{l}-0.014 \\
(0.131)\end{array}$ & $\begin{array}{l}-0.013 \\
(0.019)\end{array}$ & $\begin{array}{l}0.017 \\
(0.100)\end{array}$ & $\begin{array}{l}0.092 \\
(0.187)\end{array}$ \\
\hline$\beta_{-1}$ & $\begin{array}{l}-0.068 \\
(0.042)\end{array}$ & $\begin{array}{l}0.011 \\
(0.046)\end{array}$ & $\begin{array}{l}0.142^{* * *} \\
(0.040)\end{array}$ & $\begin{array}{l}-0.096 . \\
(0.055)\end{array}$ & $\begin{array}{l}-0.329^{*} \\
(0.130)\end{array}$ & $\begin{array}{l}0.015 \\
(0.019)\end{array}$ & $\begin{array}{l}-0.148 \\
(0.101)\end{array}$ & $\begin{array}{l}0.085 \\
(0.187)\end{array}$ \\
\hline$\lambda_{1}$ & $\begin{array}{l}-0.296^{* * *} \\
(0.058)\end{array}$ & $\begin{array}{l}-0.4^{* * *} \\
(0.051)\end{array}$ & $\begin{array}{l}0.285^{* * *} \\
(0.068)\end{array}$ & $\begin{array}{l}-0.32 * * * \\
(0.052)\end{array}$ & $\begin{array}{l}-0.396^{* * *} \\
(0.056)\end{array}$ & $\begin{array}{l}-0.16^{* *} \\
(0.055)\end{array}$ & $\begin{array}{l}-0.506^{* * *} \\
(0.055)\end{array}$ & $\begin{array}{l}-0.598^{* * *} \\
(0.038)\end{array}$ \\
\hline$\lambda_{2}$ & & & $\begin{array}{l}-0.127^{*} \\
(0.05)\end{array}$ & & & & $\begin{array}{l}-0.101 . \\
(0.057)\end{array}$ & \\
\hline F-joint & *** & $* * *$ & $* * *$ & **** & *** & * & $* * *$ & *** \\
\hline AIC & -2830.6 & -2772.2 & -3432.5 & -3286.2 & -3194.5 & -4463.6 & -3560.2 & -3460.7 \\
\hline$R^{2}$ & 0.097 & 0.183 & 0.077 & 0.12 & 0.12 & 0.035 & 0.16 & 0.29 \\
\hline $\begin{array}{l}\text { Main tal } \\
\text { The join } \\
\text { The } R^{2} \\
\text { Significa } \\
\text { In each }\end{array}$ & $\begin{array}{l}\text { Incance is } \\
\text { is calcula } \\
\text { de: } 0 \text { (*** } \\
\text { he consta }\end{array}$ & as the sq & $\begin{array}{l}\text { ient estim } \\
\text { st. } \\
\text { e of the c } \\
{ }^{*}, 5 \% \text { ". } \\
\text { standard }\end{array}$ & $\begin{array}{l}\text { end en } \\
\text { elation co } \\
, \quad 100 \%\end{array}$ & $\begin{array}{l}\text { s in pare } \\
\text { cient betv }\end{array}$ & $\begin{array}{l}\text { ses are } \\
\text { the ac }\end{array}$ & $\begin{array}{l}\text { ard errors. } \\
\text { nd modele }\end{array}$ & data values \\
\hline
\end{tabular}




\section{Chapter 7}

\section{Conclusion}

Efficiency reflects the speed and extent to which markets incorporate and reflect new information. Typically, studies of efficiency look to test whether the price data could be explained by a random walk model. Given that such models suggest that future prices cannot be predicted, a good fit suggests that there is no systematic way of generating abnormal returns and thus the market is efficient. This absence of abnormal profits includes an absence of arbitrage profits. Thus one way to test for inefficiency is to look for arbitrage opportunities. In other words, few or no significant arbitrage opportunities would be consistent with market efficiency. Many or large such opportunities suggest that the market is inefficient and that abnormal profits may be made.

Prediction markets are unique in that they will often provide bundles of contracts on the same event that are mutually exclusive in that their aggregate payout will always sum to $\$ 1$ or a $100 \%$ probability. This provides an opportunity to test whether the market is efficient because of the absence of risk-free (or negligible risk) profit-making opportunities, i.e. there are no arbitrage opportunities. There have been few detailed studies of arbitrage in prediction markets although some studies have briefly noted a lack of arbitrage opportunities. 
I examine the iPredict party vote contracts for the 2011 General Election and find that even before transaction costs were introduced, almost all the arbitrage opportunities that arose gave returns less than the relevant risk-free rate. The mean arbitrage profit (taking into account the bid and ask spread) was 0.21 cents per bundle trade (which must have a payoff of $\$ 1$ ). Around $22 \%$ of the daily (last traded) prices met the conditions for arbitrage. Thus, in line with the literature, I find that while arbitrage opportunities are not uncommon in the iPredict markets, they remain relatively small and insufficient to provide abnormal returns. After the introduction of transaction costs, the scope for profitable arbitrage is further reduced. This lack of persistent and significant arbitrage opportunities suggests that the iPredict party vote contract markets are efficient (at least in the semi-strong form).

Although random walk models are by their nature non-stationary, in order to run empirical tests on prediction market data, it is necessary to ensure that the testing is not subject to spurious regression. None of the literature in prediction markets to date has addressed this issue even though the typical finding is that market prices follow a random walk (and are therefore implicitly non-stationary). Examining the iPredict data, I find that 7 of the 8 party vote contracts for the 2011 General Election are non-stationary, meaning that the data must be transformed for standard regressions to avoid the spurious regression issue.

In line with other studies, I find that the iPredict prices are generally more accurate than the opinion polls in the comparison of forecast errors. This suggests that the information contained in the market prices is to some extent better than opinion polls for prediction of the electoral outcome. In order to examine whether opinion polls have any influence on iPredict prices, I use the first difference of market price data and construct three types of model namely a simple model in which the opinion poll is the only explanatory variable, an autoregressive model in which the price change is assumed to be serially correlated 
and a moving average model. The autoregressive models are derived from the stationarity tests (dropping the lagged price level because of its insignificance) and with the number of lagged price changes determined by a paring down process. The empirical results show that opinion polls have a consistently significant effect on the National, Labour and New Zealand First prices. Prices in these contracts not only react to the opinion poll on the day of its release day but that reaction persists until the a day after. The event studies examine the ex-ante and ex-post effect of opinion polls to see if markets anticipated or reacted with a delay in incorporating poll information and show that no contracts show significant anticipation, except for the Green and ACT contracts and the lagged response at two day later is present in the New Zealand First contract. However, these effect of anticipation and lagged responses of poll information do not contribute considerably more to the $R^{2}$. If the addition of the polling data does not significantly increase $R^{2}$ which represents the explanatory power of the variables then the implication is that the polling data has little additional ability to explain the movement in market prices. This is consistent with markets being efficient in that the additional information may already be largely incorporated into trading behaviour.

The fact that the various models I have used have little explanatory power is consistent with the hypothesis that the iPredict markets are efficient. One possible avenue for further research is to incorporate other polls (and thus also increasing the number of observations). The effect of the polls may be understated due to the fact that I have used data only from one polling company which provides me with a set of polling data consisting of solely 27 observations. Furthermore, the information contained in individual pollsters' poll results may be biased due to their particular polling technique. Polls are subject to sampling error so even if opinion polls reveal information that has not been anticipated by market participants, that information has to be sufficiently distinct after being discounted by the sampling error so that it will affect market prices. 


\section{Bibliography}

(2008). Liquidity and Prediction market liquidity. SSRN Working Paper, 929916.

Abramowicz, M. (2007). Predictocracy: Market mechanisms for public and private decision making. Yale University Press.

Ait-Sahalia, Y. (1996). Testing continuous-time models of the spot interest rare. Review of Financial Studies, 9:385-426.

Banerjee, A., Dolado, J., Galbraith, J., and Hendry, D. (1993). Cointergration, Error Correction, and the Econometric Analysis of Non-Stationary Data. Oxford University Press.

Beckmann, K. and Werding, M. (1996). 'Passauer Wahlborse': Information processing in a political market experiment. Kyklos, 49:171-204.

Berg, J., Forsythe, R., Nelson, F., and Rietz, T. (2001). Accuracy and forecast standard error of prediction markets. Technical report, University of Iowa, College of Business Administration.

Berg, J. E., Forsythe, R., Nelson, F. D., and Rietz, T. A. (2000). Results from a dozen years of election futures markets research.

Berg, J. E. and Rietz, T. (2010). Longshots, overconfidence and efficiency on the Iowa Electronic Market. Working Paper Series. 
Berg, J. E. and Rietz, T. A. (2003). Prediction markets as decision support systems. Information Systems Frontiers, 5(1):79-93.

Berg, J. E. and Rietz, T. A. (2006). The Iowa Electronic Markets: Stylized facts and open issues. In Hahn, R. W. and Tetlock, P. C., editors, Information Markets: A New Way of Making Decisions, pages 142-169. AEI Press, Washington D.C.

Blume, M. E. and Stambaugh, R. (1983). Biases in computed returns: An application to the size effect. Journal of Financial Economics, 12:387-404.

Bondarenko, O. and Bossaerts, P. (2000). Expectations and learning in Iowa. Journal of Banking E Finance, 24:1535-1555.

Bremer, M. and Sweeney, R. (1991). The reversal of large stock-price decreases. Journal of Finance, 46:747-754.

Bruggelambert, G. (2004). Information and efficiency in political stockmarkets: using computerized markets to predict election results. Applied Economics, 36:753-768.

Caldeira, G. A. (2004). Expert Judgement versus Statistical Models: Explanation versus Prediction. Perspectives on Politics, 2:777-780.

Campbell, J. E. (1996). Polls and Votes: The Trial-Heat Presidential Elections Forecasting Model, Certainty and Political Campagins. American Politics Research, 24:408-433.

Chan, K., Karolyi, G., Longstaff, F., and Sanders, A. (1992). An empirical comparison of alternative models of the short term interest rate. Journal of Finance, 47:1210-1227.

Chen, Y., Chu, C., Mullen, T., and Pennock, D. (2005). Information markets vs. opinion polls: an empirical comparison. In Proceedings of the 6th ACM Conference on Electronic commerce. Vancouver, BC, Canada.

Dahlquist, M. (1996). On alternative interest rate processes. Journal of Banking $\&$ Finance, 20:1093-1119. 
Daniel, K., Hirsgleifer, D., and Subrahmanyam, A. (1998). Investor psychology and security market under- and overreactions. Journal of Finance, 58(6):1839-1885.

David, R. and Justin, W. (2012). Forecasting elections: Voter intentions versus expectations. Working Paper.

DeBondt, W. and Thaler, R. (1985). Does the stock market overreact? Journal of Finance, 40:793-805.

Diemer, S. and Poblete, J. (2010). Real-money vs. play-money forecasting accuracy in online prediction markets - empirical insights from iPredict. The Journal of Prediction Markets, 4(3):21-58.

Enders, W. (2004). Applied econometric time series. John Wiley \& Sons, 2 edition.

Erikson, R. S. and Wlezien, C. (2008). Are political markets really superior to polls as election predictors? Public Opinion, 72(2):190-215.

Erikson, R. S. and Wlezien, C. (2012). Markets vs. polls as election predictors: An historical assessment. Electoral Studies, 31:532-539.

Fama, E. F. (1965a). The behavior of stock-market prices. The Journal of Business, $38(1): 34-105$.

Fama, E. F. (1965b). Random walks in stock market prices. Financial Analysts Journal, 21(5):55-59.

Fama, E. F. (1969). Efficient capital markets: A review of theory and empirical work. The Journal of Finance, 25(2):383-417.

Fisher, F. M. (1981). Stability, disequilibrium awareness, and the perception of new opportunities. Econometrica, 49(2):279-317.

Foley, D. K. (1999). Statistical equilibrium in economics: Method, interpretation, and an example. Unpubished paper. 
Forsythe, R., Nelson, F., Neumann, G. R., and Wright, J. (1992). Anatomy of an experimental political stock market. The American Economic Review, 82(5):1142-1161.

Forsythe, R., Rietz, T., and Ross, T. (1999). Wishes, expectations and actions: a survey on price formation in election stock markets. Journal of Economic Behavior \& Organization, 39:83-110.

Ghosal, S. and Porter, J. (2013). Decentralized exchange, out of equilibrium dynamics and convergence to efficiency. Mathematical Social Sciences, 66:1-21.

Gode, D. and Sunder, S. (1993). Allocative efficiency of markets with zero intelligence traders: market as a partial substitute for individual rationality. The Journal of Political Economy, 101:119-137.

Goldman, S. M. and Starr, R. M. (1982). Pairwise, t-wise, and Pareto optimalities. Econometrica, 50(3):593-606.

Granger, C. and Newbold, P. (1974). Spurious regressions in econometrics. Journal of Econometrics, 2:111-120.

Gray, P. and Gray, S. (1997). Testing market efficiency: Evidence from the NFL sports betting market. Journal of Finance, 52:1725-1737.

Grossman, S. J. and Stiglitz, J. E. (1976). Information and competitive price systems. The American Economic Review, 66(2):246-253.

Hall, C. (2010). Prediction markets: Issues and applications. The Journal of Prediction Markets, 4(1):27-58.

Hanson, R. (2003). Combinatorial information market design. Information Systems Frontiers, 5(1):107-119.

Hanson, R. and Oprea, R. (2009). A manipulators can add prediction market accuracy. Economica, 76:304-314. 
Hascrouck, J. (2007). Empirical Market Microstructure: The Institution, Economic and Econometrics of Securities Trading. Oxford University Press.

Hayek, F. A. (1945). The use of knowledge in society. The American Economic Review, $35(4 h): 519-530$.

Jullien, B. and Salanie, B. (2000). Estimating preferences under risk: The case of racetrack bettors. Journal of Political Economy, 108:503-530.

Kaul, G. and Nimalendran, M. (1990). Price reversals: bid-ask errors or market overreaction? Journal of Financial Economics, 28:67-93.

Keim, D. (1989). Trading patterns, bid-ask spreads and estimated security returns: The case of common stocks at calendar turning points. Journal of Financial Economics, 25:79-97.

Kondor, P. (2009). Risk in dynamic arbitrage: Price effects of convergence trading. Journal of Finance, 64:638-658.

Kou, S. G. and Sobel, M. E. (2004). Forecasting the vote: A theoretical comparison of Election Markets and Public Opinion Polls. Political Analysis, 12:277-295.

Kwiatkowski, D., Pillips, P., Schmidt, P., and Shin, Y. (1992). Testing the null hypothesis of stationarity against the alternative of a unit root: How sure are we that economic time series have a unit root? Journal of Econometrics, 54:159-178.

Leigh, A. and Wolfers, J. (2006). Competing approaches to forecasting elections: Economic models, opinion polling and prediction markets. NBER Working Paper 12053.

Leigh, A., Wolfers, J., and Zitzewitz, E. (2003). What do financial markets think of war in Iraq? NBER Working Paper No. 9587.

LeRoy, S. (1973). Risk aversion and the martingale property of stock prices. International Economic Review, 14:436-466. 
Lichtenstein, S., Fischhoff, B., and Phillips, L. (1982). Judgement Under Uncertainty: Heuristics and Biasese, chapter Calibration of Probabilities: The State of the Art to 1980, pages 306-334. Cambridge: Cambridge University Press.

Long, J. D., Shleifer, A., Summers, L., and Waldman, R. (1990). Positive feedback investment strategies and destabilizing rational speculation. Journal of Finance, 45:379-395.

Lucas, R. (1978). Asset prices in an exchange economy. Econometrica, 46:1429-1445.

Luckner, S., Schröder, J., Slamka, C., Skiera, B., Spann, M., Weinhardt, C., GeyerSchulz, A., and Franke, M. (2012). Prediction Markets: Fundamentals, Designs, and Applications, chapter 3: Application of Prediction Markets, page 86. Springer Fachmedien Wiesbaden.

Majumder, S. R., Diermeier, D., Rietz, T. A., and Amaral, L. A. N. (2009). Price dynamics in political prediction markets. Proceedings of the National Academy of Sciences of the United States of America, 106:679-684.

Malkiel, B. (2003). The efficient market hypothesis and its critics. Journal of Economic Perspectives, 17:59-82.

McGirr, S. and Salmond, R. (2010). Key to Victory: The New Zealand General Election of 2008, chapter 2008: Opinion Polls and Prediction Markets in New Zealand, pages 254-271. Victoria University Press.

Moon, N. (1999a). Opinion Polls: History, Theory and Practice, chapter Methodology in Practice: Interview, pages 65-93. Manchester University Press.

Moon, N. (1999b). Opinion Polls: History, Theory and Practice, chapter Polling Methoology: The Theory, pages 24-43. Manchester University Press.

Nelson, C. R. and Plosser, C. I. (1982). Trends and random walk in macroeconomic time series. Jornal of Monetary Economics, 10:139-162. 
Nicolau, J. (1999). Modelling the DEM/USD exchange rate as an ergodic stationarity continuous time process. Working paper 2-99, CEMAPRE-Instituto Superior de Economia e Gestão.

Nicolau, J. (2002). Stationarity processes that look like random walks: The bounded random walk process in discrete and continuous time. Econometric Theory, 18:99-118.

Niederhoffer, V. and Osborne, M. (1966). Market making and reversal on the stock exchange. Journal of the American Statistical Association, 61:897-916.

Oi, W. Y. (1974). On the Economics of Industrial Safety. Law and Contemporary Problems, Summer/Autumn, 38:669-699.

Oliven, K. and Rietz, T. A. (2004). Suckers are Born but Markets Are Made: Individual Rationality, Arbitrage, and Market Efficiency on an Electronic Futures Market. Management Science, 50(3):336-351.

Othman, A. (2008). Zero-intelligence agents in prediction markets. In In proceedings of the Yth International Joint Conference on Autonomous agents and multiagent systems (AAMAS), pages 879-886.

Page, L. (2008). Comparing Prediciton Market Prices and Opinion Polls in Political Elections. The Jounal of Prediction Markets, 2(1):91-97.

Perron, P. (1989). The great cash, the oil price shock and the unit root hypothesis. Econometrica, 57:1361-1402.

Rhee, S. and Wanga, C.-J. (1997). The bid-ask bounce effect and the spread size effect: Evidence from the Taiwan stock market. Pacific-Basin Finance Journal, 5(2):231-258.

Rhode, P. W. and Strumpf, K. S. (2004). Historic Presidential Betting Markets. Journal of Economic Perspectives, 18:127-142.

Rogoff, K. (1996). The purchasing power parity puzzle. Journal of Economic Literature, $34: 647-668$. 
Roll, R. (1984). A simple implicit measure of the effective bid-ask spread in an efficient market. Journal of Finance, 39:1127-1139.

RoyMorgan (2011). Sample electorate voters profile.

Said, S. E. and Dickey, D. A. (1984). Testing for unit roots in autoregressive-moving average models of unknown order. Biometrika, 71:599-607.

Sharpe, W. and Alexander, G. (1990). Investments. Prentice Hall, 4th edition.

Shefrin, H. and Statman, M. (1985). The disposition to ride winners too long and sell losers too soon: Theory and evidence. Journal of Finance, 41:774-790.

Shleifer, A. and Vishny, R. (1997). The limits of arbitrage. Journal of Finance, 52:35-55.

Smith, V. (1982). Markets as economizers of information: Experimental examination of the "Hayek Hypothesis". Economic Inquiry, 20(2):165-179.

Sunstein, C. (2005). Group Judgements: Deliberations, Statistical Means, and Information Markets. New York University Law Review, 80:962-1049.

Surowiecki, J. (2004). The Wisdom of Crowds: Why the Many Are Smarter Than the Few and How Collective Wisdom Shapes Business, Economies, Societies and Nations. Doubleday; Anchor.

Tetlock, P. C. (2004). How efficient are information markets? evidence from an Online Exchange. In Social Science Research Network.

Thaler, R. H. and Ziemba, W. T. (1988). Parimutuel betting markets: Racetracks and lotteries. Journal of Economic Perspectives, 2:161-174.

Tobin, J. (1958). Liquidity preference as behavior towards risk. The Review of Economic Studies, 25(2):65-86.

Viscusi, W. K. (1979). Job Hazards and Worker Quit Rates: An Analysis of Adaptive Work Behavior. International Economic Review, 20:29-58. 
Viscusi, W. K. (1983). Risk by choice: Regulating Health and Safety in the Workplace. Harvard University Press.

Wolfers, J. and Leigh, A. (2002). Three tools for forecasting Federal elections: Lessons from 2001. Australian Journal of Political Science, 37(2):223-240.

Wolfers, J. and Zitzewitz, E. (2004). Prediction markets. Journal of Economic Perspectives, 18(2):107-126.

Wolfers, J. and Zitzewitz, E. (2006a). Interpreting prediction market prices as probabilities. In Information Markets: A New Way of Making Decisions. AEI Press. Washington, DC.

Wolfers, J. and Zitzewitz, E. (2006b). Prediction markets in theory and practice. The Rodney L. White Center for Financial Research.

Woodland, L. M. and Woodland, B. M. (1994). Market efficiency and the FavouriteLongshot Bias: The baseball betting market. Journal of Finance, 49:269-279.

Woodland, L. M. and Woodland, B. M. (2001). Market efficiency and profitable waggering in the National Hockey League: Can bettors score on longshots? Southern Economic Journal, 67:983-995.

Xiong, W. (2001). Convergence trading with wealth effects. Journal of Financial Economics, 62:247-292.

Ziemba, W. T. and Hausch, D. B. (1986). Betting at the racetrack. Vancouver and Los Angeles: Dr. Z Investments, Inc. 